\title{
Died with or Died of? Development and Testing of a SARS CoV-2 Significance Score to Assess the Role of COVID-19 in the Deaths of Affected Patients
}

\author{
Arianna Giorgetti ${ }^{1}$, Vasco Orazietti ${ }^{2}$, Francesco Paolo Busardò ${ }^{2}$, Filippo Pirani ${ }^{2}$ *(D) and Raffaele Giorgetti ${ }^{2}$ (D) \\ 1 Department of Medical and Surgical Sciences, Unit of Legal Medicine, University of Bologna, Via Irnerio 49, \\ 40126 Bologna, Italy; ari.giorgetti@gmail.com \\ 2 Department of Excellence of Biomedical Sciences and Public Health, \\ University "Politecnica delle Marche" of Ancona, Via Conca 71, 60126 Ancona, Italy; \\ vasco.orazietti@gmail.com (V.O.); f.busardo@staff.univpm.it (F.P.B.); r.giorgetti@staff.univpm.it (R.G.) \\ * Correspondence: filippo.pirani.90@gmail.com; Tel.: +39-3337639523
}

Citation: Giorgetti, A.; Orazietti, V.; Busardò, F.P.; Pirani, F.; Giorgetti, R. Died with or Died of? Development and Testing of a SARS CoV-2 Significance Score to Assess the Role of COVID-19 in the Deaths of Affected Patients. Diagnostics 2021, 11, 190. https://doi.org/10.3390/

diagnostics 11020190

Academic Editor: Elizabeth Soilleux Received: 19 December 2020

Accepted: 26 January 2021

Published: 28 January 2021

Publisher's Note: MDPI stays neutral with regard to jurisdictional claims in published maps and institutional affiliations.

Copyright: (c) 2021 by the authors. Licensee MDPI, Basel, Switzerland. This article is an open access article distributed under the terms and conditions of the Creative Commons Attribution (CC BY) license (https:// creativecommons.org/licenses/by/ $4.0 /)$.

\begin{abstract}
Since December 2019, a new form of coronavirus, SARS-CoV-2, has spread from China to the whole word, raising concerns regarding Coronavirus Disease 2019 (COVID-19) endangering public health and life. Over 1.5 million deaths related with COVID-19 have been recorded worldwide, with wide variations among countries affected by the pandemic and continuously growing numbers. The aim of this paper was to provide an overview of the literature cases of deaths involving COVID19 and to evaluate the application of the COVID-19 Significance Score (CSS) in the classification of SARS CoV-2-related fatalities, comparing it with the Hamburg rating scale. The results obtained allowed us to highlight that CSS used after a complete accurate post-mortem examination, coupled to the retrieval of in vivo data, post-mortem radiology, histology and toxicology, as well as to additional required analyses (e.g., electronic microscopy) is a useful and concise tool in the assessment of the cause of death and the role played by this virus. A shared use of this scale might hopefully lower the inhomogeneities in forensic evaluation of SARS CoV-2-related fatalities.
\end{abstract}

Keywords: COVID-19 Significance Score (CSS); COVID-19; SARS CoV-2 related fatalities; death; cause of death

\section{Introduction}

In December 2019, starting from the urban area of Wuhan, a new form of coronavirus, SARS CoV-2, began to spread firstly to a national level, and rapidly to the whole world. Its diffusion was so fast that on March 11, the World Health Organization (WHO) declared Coronavirus Disease 2019 (COVID-19) a pandemic [1]. At the time of the present article (December 2020), the cases of COVID-19 registered in the world have reached 68,679,195, with $47,583,441$ patients completely recovered. Active cases amount to $19,530,028,0.5 \%$ of which are in severe or critical conditions. Most affected countries include the United States, India and Brazil. Deaths related to COVID-19 amount to 1,565,726, with wide variations among countries affected by the pandemic and continuously growing numbers [2].

Global research efforts have been, since then, focused on studying the natural history of the disease, the immune responses, rapid and reliable diagnostic testing and on understanding the mechanisms underlying the clinical picture, with the aim of better treating affected patients and developing an effective vaccine as soon as possible. Although several vaccines have shown promising results in phases 2 and 3 of the experimental studies $[3,4]$, long-term effects of COVID-19 and of related counteracting drugs and therapies might continue for years. The COVID-19 death toll is reported everyday nation by nation and is one of the main aspects of health surveillance, which guides health and social policies.

In this context, the distinction between "died from" and "died with" COVID-19 still represents an under-addressed and unsolved issue [5,6]. Often it is a difficult task for 
a medical practitioner to establish into which of these categories a death falls; indeed, distinguishing between "dying with" and "dying from" COVID-19 requires more complex investigation into the cause of a death, beyond citing a positive SARS-CoV-2 test. Although some clinical conditions, as well as laboratory and imaging alterations, are known to be associated with a worse outcome [7-13], there are still difficulties in classifying COVID19 related deaths [14], due to the lack of consensus criteria. Throwing light on what is being counted as a COVID-19 death is also essential to understand the impact of the virus and to inform the public. According to the "International guidelines for certification and classification of COVID-19 as cause of death", published last April by the World Health organization (WHO) and based on the International Classification of Diseases (ICD), a clinical-based categorization of COVID-19 deaths can be performed by recording a pathophysiological sequence of the clinical conditions leading to death, as well as other contributing causes $[15,16]$. Medical certifications of death compiled for research and surveillance purposes by treating physicians have relevant consequences, e.g., they might bias scientific studies for the development of clinical risk prediction models or prevent the development of public health safety measures $[17,18]$. COVID-19 might be a direct cause, an underlying cause of death or a contributing condition. Even probable infections are acceptable in death certificates and do not necessarily point to the need for a judicial autopsy or a coroner intervention, even if it is a notifiable disease [15]. Though most autopsies are not necessary for laboratory-confirmed deaths [15], in the absence of a probable cause of death or when there is a suspect of medical liability, a post-mortem examination might be necessary $[15,17]$. It is well documented that the clinical cause of death might not coincide with the pathological one $[19,20]$ and, notwithstanding increasingly accurate laboratory and instrumental techniques, the role of the autopsy still remains relevant [21]. Since this virus belongs to Hazard group 3, in the early stages, very few autopsies were performed on COVID-19 patients, leading to a loss of valuable information. With the aim of reducing biological risk for contagion, several guidelines have been developed [22-31]. While some authors have proposed the use of "special autopsy facilities", others promoted a shift towards minimally invasive autopsies, performed by ultrasound-guided biopsies in different organs $[32,33]$. However, the latter may not provide a complete picture, making it difficult to answer questions about exact causes of death and SARS CoV-2 liability.

\section{COVID-19 Significance Score (CSS)}

As recently reported, a COVID-19 Significance Score (CSS) has been proposed [34]. The CSS classifies fatalities involving COVID-19 into four categories (as also suggested in other forensic disciplines, e.g., toxicology) [35,36]:

- $\quad 0$ : COVID-19 is merely an occasion; it has no role in the patient's death.

- 1: A role of COVID-19 in the patient's death cannot be excluded, although an alternative cause of death is likely.

- 2: COVID-19 likely contributed to the death, together with other factors that may have played a prominent role.

- 3: COVID-19 is the leading cause of death.

- U (unclassified or unclear), when not enough data are available, when further instrumental and laboratory tests are needed to clarify the situation or when the role of COVID-19 remains unclear despite all tests and analyses.

In the application of the CSS, the following features must be taken into consideration:

1. Presence and severity of COVID-19, considering both in vivo and postmortem data (natural history of disease, results of upper and lower airway swabs, clinical records, laboratory tests).

2. Presence and severity of comorbidities. It has been widely demonstrated that the presence of comorbidities is more frequently related to a different natural history in SARS-Cov-2 infection.

3. Circumstances of death. External traumatic events, e.g., a fatal car accident, involving a patient infected by SARS CoV-2 might rule out the responsibility of the virus in 
the death. This might be less evident in suicides. Indeed, cases of Corona Suicide have been reported worldwide [37] and COVID-19 might play an indirect role, by ingenerating fear, burden and a sense of responsibility for having infected other people, especially the closest relations.

4. Post-mortem imaging. Together with the tests performed in vivo or individually, post mortem radiology, including $X$-rays and post-mortem computed tomography (PMCT), may offer prominent information about the severity of the infection, as well as on any other alterations not clinically appreciable. However, due to the biological risk, these examinations should be carried out according to appropriate safety protocols and in any case should not hinder the hospital routine.

5. Macroscopic and microscopic autopsy findings. Autopsy plays a central role in the development of this score, as information that can be obtained from this examination cannot be provided by any other imaging or laboratory test.

6. Toxicological evaluation. A screening of the most common substances of abuse could be useful to exclude acute intoxications. As often happens in comorbid patients, the consumption of multiple drugs might lead to adverse events and exitus even at concentrations lower than the toxic levels, due to synergic effects. Insufficient dosages of a necessary drug might as well explain a death and these possibilities require a quantitative analysis.

7. Additional analyzes. When required by the case in question, such as bacterial culture, virological tests and other specific exams.

The aim of the present work is to provide an overview of the literature cases of deaths involving COVID-19 and to evaluate the application of the CSS in the classification of SARS CoV-2-related fatalities, comparing it with other rating scales currently available

\section{Material and Methods}

\subsection{Literature Review and Data Extraction}

A systematic review of the available literature was performed, seeking information regarding post-mortem examinations performed on the deceased who had tested positive for SARS Cov-2, with the infection confirmed in vivo and/or after death (topic of the search and main inclusion criteria). Data was collected from May 2020 to August 2020, by performing a search on an international database (Pubmed) using the following search terms. The keyword "covid" (variably written) was linked through the Boolean operator "AND" to the following terms, alternatively: "autopsy", "full autopsy", "post-mortem".

Inclusion criteria were: relevance to the topic; English, Spanish, German or Italian language; date of publication (up to 31 July 2020); retrievability of a full-text.

Papers that did not report the results of a post-mortem examination, e.g., publications dealing with the health care personnel safety or technical aspects of post-mortem examinations, cases analyzed only by post-mortem biopsies performed on a single organ and papers from which individual patient data could not be extracted, were excluded from the work (exclusion criteria).

A database with the results was created in Microsoft Excel and the following data, organized in two sections, were extracted.

- In vivo data: in addition to the patient's personal details (age and sex), the history of the disease, any comorbidities, medications taken before and during the SARS $\mathrm{CoV}-2$ infection, information about the swab, laboratory and imaging (e.g., X-rays and computed tomography or CT) data.

- Post-mortem data: death circumstances, any post-mortem imaging examinations, type of postmortem examination (full, partial, histology), macro and microscopic features emerged from the autopsy and related analyses, cause of death (when specified) and the role played by SARS CoV-2 as reported by the authors. 


\subsection{CSS Guiding Tool Development and Score Application}

A short and easy guiding tool has been developed in order to facilitate the application of the CSS across original points 1 to 6 [34]. The features considered in this guide refer to the most frequent pictures described in literature to date. For this reason, the CSS is not to be considered as a definitive tool, but susceptible to modifications and improvements along with the progress of the state of the art.

1. in vivo and/or post mortem positivity of the swab for SARS CoV2 (YES/NO)

- $\quad$ any reported symptoms compatible with COVID-19 (YES/NO) and severity of them (MILD, MODERATE = the situation required non-invasive techniques, SEVERE $=$ the situation required invasive techniques, such as intubation)

- any symptoms referable to other causes (YES/NO)

- $\quad$ drug therapy administered during COVID-19

- $\quad$ any changes in laboratory tests compatible with COVID-19 (YES/NO)

- $\quad$ any alterations in the laboratory tests due to other causes (YES/NO)

- evidence of bacterial, fungal or viral superinfection (YES/NO)

- radiological evidence (X-ray, CT compatible with COVID-19) (YES/NO)

2. presence (YES/NO) and number of comorbidities (1, 2 OR MORE)

- $\quad$ severity of comorbidities

- drugs consumed prior to COVID-19

3. external traumatic cause of death (e.g., car accident, gunshot, electrocution, drowning) or suicidal/homicidal manner of death (YES/NO)*

4. radiological evidence (XR, CT compatible with COVID-19) (YES/NO)

- presence of any other pathological alterations (YES/NO)

5. macroscopic and/or microscopic findings compatible with COVID-19 (YES/NO)

- presence (YES/NO), type (as chronic obstructive pulmonary disease (COPD), cardiomyopathy, thromboembolism, coronary thrombosis] and severity of other pathological conditions

6. presence of drugs/substances of abuse (YES/NO)

- presence and concentration of drugs taken regularly in chronic or during COVID-19.

* in case of suicide, the liability, even if indirect, for SARS CoV-2 cannot be excluded. Any useful information, such as a history of psychiatric pathologies, should therefore be evaluated carefully.

All literature cases were classified according to the CSS by three independent blinded investigators and the inter-rater agreement was assessed by non-parametric ANOVA.

\subsection{The Hamburg Score}

In a recent study performed at the University of Hamburg-Eppendorf, Edler et al. also proposed a classification system for deaths involving COVID-19 [38]. In the paper, the first 80 consecutive autopsies carried out on patients positive to COVID-19, who died in Hamburg, were reported. In fact, the approach used in the federal state of Hamburg is to examine all the deceased citizens with a confirmed SARS-CoV-2 infection, subjecting the bodies to a PMCT and performing a complete autopsy (by opening the three cavities and dissection of all organs). The results of the exams are then progressively uploaded to a national register, with the purpose of collecting data from all the autopsies performed in Germany on COVID-19 patients. Based on clinical information, PMCT and autopsy findings, the researchers propose a categorization of COVID-19 positive deaths, in order to determine whether the virus was the cause of death or whether exitus occurred independently from it.

This scale, just like the CSS, ranks COVID-19 related death into 4 categories: 1-definite COVID-19 death: autoptic pneumonia and/or acute respiratory distress syndrome (ARDS); 2-probable COVID-19 death: Autoptic pneumonia and/or ARDS and other infectious causes of death (e.g., pulmonary embolism); 3-possible COVID-19 death: cause of death 
that cannot be determined with certainty by autopsy (e.g., cardiac arrhythmia in cardiomyopathy) OR autoptic respiratory tract infection/pneumonia of other genesis (e.g., aspiration pneumonia, exacerbated COPD); 4-SARS-CoV-2 detection with cause of death not associated to COVID-19: Clear non-SARS-CoV-2-related cause of death (e.g., brain mass hemorrhage in hypertension, acute myocardial infarction in coronary thrombosis.

A death corresponding to categories 1-3 is defined as "COVID-19 death" (corresponding to CSS 3-1), therefore, COVID-19 related, while category 4 contains deaths not related to COVID-19 (corresponding to CSS $=0$ ).

Within the post-mortem cases reported by the University of Hamburg-Eppendorf, the mean among the CSS assigned by the three raters and the Hamburg scores were compared by means of non-parametric $t$-test.

\section{Results}

\subsection{Literature Review}

Thirty articles were included in the present literature review, corresponding to 84 post mortem examinations. Results of the selection process are shown in Figure 1, and detailed data for each case are reported in Table 1. Fourteen studies describe multiple cases [39-52], while 16 were case reports [53-68]. The highest sample size corresponded to 14 cases.

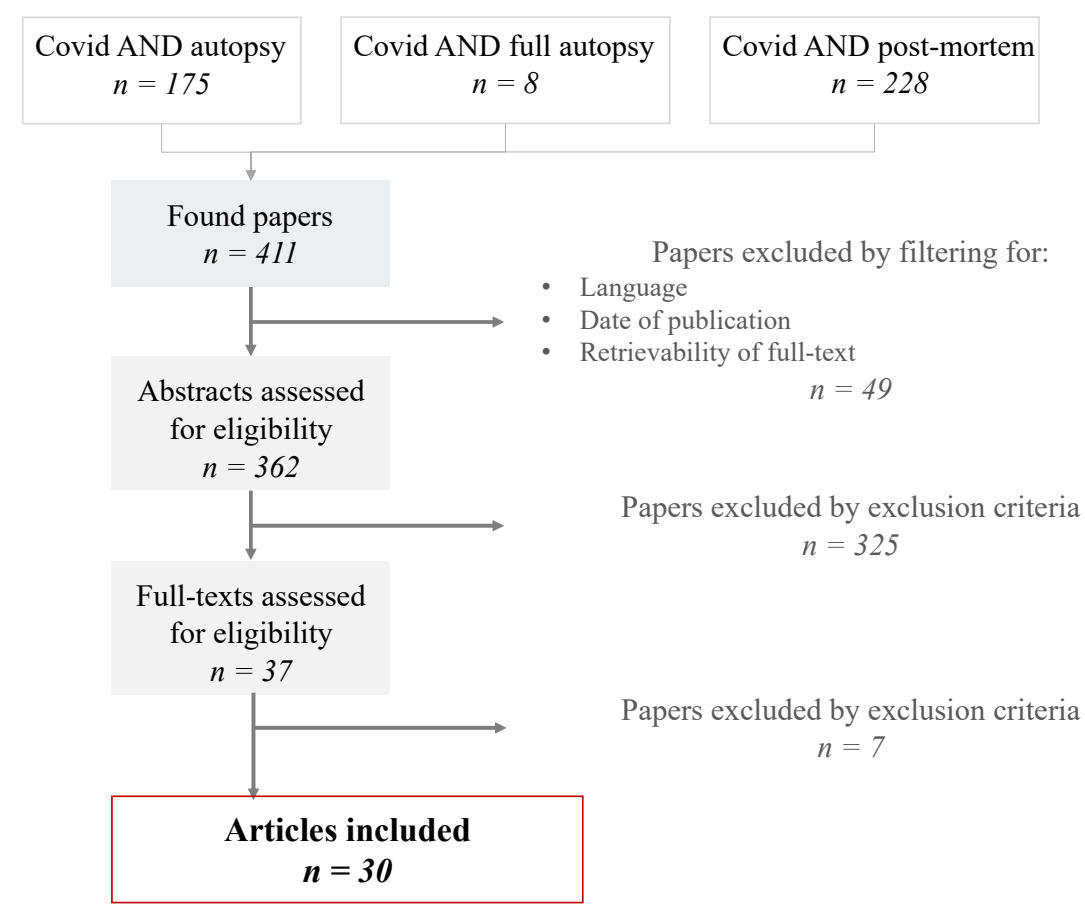

Figure 1. PRISMA flow chart of the selection process. 
Table 1. Detailed results of the literature cases.

\begin{tabular}{|c|c|c|c|c|c|c|c|c|c|c|c|c|c|c|}
\hline \multirow[b]{2}{*}{ Author } & \multirow[b]{2}{*}{ A } & \multirow[b]{2}{*}{ G } & \multicolumn{5}{|c|}{ IN VIVO DATA } & \multicolumn{7}{|c|}{ POSTMORTEM DATA } \\
\hline & & & $\begin{array}{c}\text { Comorbidities and } \\
\text { Past Drugs }\end{array}$ & Therapy & Labor & Imaging & $\begin{array}{l}\text { Course of the } \\
\text { Disease/Circumstances } \\
\text { of Death }\end{array}$ & Imaging & $\begin{array}{c}\text { Macroscopic } \\
\text { Features }\end{array}$ & Microscopic Features & Tox & $\begin{array}{c}\text { Additional } \\
\text { Analyses }\end{array}$ & Cause of Death & Swabs \\
\hline \multirow{4}{*}{$\begin{array}{l}\text { Benjiamin } \\
\text { Bradley } \\
\text { et al. } \\
\text { Ball }\end{array}$} & 57 & M & $\begin{array}{l}\text { CKD, DM2, HTN, } \\
\text { OSAS, obesity }\end{array}$ & Intubation & $\begin{array}{l}\text { elevated } \\
\text { creatinine, } \\
\text { lymphocy- } \\
\text { topenia }\end{array}$ & $\begin{array}{l}\text { Chest X-ray: } \\
\text { bilateral multifocal } \\
\text { patchy airspace } \\
\text { opacities }\end{array}$ & $\begin{array}{l}\text { Hospital presentation: } \\
\text { 4-day history of cough, } \\
\text { fever, chills, fecal } \\
\text { incontinence, fatigue } \\
\text { and onset of respiratory } \\
\text { distress. Intubated, died } \\
6 \text { dass after admission }\end{array}$ & $\mathrm{N} / \mathrm{D}$ & $\begin{array}{l}\text { LUNGS: heavy and } \\
\text { edematous }\end{array}$ & 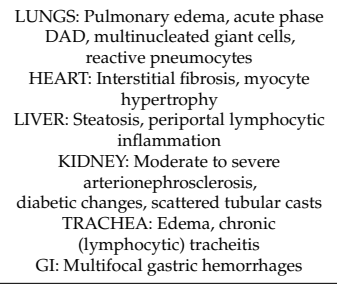 & N/D & $\mathrm{N} / \mathrm{D}$ & $\begin{array}{l}\text { (ICD-10 code) } \\
\text { A: Coronavirus } \\
\text { Disease 2019 } \\
\text { (COVID-19) } \\
\text { pneumonia } \\
\text { OSC: DM, end } \\
\text { stage CKD, HTN }\end{array}$ & $\begin{array}{c}\text { Positive for SARS } \\
\text { CoV-2 } \\
\text { (unspecified) }\end{array}$ \\
\hline & 74 & $\mathrm{~F}$ & $\begin{array}{l}\text { DM2, OSAS, AF, } \\
\text { pulmonary } \\
\text { hypertension, CKD, } \\
\text { obesity }\end{array}$ & Intubation & $\begin{array}{c}\text { elevated } \\
\text { creatinine }\end{array}$ & $\begin{array}{l}\text { Chest X-ray: increase } \\
\text { in vascular and } \\
\text { interstitial opacities }\end{array}$ & $\begin{array}{l}\text { Hospital presentation: } \\
\text { 2-day history of AKI, } \\
\text { delirium, cough, acute } \\
\text { cardiomyopathy and } \\
\text { respiratory distress. } \\
\text { Intubated, died on the } \\
\text { day of admission }\end{array}$ & $\mathrm{N} / \mathrm{D}$ & $\mathrm{N} / \mathrm{D}$ & $\begin{array}{l}\text { LUNGS: Organizing phase DAD, } \\
\text { reactive peumocytes, caute } \\
\text { bronchiolitis, alveolar septal thickening } \\
\text { HEART: Interstitial fibrosis, myocyte } \\
\text { hypertrophy, replacement fibrosis } \\
\text { LIIERR Steatosis, congestion } \\
\text { KIDNEY: Moderate to severe } \\
\text { arterionephrosclerosis, diabetic changes } \\
\text { TRACHEA: Edema, chronic } \\
\text { (Iymphocytic) tracheitisi }\end{array}$ & $\mathrm{N} / \mathrm{D}$ & $\mathrm{N} / \mathrm{D}$ & $\begin{array}{l}\text { (ICD-10 code) } \\
\text { A: } \\
\text { cardiomyopathy } \\
\text { B: COVIID-19 } \\
\text { OSC: DM, } \\
\text { pulmonary } \\
\text { hypertension, } \\
\text { immunosuppres- } \\
\text { sion } \\
\end{array}$ & $\begin{array}{c}\text { Positive for SARS } \\
\text { CoV-2 } \\
\text { (unspecified) }\end{array}$ \\
\hline & 54 & $\mathrm{M}$ & $\begin{array}{c}\text { Neurological } \\
\text { alteration and } \\
\text { dysphagia from } \\
\text { previous head injury }\end{array}$ & $\mathrm{N} / \mathrm{D}$ & N/D & $\begin{array}{l}\text { Chest X-ray: } \\
\text { bilateral patchy } \\
\text { opacities }\end{array}$ & $\begin{array}{l}\text { Hospital presentation: } \\
\text { 1-day history of fever, } \\
\text { respiratory distress and } \\
\text { tachycardia. Refused } \\
\text { intubation and died the } \\
\text { day after admission }\end{array}$ & $\mathrm{N} / \mathrm{D}$ & $\mathrm{N} / \mathrm{D}$ & 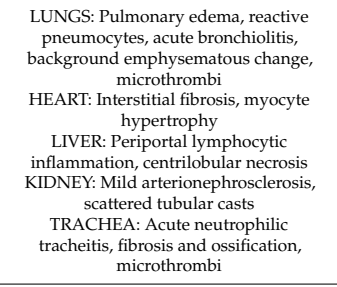 & $\mathrm{N} / \mathrm{D}$ & $\mathrm{N} / \mathrm{D}$ & $\begin{array}{l}\text { (ICD-10 code) } \\
\text { A: aspiration } \\
\text { pneumonia and } \\
\text { sepsis } \\
\text { B: COVID-19 } \\
\text { OSC: dysphagia } \\
\text { due to traumatic } \\
\text { neurological } \\
\text { damage }\end{array}$ & $\begin{array}{c}\text { Positive for SARS } \\
\text { CoV-2 } \\
\text { (unspecified) }\end{array}$ \\
\hline & 74 & M & $\begin{array}{l}\text { Heart failure with } \\
\text { preserved EF, } \\
\text { frontotemporal } \\
\text { dementia, HTN, } \\
\text { OSAS }\end{array}$ & Intubation & $\mathrm{N} / \mathrm{D}$ & $\begin{array}{l}\text { Chest X-ray: diffuse } \\
\text { bilateral scattered } \\
\text { opacities }\end{array}$ & $\begin{array}{l}\text { Hospital presentation: } \\
\text { counh, yyalgiais } \\
\text { respiratory distress and } \\
\text { fever Inthubated, died } \\
\text { on the day of admission }\end{array}$ & $\mathrm{N} / \mathrm{D}$ & $\mathrm{N} / \mathrm{D}$ & $\begin{array}{l}\text { LUNGS: Pulmonary edema, acute phase } \\
\text { DAD, multinucleated giant cells, } \\
\text { reactive } \\
\text { pneumocytes, alveolar septal thickening, } \\
\text { patchy perivascular lymphocytic } \\
\text { inflammation } \\
\text { HEART: Interstitial fibrosis, myocyte } \\
\text { Hypertrophy, replacement fibrosis } \\
\text { LIVER: Steatosis, congestion, features of } \\
\text { toxic or metabolic disease } \\
\text { KIDNEY: Mild to moderate } \\
\text { arteriolosclerosis, scattered tubular casts } \\
\text { TRACHEA: Acute neutrophilic tracheitis }\end{array}$ & $\mathrm{N} / \mathrm{D}$ & $\mathrm{N} / \mathrm{D}$ & $\begin{array}{l}\text { (ICD-10 code) } \\
\text { A: ARDS } \\
\text { B: viral } \\
\text { pneumonia } \\
\text { C: COVID-19 } \\
\text { OSC: CKD }\end{array}$ & $\begin{array}{l}\text { Positive for SARS } \\
\text { CoV-2 } \\
\text { (unspecified) }\end{array}$ \\
\hline
\end{tabular}


Table 1. Cont.

\begin{tabular}{|c|c|c|c|c|c|c|c|c|c|c|c|c|c|c|}
\hline \multirow[b]{2}{*}{ Author } & \multirow[b]{2}{*}{ A } & \multirow[b]{2}{*}{ G } & \multicolumn{5}{|c|}{ IN VIVO DATA } & \multicolumn{7}{|c|}{ POSTMORTEM DATA } \\
\hline & & & $\begin{array}{c}\text { Comorbidities and } \\
\text { Past Drugs }\end{array}$ & Therapy & Labor & Imaging & $\begin{array}{l}\text { Course of the } \\
\text { Disease/Circumstances } \\
\text { of Death }\end{array}$ & Imaging & $\underset{\text { Features }}{\text { Macroscopic }}$ & Microscopic Features & Tox & $\begin{array}{l}\text { Additional } \\
\text { Analyses }\end{array}$ & Cause of Death & Swabs \\
\hline & 73 & $\mathrm{~F}$ & $\begin{array}{l}\text { DM2, HTN, } \\
\text { congestive heart } \\
\text { failure } \\
\text { hypothyroidism, } \\
\text { obesity, } \\
\text { schizoaffective } \\
\text { disorder, bipolar } \\
\text { disorder }\end{array}$ & Intubation & $\mathrm{N} / \mathrm{D}$ & $\begin{array}{c}\text { Chest X-ray: } \\
\text { widespread bilateral } \\
\text { opacities }\end{array}$ & $\begin{array}{l}\text { Hospital presentation: } \\
\text { 5-day history of cough, } \\
\text { respiritory distress and } \\
\text { fever Intubatede, died } 8 \\
\text { days affer admission }\end{array}$ & $\mathrm{N} / \mathrm{D}$ & $\mathrm{N} / \mathrm{D}$ & 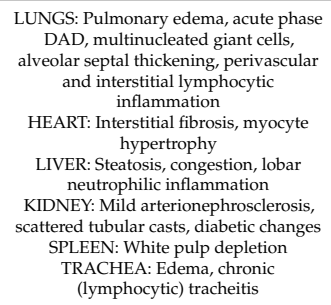 & $\mathrm{N} / \mathrm{D}$ & $\mathrm{N} / \mathrm{D}$ & $\begin{array}{l}\text { (ICD-10 code) } \\
\text { A: ARDS } \\
\text { B: viral } \\
\text { pneumonia } \\
\text { C: COVII-19 } \\
\text { OSC: obesity, } \\
\text { HTN, DM }\end{array}$ & $\begin{array}{c}\text { Positive for SARS } \\
\text { CoV-2 } \\
\text { (unspecified) }\end{array}$ \\
\hline & 84 & $\mathrm{~F}$ & $\begin{array}{l}\text { COPD, congestive } \\
\text { hear, failure, AF, } \\
\text { aoctic thenosis, HTN, } \\
\text { CKD, osteoporosis }\end{array}$ & N/D & lymphocytopenia & $\begin{array}{l}\text { Chest X-ray: } \\
\text { bibasilar atelectasis } \\
\text { or consoldations } \\
\text { with solil pleural } \\
\text { effusions }\end{array}$ & $\begin{array}{l}\text { Hospital presentation: } \\
\text { 1-day history of } \\
\text { respiratory distress and } \\
\text { deliriumm. Refused } \\
\text { intubation and died the } \\
\text { day after admission }\end{array}$ & $\mathrm{N} / \mathrm{D}$ & $\begin{array}{l}\text { LUNGS: presence of } \\
\text { intraparenchymal } \\
\text { hemorrhages }\end{array}$ & $\begin{array}{l}\text { LUNGS: Acute phase DAD, reactive } \\
\text { pneumocytes, pulmonary hemorrhage, } \\
\text { acute bronchopneumonia, background } \\
\text { emphysematous hhanges } \\
\text { HEART: Interstitial fibrosis, myocyte } \\
\text { hypertrophy , my } \\
\text { LIVER: Congestion, portal lymphocytic } \\
\text { inflammation } \\
\text { KIDNEY: Mild to moderate } \\
\text { arterionephrosclerosis, ccattered tubular } \\
\text { casts } \\
\text { TRACHEA: Edema, chronic } \\
\text { (lymphocytic) tracheitis }\end{array}$ & $\mathrm{N} / \mathrm{D}$ & $\mathrm{N} / \mathrm{D}$ & 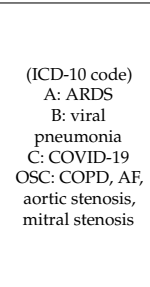 & $\begin{array}{c}\text { Positive for SARS } \\
\text { CoV-2 } \\
\text { (unspecified) }\end{array}$ \\
\hline & 71 & M & $\begin{array}{l}\text { HTN, dyslipidemia, } \\
\text { coronary heart } \\
\text { disease, AF, KD, } \\
\text { OSAS }\end{array}$ & N/D & $\begin{array}{l}\text { elevated } \\
\text { creatinine, } \\
\text { lymphocy- } \\
\text { topenia }\end{array}$ & $\begin{array}{l}\text { Chest X-ray: } \\
\text { bilateral multifocal } \\
\text { opacities }\end{array}$ & 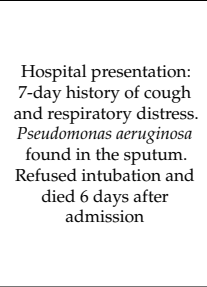 & $\mathrm{N} / \mathrm{D}$ & $\mathrm{N} / \mathrm{D}$ & 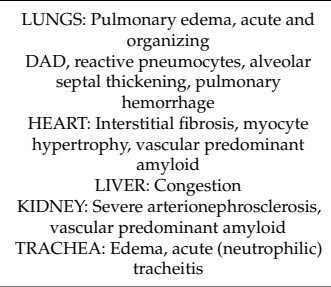 & $\mathrm{N} / \mathrm{D}$ & $\begin{array}{l}\text { P. aeruginosa found } \\
\text { in the sputum }\end{array}$ & $\begin{array}{l}\text { (ICD-10 code) } \\
\text { A: viral } \\
\text { pneumonia } \\
\text { B: COVID-19 } \\
\text { C: immunosup- } \\
\text { pression } \\
\text { OSC: end-stage } \\
\text { CKD, coronary } \\
\text { heart disease, } \\
\text { stroke }\end{array}$ & $\begin{array}{c}\text { Positive for SARS } \\
\text { CoV-2 } \\
\text { (unspecified) }\end{array}$ \\
\hline & 76 & $\mathrm{~F}$ & $\begin{array}{l}\text { Dyslipidemia, } \\
\text { osteoporosis }\end{array}$ & Intubation & $\begin{array}{l}\text { elevated } \\
\text { creatinine, } \\
\text { lymphocy- } \\
\text { topenia, } \\
\text { elevated } \\
\text { troponin }\end{array}$ & $\begin{array}{l}\text { Chest X-ray: } \\
\text { bilateral multifocal } \\
\text { opacities }\end{array}$ & $\begin{array}{l}\text { Hospital presentation: } \\
\text { 3-day history of } \\
\text { respiratory distress, } \\
\text { hypotension, } \\
\text { tachycardia and fever. } \\
\text { Stathlylococcus aureus e } \\
\text { Virus influenza A } \\
\text { detected. Intubated, } \\
\text { died } 4 \text { days after } \\
\text { admission }\end{array}$ & $\mathrm{N} / \mathrm{D}$ & $\begin{array}{l}\text { LUNGS: heavy and } \\
\text { edematousSPLENN: } \\
\text { splenomegalyCNS: } \\
\text { scattered punctate } \\
\text { subarachnoid } \\
\text { hemorrhages }\end{array}$ & 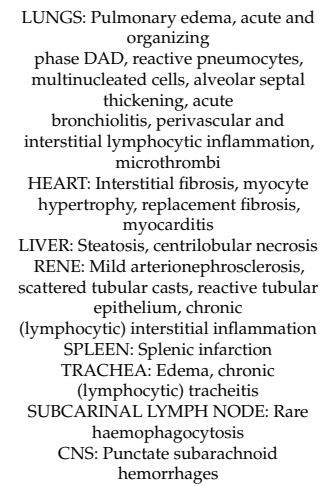 & $\mathrm{N} / \mathrm{D}$ & 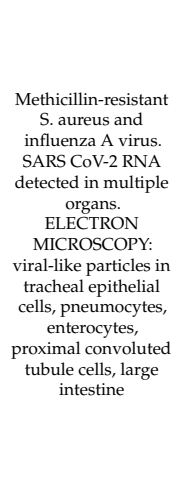 & 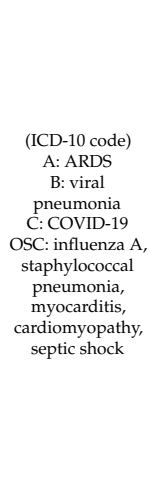 & $\begin{array}{c}\text { Positive for SARS } \\
\text { CoV-2 } \\
\text { (unspecified) }\end{array}$ \\
\hline
\end{tabular}


Table 1. Cont.

\begin{tabular}{|c|c|c|c|c|c|c|c|c|c|c|c|c|c|c|}
\hline \multirow[b]{2}{*}{ Author } & \multirow[b]{2}{*}{ A } & \multirow[b]{2}{*}{ G } & \multicolumn{5}{|c|}{ IN VIVO DATA } & \multicolumn{7}{|c|}{ POSTMORTEM DATA } \\
\hline & & & $\begin{array}{c}\text { Comorbidities and } \\
\text { Past Drugs }\end{array}$ & Therapy & Labor & Imaging & $\begin{array}{l}\text { Course of the } \\
\text { Disease/Circumstances } \\
\text { of Death }\end{array}$ & Imaging & $\begin{array}{c}\text { Macroscopic } \\
\text { Features }\end{array}$ & Microscopic Features & Tox & $\begin{array}{c}\text { Additional } \\
\text { Analyses }\end{array}$ & Cause of Death & Swabs \\
\hline & 75 & $\mathrm{~F}$ & $\begin{array}{l}\text { Dyslipidemia, , DM2, } \\
\text { coronary haert } \\
\text { disease, } 0 \text { - gestive } \\
\text { heart failure, cKRD, } \\
\text { COPD, DVT }\end{array}$ & N/D & lymphocytopenia & $\begin{array}{l}\text { Chest X-ray: } \\
\text { bilateral interstitial } \\
\text { opacites } \\
\text { asymmetrice demama } \\
\text { on the right }\end{array}$ & $\begin{array}{l}\text { The patient presented to } \\
\text { the hospitat with a } \\
\text { 3-day history of } \\
\text { delirum, fever and } \\
\text { respiritatory distress. She } \\
\text { refusuded intubation and } \\
\text { died } 9 \text { days after } \\
\text { admission }\end{array}$ & N/D & $\mathrm{N} / \mathrm{D}$ & 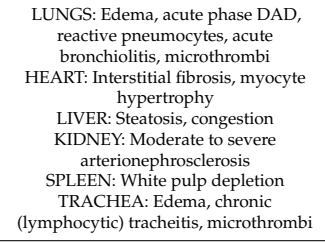 & $\mathrm{N} / \mathrm{D}$ & $\mathrm{N} / \mathrm{D}$ & $\begin{array}{l}\text { (ICD-10 code) } \\
\text { A: ARDS } \\
\text { B: pneumonia } \\
\text { C: COVID-19 } \\
\text { OSC: CKD, DM, } \\
\text { thromboembolism }\end{array}$ & $\begin{array}{c}\text { Positive for SARS } \\
\text { CoV-2 } \\
\text { (unspecified) }\end{array}$ \\
\hline & 81 & $\mathrm{~F}$ & 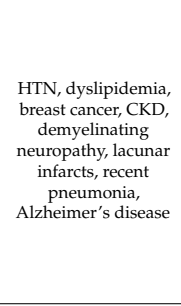 & Intubation & $\begin{array}{l}\text { elevated } \\
\text { troponin, lym- } \\
\text { phocytopenia }\end{array}$ & $\begin{array}{l}\text { Chest X-ray: } \\
\text { bilateral multifiocal } \\
\text { opacities }\end{array}$ & $\begin{array}{l}\text { Hospital presentation: } \\
\text { 1-day history of fever, } \\
\text { cough nausea and } \\
\text { vomit. Intubated after } 4 \\
\text { days, died } 6 \text { days after } \\
\text { admission }\end{array}$ & $\mathrm{N} / \mathrm{D}$ & $\begin{array}{l}\text { LUNGS: heavy and } \\
\text { edematous }\end{array}$ & 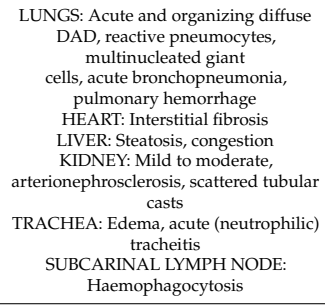 & $\mathrm{N} / \mathrm{D}$ & $\mathrm{N} / \mathrm{D}$ & $\begin{array}{l}\text { (ICD-10 code) } \\
\text { A: :ypoxemic } \\
\text { respiratory } \\
\text { failure } \\
\text { B: ARDS } \\
\text { C: iral and } \\
\text { bacterial } \\
\text { pneumoniaD: } \\
\text { COVID-19 } \\
\text { OSC: HTN }\end{array}$ & $\begin{array}{c}\text { Positive for SARS } \\
\text { CoV-2 } \\
\text { (unspecified) }\end{array}$ \\
\hline & 42 & $\mathrm{~F}$ & $\begin{array}{l}\text { History of lobular } \\
\text { breast cancer with } \\
\text { bilatera mastectomy } \\
\text { and neoadjuvant } \\
\text { chemotherapy }\end{array}$ & Intubation & $\begin{array}{l}\text { leukocytosis, } \\
\text { lymphocy- } \\
\text { topenia }\end{array}$ & $\begin{array}{l}\text { Chest X-ray: } \\
\text { bilateral multifiocal } \\
\text { opacities }\end{array}$ & $\begin{array}{l}\text { Hospital presentation: } \\
\text { 5-day history of fever } \\
\text { and headache. } \\
\text { Intubated after } 7 \text { days, } \\
\text { died } 9 \text { days after } \\
\text { admission }\end{array}$ & $\mathrm{N} / \mathrm{D}$ & $\begin{array}{l}\text { LUNGS: heavy and } \\
\text { edematous, } \\
\text { subsegenmental } \\
\text { emboli }\end{array}$ & $\begin{array}{l}\text { LUNGS: Pulmonary edema, acute and } \\
\text { organizing } \\
\text { phase DAD, reactive pneumocytes, } \\
\text { multinucleated giant cells, acute } \\
\text { bronchiolitis, subsegmental pulmonary } \\
\text { emboli } \\
\text { HEART: Interstititil firosis, myocyte } \\
\text { hypertrophy, replacement fibrosis } \\
\text { LIVERR Steatosis, congestion, } \\
\text { centrilobular necrosis } \\
\text { KIDNEY: Mild to moderate } \\
\text { arteriolosclerosis, scattered granular } \\
\text { casts } \\
\text { SPLEEN: White pulp depletion } \\
\text { TRACHEA: Edema }\end{array}$ & $\mathrm{N} / \mathrm{D}$ & $\mathrm{N} / \mathrm{D}$ & $\begin{array}{l}\text { (ICD-10 code) } \\
\text { A: ARDS } \\
\text { B: COID-19 } \\
\text { OSC: adjuvant } \\
\text { therapy for breast } \\
\text { cancer }\end{array}$ & $\begin{array}{c}\text { Positive for SARS } \\
\text { CoV-2 } \\
\text { (unspecified) }\end{array}$ \\
\hline
\end{tabular}


Table 1. Cont.

\begin{tabular}{|c|c|c|c|c|c|c|c|c|c|c|c|c|c|c|}
\hline \multirow{4}{*}{ Author } & \multirow[b]{2}{*}{ A } & \multirow[b]{2}{*}{ G } & \multicolumn{5}{|c|}{ IN VIVO DATA } & \multicolumn{7}{|c|}{ POSTMORTEM DATA } \\
\hline & & & $\begin{array}{c}\text { Comorbidities and } \\
\text { Past Drugs }\end{array}$ & Therapy & Labor & Imaging & $\begin{array}{l}\text { Course of the } \\
\text { Disease/Circumstances } \\
\text { of Death }\end{array}$ & Imaging & $\begin{array}{c}\text { Macroscopic } \\
\text { Features }\end{array}$ & Microscopic Features & Tox & $\begin{array}{c}\text { Additional } \\
\text { Analyses }\end{array}$ & Cause of Death & Swabs \\
\hline & 71 & M & 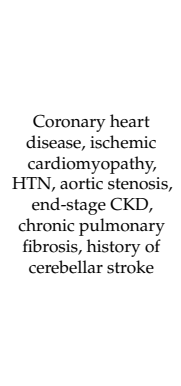 & $\mathrm{N} / \mathrm{D}$ & $\begin{array}{c}\text { elevated } \\
\text { creatinine, } \\
\text { elevated } \\
\text { troponin, lym- } \\
\text { phocytopenia }\end{array}$ & $\begin{array}{l}\text { Chest X-ray: } \\
\text { reduced lung } \\
\text { volumes, diffuse } \\
\text { pulmonary changes, } \\
\text { compatible with } \\
\text { pulmonary fibrosis }\end{array}$ & $\begin{array}{l}\text { Hospital presentation: } 1 \\
\text { day-history of shortness } \\
\text { of breath, bradycardia, } \\
\text { new onset AV block and } \\
\text { delirium. Worsening } \\
\text { hypoxia, refused } \\
\text { intubation. 4 days after } \\
\text { hospitalization, died of } \\
\text { cardiac arrest }\end{array}$ & N/D & $\begin{array}{l}\text { LUNGS: heavy and } \\
\text { edematousSPLEEN: } \\
\text { splenomegaly }\end{array}$ & $\begin{array}{l}\text { LUNGS: Pulmonary edema, acute phase } \\
\text { DAD, pulmonary hemorrhage, chronic } \\
\text { fibrosis, microthrombi } \\
\text { HEART: Interstitiat fibrosis, myocyte } \\
\text { hypertrophy, replacement fibrosis, } \\
\text { myocardial amyloid } \\
\text { LIVER: Congestion } \\
\text { KIDNEY: Severe arterionephrosclerosis, } \\
\text { scattered tubular casts, reactive tubular } \\
\text { epithelium, renal vein organizing } \\
\text { thrombuse } \\
\text { TRACHEA: Sloughed epithelium }\end{array}$ & $\mathrm{N} / \mathrm{D}$ & 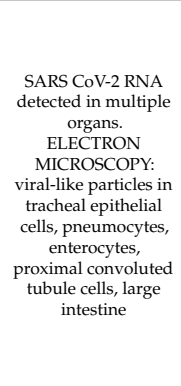 & $\begin{array}{c}\text { (ICD-10 code) } \\
\text { A: ventricular } \\
\text { fibrillation } \\
\text { B: ARDS } \\
\text { C: CDVID-19 } \\
\text { OSC: cardiac } \\
\text { conduction } \\
\text { system } \\
\text { anomalies, } \\
\text { cardiac, } \\
\text { amyloidosis, } \\
\text { ischemic heart } \\
\text { disease, HHN, } \\
\text { pulmonary } \\
\text { fibrosisy } \\
\text { end-stage CKD, } \\
\text { cervical spinal } \\
\text { stenosis }\end{array}$ & $\begin{array}{c}\text { Positive for SARS } \\
\text { CoV-2 } \\
\text { (unspecified) }\end{array}$ \\
\hline & 73 & $\mathrm{~F}$ & $\begin{array}{l}\text { HTN, asthma, DM, } \\
\text { dyslipidemia, } \\
\text { obesity }\end{array}$ & intubation & $\begin{array}{l}\text { elevated LDH } \\
\text { and } \\
\text { leukocytosis }\end{array}$ & $\begin{array}{l}\text { Chest X-ray: } \\
\text { reduced lung } \\
\text { volume, diffuse } \\
\text { bilateral changes }\end{array}$ & $\begin{array}{l}\text { Hospital presentation: } 2 \\
\text { day-history of } \\
\text { progressive shortrness of } \\
\text { breath and respiratory } \\
\text { distress. Prysical } \\
\text { examination revealed } \\
\text { hypoxia and signs of } \\
\text { shock. Developed } \\
\text { multifactorial } \\
\text { encephalopathy, AF and } \\
\text { presumed } \\
\text { ventilator-associated } \\
\text { pneumoniai. Intubated, } \\
\text { died } 21 \text { days after } \\
\text { hospitalization }\end{array}$ & N/D & $\begin{array}{l}\text { LUNGS: heavy and } \\
\text { edematous. } \\
\text { Parenchyal } \\
\text { consolidations }\end{array}$ & 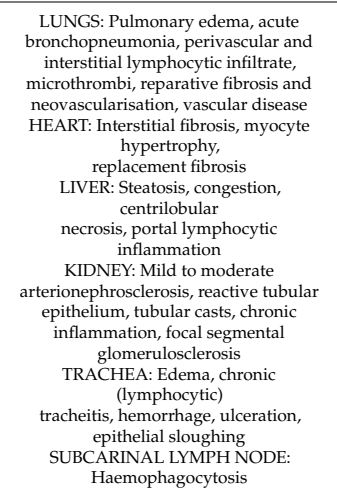 & $\mathrm{N} / \mathrm{D}$ & $\begin{array}{l}\text { SARS CoV-2 RNA } \\
\text { detected in multiple } \\
\text { organs }\end{array}$ & $\begin{array}{c}\text { (ICD-10 code) } \\
\text { A: ARDS } \\
\text { B: COVID-19 } \\
\text { OSC: HTN, } \\
\text { asthma, DM2, }{ }^{2} \text { AF, } \\
\text { obesity }\end{array}$ & $\begin{array}{c}\text { Positive for SARS } \\
\text { CoV-2 } \\
\text { (unspecified) }\end{array}$ \\
\hline $\begin{array}{l}\text { Dominic } \\
\text { Wich- } \\
\text { mann } \\
\text { et al. }\end{array}$ & 52 & M & $\begin{array}{l}\text { Obesity (BMI } 38.8 \\
\quad \mathrm{~kg} / \mathrm{m}^{2} \text { ) }\end{array}$ & $\mathrm{N} / \mathrm{D}$ & N/D & N/D & $\mathrm{N} / \mathrm{D}$ & $\begin{array}{l}\text { CT: diffuse bilateral } \\
\text { pulmonary } \\
\text { consolidations }\end{array}$ & $\begin{array}{l}\text { LUNGS: pulmonary } \\
\text { embolism, } \\
\text { pneumonia } \\
\text { HEART AND } \\
\text { VESSELS: } \\
\text { cardiomegaly, DVT, } \\
\text { atherosclerosis } \\
\text { OTHERS: } \\
\text { splenomegaly, } \\
\text { hepatomegaly, shock } \\
\text { organs l(liver, } \\
\text { kidneys) }\end{array}$ & $\begin{array}{l}\text { LUNGS: DAD, reactive pneumocytes, } \\
\text { fibroblasts, giant cells, scattered hyeline } \\
\text { membranes, slight fibrosis, congestion of } \\
\text { smmall vessels, }\end{array}$ & $\mathrm{N} / \mathrm{D}$ & $\mathrm{N} / \mathrm{D}$ & $\begin{array}{c}\text { CLINICAL: } \\
\text { sudden cardiac } \\
\text { death } \\
\text { PATHOLOGICAL: } \\
\text { pulmonary } \\
\text { embolism, } \\
\text { pneumonia }\end{array}$ & $\begin{array}{r}\text { POST MORTEM: } \\
\text { positive for SARS } \\
\text { CoV-2 } \\
\text { (nasopharyngeal) }\end{array}$ \\
\hline
\end{tabular}


Table 1. Cont.

\begin{tabular}{|c|c|c|c|c|c|c|c|c|c|c|c|c|c|c|}
\hline \multirow[b]{2}{*}{ Author } & \multirow[b]{2}{*}{ A } & \multirow[b]{2}{*}{ G } & \multicolumn{5}{|c|}{ IN VIVO DATA } & \multicolumn{7}{|c|}{ POSTMORTEM DATA } \\
\hline & & & $\begin{array}{l}\text { Comorbidities and } \\
\text { Past Drugs }\end{array}$ & Therapy & Labor & Imaging & $\begin{array}{l}\text { Course of the } \\
\text { Disease/Circumstances } \\
\text { of Death }\end{array}$ & Imaging & $\begin{array}{c}\text { Macroscopic } \\
\text { Features }\end{array}$ & Microscopic Features & Tox & $\begin{array}{l}\text { Additional } \\
\text { Analyses }\end{array}$ & Cause of Death & Swabs \\
\hline & 70 & M & $\begin{array}{l}\text { Parkinson's disease, } \\
\text { coronary heart } \\
\text { disease, PVD, CKD }\end{array}$ & $\begin{array}{l}\text { Rivaroxaban, } \\
\text { piperacillin/tazo- } \\
\text { bactan }\end{array}$ & $\begin{array}{l}\text { Elevated LDH, } \\
\text { elevated } \\
\text { creatinine, } \\
\text { elevated CRP }\end{array}$ & $\mathrm{N} / \mathrm{D}$ & $\mathrm{N} / \mathrm{D}$ & $\mathrm{N} / \mathrm{D}$ & $\begin{array}{l}\text { LUNGSS AND } \\
\text { AIRWAYS: } \\
\text { pneumonia, } \\
\text { purulent bronchitis } \\
\text { HEATT: coronary } \\
\text { heart disease, signs } \\
\text { of previous AMI, car- } \\
\text { diomegalyOTHES: } \\
\text { muscle stiffness, } \\
\text { shock liver }\end{array}$ & $\begin{array}{l}\text { LUNGS: DAD, activated pneumocytes, } \\
\text { hyaline membranes, scattered } \\
\text { lymphocytes. Focal granuluccte } \\
\text { infiltrates, acute and chronic bronchitis }\end{array}$ & $\mathrm{N} / \mathrm{D}$ & $\mathrm{N} / \mathrm{D}$ & $\begin{array}{l}\text { CLINICAL: } \\
\text { respiratory } \\
\text { failure, } \\
\text { pneumonia } \\
\text { PATHOLOICAL: } \\
\text { pneumonia with } \\
\text { bronchopneumo- } \\
\text { nia }\end{array}$ & $\begin{array}{l}\text { POST MORTEM: } \\
\text { positive for SARS } \\
\text { CoV-2 } \\
\text { (nasopharyngeal) }\end{array}$ \\
\hline & 71 & M & $\begin{array}{c}\text { HTN, smoking, } \\
\text { granulomatous } \\
\text { pneumonia, obesity } \\
\text { (BMI } 36.8 \mathrm{~kg} / \mathrm{m} 2)\end{array}$ & $\begin{array}{l}\text { Vasopressors, } \\
\text { intubation, } \\
\text { meropenem, } \\
\text { levofloxacin, } \\
\text { enoxaparin }\end{array}$ & $\begin{array}{c}\text { Elevated } \\
\text { aPTT, } \\
\text { Elevated LDH, } \\
\text { Elevated CRP, } \\
\text { Elevated } \\
\text { creatinine }\end{array}$ & N/D & N/D & $\begin{array}{l}\text { CT: emphysema, subtle } \\
\text { reticular pattern in each } \\
\text { lobe, consolidations in } \\
\text { the lower right and } \\
\text { lower left lobe }\end{array}$ & $\begin{array}{l}\text { LUNGS pulmonary } \\
\text { embolism, } \\
\text { pneumbonia HEART } \\
\text { AND VASES: } \\
\text { coronary heart } \\
\text { disease, DVI, } \\
\text { atherosclorosis } \\
\text { OTHERS: anasarca }\end{array}$ & $\begin{array}{l}\text { LUNGS: DAD, squamous metaplasia, } \\
\text { fibroblasts, ,hyaline membranes, } \\
\text { activated nneumocytes, thromboemboli } \\
\text { HEART: lymphocytic myocardititi in the } \\
\text { right ventricle }\end{array}$ & $\mathrm{N} / \mathrm{D}$ & $\mathrm{N} / \mathrm{D}$ & $\begin{array}{l}\text { CLINICAL: } \\
\text { respiratory } \\
\text { failure, } \\
\text { preumonia } \\
\text { PATHOLOLICAL: } \\
\text { pulmonary } \\
\text { embolism, } \\
\text { pneumonia }\end{array}$ & $\begin{array}{l}\text { POST MORTEM: } \\
\text { positive for SARS } \\
\text { CoV-2 } \\
\text { (nasopharyngeal) }\end{array}$ \\
\hline & 63 & M & $\begin{array}{c}\text { DM2, obesity (BMI } \\
37.3 \mathrm{~kg} / \mathrm{m}^{2} \text { ), asthma }\end{array}$ & $\begin{array}{c}\text { Vasopressors, } \\
\text { intubation, } \\
\text { cefpodoxime }\end{array}$ & $\begin{array}{l}\text { Elevated } \\
\text { D-dimer, } \\
\text { Elevated LDH, } \\
\text { Elevated CRP }\end{array}$ & $\mathrm{N} / \mathrm{D}$ & $\mathrm{N} / \mathrm{D}$ & $\mathrm{N} / \mathrm{D}$ & $\begin{array}{l}\text { LUNGS: pulmonary } \\
\text { embolism, } \\
\text { pneumonia HEART } \\
\text { AND VESSES: } \\
\text { cardiomegaly, DVT } \\
\text { OTHERS: ischemic } \\
\text { colitis, ,iver in shock }\end{array}$ & $\begin{array}{l}\text { LUNGS: DAD, fibroblasts, activated } \\
\text { pneumocytes, ,hyaline membranes, } \\
\text { squamoun metaplasia, hemorrhagic } \\
\text { infarcts, thrombemborli }\end{array}$ & $\mathrm{N} / \mathrm{D}$ & $\mathrm{N} / \mathrm{D}$ & $\begin{array}{c}\text { CLINICAL: } \\
\text { cardiopulmonary } \\
\text { failure, } \\
\text { pulmonary } \\
\text { embolism } \\
\text { PATHOLOGCAL: } \\
\text { pulmonary } \\
\text { embolism, } \\
\text { pneumonia }\end{array}$ & $\begin{array}{l}\text { POST MORTEM: } \\
\text { positive for SARS } \\
\text { CoV-2 } \\
\text { (nasopharyngeal) }\end{array}$ \\
\hline & 66 & M & $\begin{array}{l}\text { Coronary heart } \\
\text { disease }\end{array}$ & N/D & N/D & $\mathrm{N} / \mathrm{D}$ & $\mathrm{N} / \mathrm{D}$ & $\begin{array}{l}\text { CT: consolidations in } \\
\text { each lobe, reticular } \\
\text { pattern in the upper and } \\
\text { lower right lobes and in } \\
\text { both left lobes }\end{array}$ & $\begin{array}{l}\text { LUNGS: evidence of } \\
\text { pneumonia } \\
\text { HEART AND } \\
\text { VESSELS: coronary } \\
\text { heart disease, } \\
\text { previous AMI, DVT }\end{array}$ & $\begin{array}{l}\text { LUNGS: DAD, activated pneumocytes, } \\
\text { fibroblasts, hyaline membranes, necrosis, } \\
\text { lymphocytes, thromboemboli }\end{array}$ & $\mathrm{N} / \mathrm{D}$ & $\mathrm{N} / \mathrm{D}$ & $\begin{array}{l}\text { CLINICAL: } \\
\text { sudden Cardiac } \\
\text { death } \\
\text { PATHOLOGICAL: } \\
\text { pneumonia }\end{array}$ & $\begin{array}{l}\text { POST MORTEM: } \\
\text { positive for SARS } \\
\text { CoV-2 } \\
\text { (nasopharyngeal) }\end{array}$ \\
\hline & 54 & $\mathrm{~F}$ & $\begin{array}{l}\text { Dementia, epilepsy, } \\
\text { trisomy } 21\end{array}$ & N/D & $\begin{array}{l}\text { Elevated LDH, } \\
\text { Elevated CRP }\end{array}$ & $\mathrm{N} / \mathrm{D}$ & $\mathrm{N} / \mathrm{D}$ & $\begin{array}{l}\text { CT: multiple right and } \\
\text { left consolidations, } \\
\text { ground glass opacities } \\
\text { in the right lobes and in } \\
\text { the upper left lobe, } \\
\text { reticular pattern }\end{array}$ & $\begin{array}{l}\text { LUNGS: pneumonia } \\
\text { OTHERS: renal } \\
\text { infarction, PEG }\end{array}$ & $\begin{array}{l}\text { LUNGS: extensive granulocytic infiltrate } \\
\text { in alveeli and bronchin, resemblhling focal } \\
\text { bacterial bronchopneumonia. Acute } \\
\text { bronchititis, congestion of small vessels }\end{array}$ & $\mathrm{N} / \mathrm{D}$ & $\mathrm{N} / \mathrm{D}$ & $\begin{array}{l}\text { CLINICAL: } \\
\text { respiratory } \\
\text { failure aspi- } \\
\text { ration pneumonia } \\
\text { PATHOLOGICAL: } \\
\text { pneumonia }\end{array}$ & $\begin{array}{c}\text { POST MORTEM: } \\
\text { positive for SARS } \\
\text { CoV-2 } \\
\text { (nasopharyngeal) }\end{array}$ \\
\hline & 75 & $\mathrm{~F}$ & $\begin{array}{l}\text { AF, smoking, } \\
\text { coronary heart } \\
\text { disease }\end{array}$ & $\mathrm{O}_{2}$, edoxaban & $\begin{array}{l}\text { Elevated } \\
\text { aPTT, } \\
\text { Elevated } \\
\text { D-dimer, } \\
\text { Elevated LDH, } \\
\text { Elevated CRP }\end{array}$ & $\mathrm{N} / \mathrm{D}$ & $\mathrm{N} / \mathrm{D}$ & $\begin{array}{l}\text { CT: reticular pattern in } \\
\text { each lobe, small areas of } \\
\text { consolidation in the } \\
\text { lower right lobe and } \\
\text { both left lobes }\end{array}$ & $\begin{array}{l}\text { LUNGS: pneumonia, } \\
\text { pulmonary } \\
\text { emphysema } \\
\text { HEART AND } \\
\text { VESSELS: coronary } \\
\text { heart disease, left } \\
\text { cardiac dilatation, } \\
\text { mitral calcicications, } \\
\text { cardiac pacemaker, } \\
\text { atherosclerosis }\end{array}$ & $\begin{array}{l}\text { LUNGS: DAD, hyaline membranes, } \\
\text { activated pneumocytes, squameus } \\
\text { metaplasia, emplysema, small vessel } \\
\text { congestion }\end{array}$ & $\mathrm{N} / \mathrm{D}$ & $\mathrm{N} / \mathrm{D}$ & $\begin{array}{l}\text { CLINICAL: } \\
\text { respiratory } \\
\text { failure, viral } \\
\text { premonia } \\
\text { PATHOLOGICAL: } \\
\text { pneumonia }\end{array}$ & $\begin{array}{l}\text { POST MORTEM: } \\
\text { positive for SARS } \\
\text { CoV-2 } \\
\text { (nasopharyngeal) }\end{array}$ \\
\hline & 82 & M & $\begin{array}{l}\text { Parkinson's disease, } \\
\text { DM2, coronary heart } \\
\text { disease }\end{array}$ & $\mathrm{N} / \mathrm{D}$ & $\begin{array}{l}\text { Elevated } \\
\text { D-dimer, } \\
\text { Elevated LDH, } \\
\text { Elevated CRP }\end{array}$ & $\mathrm{N} / \mathrm{D}$ & $\mathrm{N} / \mathrm{D}$ & $\begin{array}{l}\text { CT: emphysema, diffuse } \\
\text { consolidation in each } \\
\text { lobe, reticular pattern in } \\
\text { the upper and lower } \\
\text { right lobes and in the } \\
\text { lower left lobe. Bilateral } \\
\text { pleural effusions }\end{array}$ & $\begin{array}{l}\text { LUNGS: pneumonia, } \\
\text { emphysema } \\
\text { HEART AND } \\
\text { VESSELS coronary } \\
\text { heart diseaser } \\
\text { previous AMI with } \\
\text { left heart aneurysm, } \\
\text { atherosclerosis, DVT }\end{array}$ & $\begin{array}{l}\text { LUNGS: extensive granulocytic infiltrate } \\
\text { in alveoli and bronchi, resembling focal } \\
\text { bacterial bronchopneumonia, } \\
\text { emphysema }\end{array}$ & $\mathrm{N} / \mathrm{D}$ & $\mathrm{N} / \mathrm{D}$ & $\begin{array}{l}\text { CLINICAL: } \\
\text { respiratory } \\
\text { failure viral } \\
\text { preumonia } \\
\text { PATHOLOGICAL: } \\
\text { bronchopheumo- } \\
\text { nia }\end{array}$ & $\begin{array}{l}\text { POST MORTEM: } \\
\text { positive for SARS } \\
\text { CoV-2 } \\
\text { (nasopharyngeal) }\end{array}$ \\
\hline
\end{tabular}


Table 1. Cont.

\begin{tabular}{|c|c|c|c|c|c|c|c|c|c|c|c|c|c|c|}
\hline \multirow[b]{2}{*}{ Author } & \multirow[b]{2}{*}{ A } & \multirow[b]{2}{*}{ G } & \multicolumn{5}{|c|}{ IN VIVO DATA } & \multicolumn{7}{|c|}{ POSTMORTEM DATA } \\
\hline & & & $\begin{array}{c}\text { Comorbidities and } \\
\text { Past Drugs }\end{array}$ & Therapy & Labor & Imaging & $\begin{array}{l}\text { Course of the } \\
\text { Disease/Circumstances } \\
\text { of Death }\end{array}$ & Imaging & $\underset{\text { Features }}{\text { Macroscopic }}$ & Microscopic Features & Tox & $\begin{array}{l}\text { Additional } \\
\text { Analyses }\end{array}$ & Cause of Death & Swabs \\
\hline & 87 & $\mathrm{~F}$ & $\begin{array}{l}\text { Pulmonary NET, } \\
\text { COPD, coronary } \\
\text { heart disease, CKD }\end{array}$ & N/D & Elevated CRP & $\mathrm{N} / \mathrm{D}$ & N/D & $\begin{array}{l}\text { CT: emphysema, } \\
\text { spherical tumor in the } \\
\text { lower right lobe, small } \\
\text { areas of consolidation in } \\
\text { the upper and lower } \\
\text { right lobes and in the } \\
\text { upper left lobe, reticular } \\
\text { pattern in the uuper and } \\
\text { lower right lobes and } \\
\text { both left lobes }\end{array}$ & $\begin{array}{l}\text { LUNGS: pneumonia, } \\
\text { purulent bronchitis, } \\
\text { bullous emphysema, } \\
\text { pulmonary NET } \\
\text { HEART: coronary } \\
\text { heart disease, } \\
\text { previous AMI } \\
\text { OTHERS: achexia, } \\
\text { atherosclerosis }\end{array}$ & 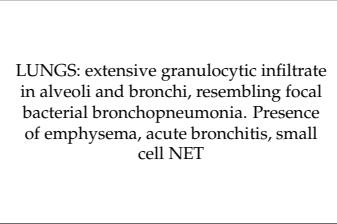 & $\mathrm{N} / \mathrm{D}$ & $\mathrm{N} / \mathrm{D}$ & $\begin{array}{l}\text { CLINICAL: } \\
\text { respiratory } \\
\text { failure, viral } \\
\text { Pneumonia } \\
\text { PTTHOLOICAL: } \\
\text { suppurative } \\
\text { bronchitis }\end{array}$ & $\begin{array}{l}\text { POST MORTEM: } \\
\text { positive for SARS } \\
\text { CoV-2 } \\
\text { (nasopharyngeal) }\end{array}$ \\
\hline & 84 & M & DM2, HTN, UC & $\mathrm{N} / \mathrm{D}$ & $\begin{array}{l}\text { Leukocytosis, } \\
\text { elevated } \\
\text { D-dimer, } \\
\text { elevated LDH, } \\
\text { elevated } \\
\text { creatinine, } \\
\text { elevated CRP }\end{array}$ & $\mathrm{N} / \mathrm{D}$ & $\mathrm{N} / \mathrm{D}$ & $\begin{array}{l}\text { CT: reticular pattern in } \\
\text { the upper and lower } \\
\text { right lobes and in both } \\
\text { the left lobes, } \\
\text { consolidation in the } \\
\text { middle and lower right } \\
\text { lobes and in both the } \\
\text { left lobes, ground glass } \\
\text { opacities in the upper } \\
\text { and middle right lobes } \\
\text { and in a portion of the } \\
\text { upper left lobee. Bilateral } \\
\text { pleural effusions }\end{array}$ & $\begin{array}{l}\text { LUNGS: pneumonia, } \\
\text { emphysema } \\
\text { HEART: revious } \\
\text { IMA } \\
\text { OTHERS: } \\
\text { septicemia, atrophic } \\
\text { kidneys }\end{array}$ & 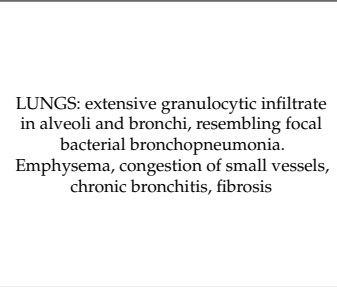 & $\mathrm{N} / \mathrm{D}$ & $\mathrm{N} / \mathrm{D}$ & $\begin{array}{l}\text { CLNICAL: } \\
\text { respiratory } \\
\text { failure, viral } \\
\text { premononia } \\
\text { PATHOLOGICAL: } \\
\text { pneumonia, } \\
\text { septic } \\
\text { encephalopathy }\end{array}$ & $\begin{array}{l}\text { POST MORTEM: } \\
\text { positive for SARS } \\
\text { CoV-2 } \\
\text { (nasopharyngeal) }\end{array}$ \\
\hline & 85 & M & $\begin{array}{l}\text { Coronary heart } \\
\text { disease, } \mathrm{HTN}, \\
\text { asthma, } \mathrm{AF}\end{array}$ & $\begin{array}{l}\text { Vasopressors, } \\
\text { intubation, } \\
\text { dialysis }\end{array}$ & $\begin{array}{l}\text { Elevated } \\
\text { aPTT, } \\
\text { elevated } \\
\text { D-dimer, } \\
\text { Delevated DDH, } \\
\text { elevated CRP, } \\
\text { elevated } \\
\text { procalcitonin }\end{array}$ & $\mathrm{N} / \mathrm{D}$ & N/D & $\begin{array}{l}\text { CT: diffuse } \\
\text { consolidations in each } \\
\text { lobe, reticular pattern in } \\
\text { the middle and lowere } \\
\text { right lobes and oth left } \\
\text { lobes, ground glass } \\
\text { opacities in the upper } \\
\text { and middle right lobes } \\
\text { and in the urpper left } \\
\text { lobe. Bilateral leural } \\
\text { effusions }\end{array}$ & $\begin{array}{l}\text { LUNGS: pneumonia, } \\
\text { minor pulmonary } \\
\text { embolism, } \\
\text { emphysema } \\
\text { HEART AND } \\
\text { VESSELS coronary } \\
\text { heart disease, } \\
\text { cardiomegaly, } \\
\text { atherosclerosis, DVT }\end{array}$ & $\begin{array}{l}\text { LUNGS: DAD, scattered hyaline } \\
\text { membranes, gantt cells, activated } \\
\text { pneumocytes, emphysema, small vessel } \\
\text { congestion, granulocyye infiltrates }\end{array}$ & $\mathrm{N} / \mathrm{D}$ & $\mathrm{N} / \mathrm{D}$ & $\begin{array}{l}\text { CLINICAL: } \\
\text { cardiac arrest due } \\
\text { to respiratory } \\
\text { failure } \\
\text { PATHOLOGICAL: } \\
\text { pneumonia }\end{array}$ & $\begin{array}{l}\text { POST MORTEM: } \\
\text { positive for SARS } \\
\text { CoV-2 } \\
\text { (nasopharyngeal) }\end{array}$ \\
\hline & 76 & M & $\begin{array}{c}\text { Obesity (BMI } 34.4 \\
\left.\mathrm{~kg} / \mathrm{m}^{2}\right)\end{array}$ & $\begin{array}{l}\text { Vasopressors, } \\
\text { intubation, } \\
\text { certainparin }\end{array}$ & $\begin{array}{l}\text { Elevated LDH, } \\
\text { elevated CRP }\end{array}$ & $\mathrm{N} / \mathrm{D}$ & $\mathrm{N} / \mathrm{D}$ & $\begin{array}{l}\text { CT: no ventilated area in } \\
\text { both lungs, except for a } \\
\text { small area in the upper } \\
\text { and middle right lobes } \\
\text { and in both the left } \\
\text { lobes. Bilateral pleural } \\
\text { effusions }\end{array}$ & $\begin{array}{l}\text { LUNGS: pulmonary } \\
\text { embolism with } \\
\text { pulmonary infarcts, } \\
\text { pneumonia, } \\
\text { purulent } \\
\text { tracheobronchitis, } \\
\text { emphysemaHEART } \\
\text { AND VESSELS: } \\
\text { cardiomegaly, DVT }\end{array}$ & $\begin{array}{l}\text { LUNGS: DAD, hyaline membranes, } \\
\text { fibrosis, activated pneumocytes, } \\
\text { lymphocytes, thrombosis, small vessel } \\
\text { congestion, plasma cells, hemorrhagic } \\
\text { infarcts }\end{array}$ & $\mathrm{N} / \mathrm{D}$ & $\mathrm{N} / \mathrm{D}$ & $\begin{array}{l}\text { CLINICAL: } \\
\text { pulmonary } \\
\text { embolim } \\
\text { PATHOLOGICAL: } \\
\text { pulmonary } \\
\text { embolis, } \\
\text { respiratory } \\
\text { infection }\end{array}$ & $\begin{array}{l}\text { POST MORTEM: } \\
\text { positive for SARS } \\
\text { CoV-2 } \\
\text { (nasopharyngeal) }\end{array}$ \\
\hline $\begin{array}{l}\text { Andrey } \\
\text { Prilut- } \\
\text { skiy } \\
\text { et al. }\end{array}$ & 72 & M & N/D & $\begin{array}{l}\text { Azithromycin, } \\
\text { HCQ, } \\
\text { anakinra, } \\
\text { intubation }\end{array}$ & $\begin{array}{l}\text { hypertriglyceridemia, } \\
\quad \text { elevated } \\
\text { ferritin, } \\
\text { elevated CRP }\end{array}$ & $\mathrm{N} / \mathrm{D}$ & $\begin{array}{l}\text { Hospital presentation: a } \\
\text { 4-day history of fever } \\
\text { and progressive } \\
\text { hypoxia. Intubated on } \\
7 \text { th dya, died } 18 \text { days } \\
\text { after hospitalization }\end{array}$ & $\mathrm{N} / \mathrm{D}$ & $\begin{array}{c}\text { Enlarged } \\
\text { mediastinal and } \\
\text { lung lymph nodes }\end{array}$ & 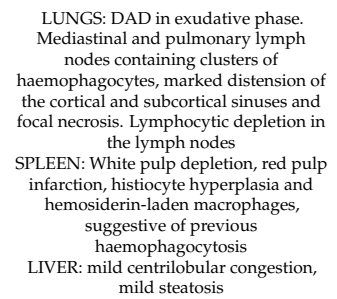 & $\mathrm{N} / \mathrm{D}$ & $\begin{array}{l}\text { immunohistochemistry } \\
\text { for HHVV, CMV and } \\
\text { EBRE for EBV in } \\
\text { lymph nodes with } \\
\text { haemophagocytosis: } \\
\text { negative } \\
\text { H-score for } \\
\text { haemophagocytic } \\
\text { lymphohhistiocytosis: } \\
217 \text { (HLH present) }\end{array}$ & ARDS, HLH & $\begin{array}{c}\text { Positive for SARS } \\
\text { CoV-2 } \\
\text { (nasopharyngeal) }\end{array}$ \\
\hline
\end{tabular}


Table 1. Cont.

\begin{tabular}{|c|c|c|c|c|c|c|c|c|c|c|c|c|c|c|}
\hline \multirow[b]{2}{*}{ Author } & \multirow[b]{2}{*}{ A } & \multirow[b]{2}{*}{ G } & \multicolumn{5}{|c|}{ IN VIVO DATA } & \multicolumn{7}{|c|}{ POSTMORTEM DATA } \\
\hline & & & $\begin{array}{c}\text { Comorbidities and } \\
\text { Past Drugs }\end{array}$ & Therapy & Labor & Imaging & $\begin{array}{l}\text { Course of the } \\
\text { Disease/Circumstances } \\
\text { of Death }\end{array}$ & Imaging & $\begin{array}{c}\text { Macroscopic } \\
\text { Features }\end{array}$ & Microscopic Features & Tox & $\begin{array}{l}\text { Additional } \\
\text { Analyses }\end{array}$ & Cause of Death & Swabs \\
\hline & 91 & M & N/D & $\begin{array}{l}\text { Azithromycin, } \\
\text { doxycycline, } \\
\text { HCQ }\end{array}$ & $\begin{array}{l}\text { elevated } \\
\text { fibrinogen, } \\
\text { elevated } \\
\text { ferrtitin, } \\
\text { elevated CRP }\end{array}$ & N/D & $\begin{array}{l}\text { Hospital presentation: } \\
\text { 1-day history of fever } \\
\text { and progressive } \\
\text { hypoxia. Refused } \\
\text { intubation and died } 8 \\
\text { days after admission }\end{array}$ & $\mathrm{N} / \mathrm{D}$ & $\begin{array}{c}\text { Enlarged } \\
\text { mediastinal and } \\
\text { pulmonary lymph } \\
\text { nodes } \\
\text { SPLEEN: enlarged, } \\
\text { with a oft and } \\
\text { crumbly appearance }\end{array}$ & $\begin{array}{l}\text { LUNGS: signs of exudative DAD. } \\
\text { Cluster of haemophagocytes in the } \\
\text { mediastinal and pulmonary lymph } \\
\text { nPLLes } \\
\text { SPLEN: large bleeding areas in red } \\
\text { pulp, focal hemophagocytosis, white } \\
\text { pulp depletion } \\
\text { LIVER: mild centrilobular congestion, } \\
\text { mild steatosis }\end{array}$ & $\mathrm{N} / \mathrm{D}$ & $\begin{array}{l}\text { immunohistochemistry } \\
\text { for HHV8, CMV and } \\
\text { EEER for EBV in } \\
\text { lymph nodes with } \\
\text { haemophagocytosis: } \\
\text { negative } \\
\text { H-score for } \\
\text { haemophagocytic } \\
\text { lymphohistiocytosis: } \\
145 \text { (incomplete } \\
\text { corer, } \\
\text { triglyceridemia } \\
\text { values were missing, } \\
\text { probable HLH) }\end{array}$ & ARDS & $\begin{array}{c}\text { Positive for SARS } \\
\text { CoV-2 } \\
\text { (nasopharyngeal) }\end{array}$ \\
\hline & 72 & M & N/D & $\begin{array}{l}\text { Azithromycin, } \\
\text { ceftriaxone, } \\
\text { sarilumab }\end{array}$ & $\begin{array}{c}\text { increase in } \\
\text { platelets, } \\
\text { elevated } \\
\text { fibringogen, } \\
\text { elevated CRP }\end{array}$ & N/D & $\begin{array}{l}\text { Hospital presentation: } \\
\text { 3-day history of fever } \\
\text { and progressive } \\
\text { hypoxia. Refused } \\
\text { intubation and died } 6 \\
\text { days after admission }\end{array}$ & $\mathrm{N} / \mathrm{D}$ & $\begin{array}{c}\text { Enlarged } \\
\text { mediastinal and } \\
\text { lung lymph nodes }\end{array}$ & 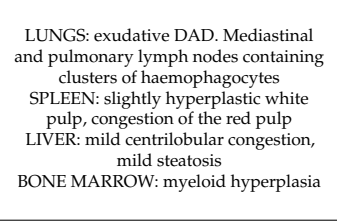 & $\mathrm{N} / \mathrm{D}$ & $\begin{array}{l}\text { immunohistochemistry } \\
\text { for HHVI, CMV and } \\
\text { EBER for EBV in } \\
\text { lymph nodes with } \\
\text { haemophagocytosis: } \\
\text { negative } \\
\text { H-score for } \\
\text { haemophagocytic } \\
\text { lymphohistiocytosis: } \\
\text { 131 (HLH absent) }\end{array}$ & ARDS & $\begin{array}{c}\text { Positive for SARS } \\
\text { CoV-2 } \\
\text { (nasopharyngeal) }\end{array}$ \\
\hline & 64 & $\mathrm{~F}$ & N/D & $\begin{array}{l}\text { Sarilumab, } \\
\text { ceftriaxone, } \\
\text { intubation }\end{array}$ & $\begin{array}{l}\text { hypertriglyceridaemia, } \\
\text { elevated } \\
\text { fibrinogen, } \\
\text { elevated } \\
\text { ferritin, } \\
\text { elevated CRP }\end{array}$ & $\mathrm{N} / \mathrm{D}$ & $\begin{array}{l}\text { Hospital presentation: } \\
\text { 5-day history of fever } \\
\text { and progressive } \\
\text { hypoxia. Intubated, } \\
\text { died } 15 \text { days after } \\
\text { hospitalization }\end{array}$ & $\mathrm{N} / \mathrm{D}$ & $\mathrm{N} / \mathrm{D}$ & $\begin{array}{l}\text { LUNGS: DAD in the exudative phase } \\
\text { SPLEEN: hyperplastic white pulp, } \\
\text { congestion of the red pulp } \\
\text { LIVER: mild centrilobular congestion, } \\
\text { mild steatosis } \\
\text { BONE MARROW: myeloid hyperplasia }\end{array}$ & $\mathrm{N} / \mathrm{D}$ & $\begin{array}{c}\text { H-score for } \\
\text { haemophagocytic } \\
\text { lymphohistioytosis: } \\
96 \text { (HLH absent) }\end{array}$ & ARDS & $\begin{array}{c}\text { Positive for SARS } \\
\text { CoV-2 } \\
\text { (nasopharyngeal) }\end{array}$ \\
\hline \multirow[b]{2}{*}{$\begin{array}{c}\text { Hans } \\
\text { Bös- } \\
\text { müller } \\
\text { et al. }\end{array}$} & 78 & $\mathrm{~F}$ & $\begin{array}{c}\text { Obesity (BMI } 35.2 \\
\text { Kg/m²,) HTNN AV } \\
\text { block treated with } \\
\text { permanent dual } \\
\text { chamber pacemaker }\end{array}$ & $\mathrm{N} / \mathrm{D}$ & N/D & $\mathrm{N} / \mathrm{D}$ & $\begin{array}{l}\text { Death at home after } 12 \mathrm{~h} \\
\text { of fever, cough and } \\
\text { vomiting }\end{array}$ & $\mathrm{N} / \mathrm{D}$ & $\begin{array}{l}\text { LUNGS: : ignificicant } \\
\text { pulmonary edema, } \\
\text { slight increase in the } \\
\text { consistency of the } \\
\text { lower lobes. } \\
\text { HEART: } 20 . \text { g. } \\
\text { dilation of both } \\
\text { ventricles }\end{array}$ & 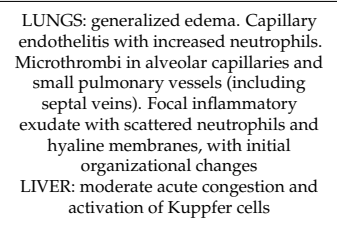 & $\mathrm{N} / \mathrm{D}$ & 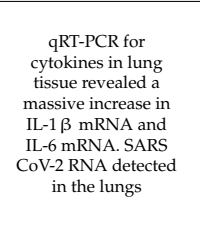 & $\begin{array}{l}\text { Early stage } \\
\text { pneumonia with } \\
\text { thrombotic } \\
\text { microangiopathy, } \\
\text { pulmonary } \\
\text { edema and acute } \\
\text { heart failure }\end{array}$ & $\begin{array}{c}\text { Positive for SARS } \\
\text { CoV-2 } \\
\text { (pharyngeal) }\end{array}$ \\
\hline & 78 & M & $\begin{array}{l}\text { Coronary heart } \\
\text { disease, HTN, DM, } \\
\text { Parkinson's disease }\end{array}$ & $\begin{array}{l}\text { Anticoagulants, } \\
\text { vasopressors, } \\
\text { intubation }\end{array}$ & $\begin{array}{l}\text { Lymphocytopenia, } \\
\text { elevated } \\
\text { D-dimer, } \\
\text { elevated } \\
\text { fibringegen, } \\
\text { elevated CRP, } \\
\text { elevated IL-6, } \\
\text { elevated LDH, } \\
\text { elevated , } \\
\text { creatine } \\
\text { kinase and } \\
\text { feritin. } \\
\text { Progressive } \\
\text { thrombocy- } \\
\text { topenia, } \\
\text { terminal } \\
\text { reduction of } \\
\text { D-dimers and } \\
\text { IL-6 }\end{array}$ & N/D & 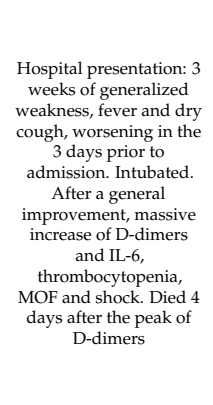 & $\mathrm{N} / \mathrm{D}$ & 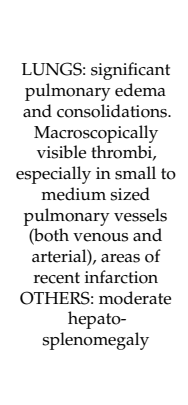 & $\begin{array}{l}\text { LUNGS: Diffuse DAD with massive } \\
\text { intra-alveolala fibrin deposits and hyaline } \\
\text { membranes. Marked hyperplasia and } \\
\text { desquamation of the alveolar epithelium. } \\
\text { Diffuse areas of organized DAD with } \\
\text { proliferation of fibroblasts and collagen } \\
\text { fiber deposition in intra alveolar } \\
\text { exudatet. Focal massive presence of } \\
\text { leukocytes in medium-sized vessels } \\
\text { LIVER: signs of haemophagocytosis }\end{array}$ & $\mathrm{N} / \mathrm{D}$ & $\begin{array}{l}\text { ELECTRON } \\
\text { MICROSCOPY: } \\
\text { viral-like particles in } \\
\text { lunge ndothelial } \\
\text { cells and type 1 } \\
\text { pneumocytes } \\
\text { Blood cultures for } \\
\text { blacteria and fungi: } \\
\text { negative. SARS } \\
\text { CoV-2 RNA detected } \\
\text { in the lungs }\end{array}$ & $\begin{array}{l}\text { ARDS, vasogenic } \\
\text { shock and liver } \\
\text { failure }\end{array}$ & $\begin{array}{c}\text { Positive for SARS } \\
\text { CoV-2 } \\
\text { (pharyngeal) }\end{array}$ \\
\hline
\end{tabular}


Table 1. Cont.

\begin{tabular}{|c|c|c|c|c|c|c|c|c|c|c|c|c|c|c|}
\hline \multirow[b]{2}{*}{ Author } & \multirow[b]{2}{*}{ A } & \multirow[b]{2}{*}{ G } & \multicolumn{5}{|c|}{ IN VIVO DATA } & \multicolumn{7}{|c|}{ POSTMORTEM DATA } \\
\hline & & & $\begin{array}{c}\text { Comorbidities and } \\
\text { Past Drugs }\end{array}$ & Therapy & Labor & Imaging & $\begin{array}{l}\text { Course of the } \\
\text { Disease/Circumstances } \\
\text { of Death }\end{array}$ & Imaging & $\begin{array}{c}\text { Macroscopic } \\
\text { Features }\end{array}$ & Microscopic Features & Tox & $\begin{array}{l}\text { Additional } \\
\text { Analyses }\end{array}$ & Cause of Death & Swabs \\
\hline & 72 & M & 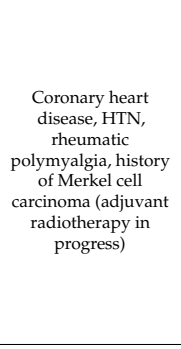 & $\begin{array}{c}\text { Meropenem, } \\
\text { dialysis, } \\
\text { intubation }\end{array}$ & $\begin{array}{l}\text { Lymphocytopenia, } \\
\text { elevated CRP, } \\
\text { elevated II-6. } \\
\text { 6 days after } \\
\text { admission } \\
\text { leukocytosis, } \\
\text { elevated } \\
\text { D-dimer, } \\
\text { elevated CRr, } \\
\text { elevated IL-6, } \\
\text { elevated } \\
\text { procalcitonin }\end{array}$ & $\mathrm{N} / \mathrm{D}$ & 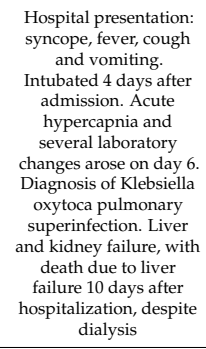 & N/D & 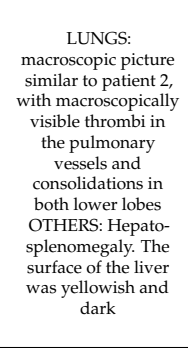 & $\begin{array}{l}\text { LUNGS: advanced DAD, with extensive } \\
\text { hyaline membranes and concentration } \\
\text { of intra-alveolar macrophages, multiple } \\
\text { giant cells and pronounced hyperplasia } \\
\text { of the alveolar epithelium (partly } \\
\text { atypical). Focal squamous metaplasia } \\
\text { and areas of organizing pneumonia. } \\
\text { Viral particleses in the endothelial cells of } \\
\text { the lung capillaries and in the interstitial } \\
\text { spaces }\end{array}$ & $\mathrm{N} / \mathrm{D}$ & $\begin{array}{l}\text { blood cultures for } \\
\text { bacteria and fungi: } \\
\text { negative. After } 6 \\
\text { days of } \\
\text { hospitilization, } \\
\text { Klebsiella oxytoca } \\
\text { superinfection. } \\
\text { SARS CoV-2 RNA } \\
\text { detected in the lungs }\end{array}$ & $\begin{array}{l}\text { ARDS; vasogenic } \\
\text { shock, liver } \\
\text { failure }\end{array}$ & $\begin{array}{c}\text { Positive for SARS } \\
\text { CoV-2 } \\
\text { (pharyngeal) }\end{array}$ \\
\hline & 59 & M & $\begin{array}{l}\text { Obesity (BMI } 35.8 \\
\left.\mathrm{Kg} / \mathrm{m}^{2}\right) \text {, asthma, } \\
\mathrm{HTN}\end{array}$ & $\begin{array}{l}\text { ECMO, } \\
\text { dialysis }\end{array}$ & $\begin{array}{l}\text { Elevated } \\
\text { D-dimer }\end{array}$ & $\mathrm{N} / \mathrm{D}$ & $\begin{array}{l}\text { Hospital presentation: } 2 \\
\text { weeks of respiratory } \\
\text { symptoms. Respiratory } \\
\text { failure, started ECMO } \\
\text { and dialysis. Elevated } \\
\text { D-dimers found on } 2 \\
\text { cccasions. Within } 6 \\
\text { weeks of the onset of } \\
\text { symptoms, death due to } \\
\text { ARDS and MOF }\end{array}$ & $\mathrm{N} / \mathrm{D}$ & $\begin{array}{l}\text { LUNGS: very heavy, } \\
\text { significant } \\
\text { consolidations in } \\
\text { both upper and } \\
\text { lower lobes } \\
\text { HEART: } \\
\text { cardiomegaly, } 590 \mathrm{~g} \\
\text { OTHERS: signs of } \\
\text { liver damage, } \\
\text { intestinal mucositis } \\
\text { and intestinal } \\
\text { hemorrhage }\end{array}$ & $\begin{array}{l}\text { LUNGS: ARDS in organizing phase, } \\
\text { with extensive firbinous exudatas and } \\
\text { diffuse thickening of the alveolar septa. } \\
\text { Massive hyperplasia of the alveolar and } \\
\text { bronchial epithelium, focal squamous } \\
\text { metaplasia and typicac concentric } \\
\text { layered formations of loose connective } \\
\text { tissue, with central a gagregantes of } \\
\text { inflammatory cells }\end{array}$ & $\mathrm{N} / \mathrm{D}$ & $\begin{array}{l}\text { SARS CoV-2 RNA } \\
\text { detected in lthe } \\
\text { lungs }\end{array}$ & ARDS, MOF & $\begin{array}{c}\text { Positive for SARS } \\
\text { CoV-2 } \\
\text { (pharyngeal) }\end{array}$ \\
\hline
\end{tabular}


Table 1. Cont.

\begin{tabular}{|c|c|c|c|c|c|c|c|c|c|c|c|c|c|c|}
\hline \multirow[b]{2}{*}{ Author } & \multirow[b]{2}{*}{ A } & \multirow[b]{2}{*}{ G } & \multicolumn{5}{|c|}{ IN VIVO DATA } & \multicolumn{7}{|c|}{ POSTMORTEM DATA } \\
\hline & & & $\begin{array}{c}\text { Comorbidities and } \\
\text { Past Drugs }\end{array}$ & Therapy & Labor & Imaging & $\begin{array}{l}\text { Course of the } \\
\text { Disease/Circumstances } \\
\text { of Death }\end{array}$ & Imaging & $\begin{array}{c}\text { Macroscopic } \\
\text { Features }\end{array}$ & Microscopic Features & Tox & $\begin{array}{l}\text { Additional } \\
\text { Analyses }\end{array}$ & Cause of Death & Swabs \\
\hline & 34 & M & $\begin{array}{l}\text { Obesity (BMI } 51.65 \\
\text { Kg/m²), HTTN, heart } \\
\text { failure with reduced } \\
\text { EF ( > 20\%), DM2 }\end{array}$ & $\begin{array}{c}\text { Antibiotics, } \\
\mathrm{O}_{2}\end{array}$ & $\begin{array}{c}\text { Leukocytosis, } \\
\text { mild anemia, } \\
\text { mildly } \\
\text { elevated } \\
\text { troponin, } \\
\text { elevated } \\
\text { creatinine }\end{array}$ & 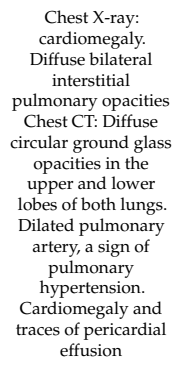 & 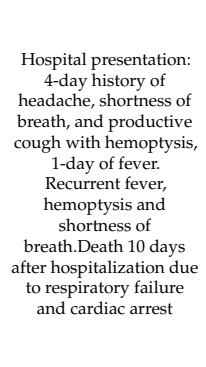 & $\mathrm{N} / \mathrm{D}$ & 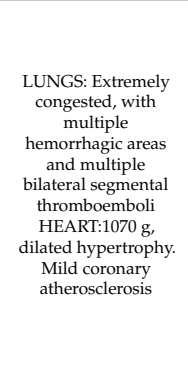 & 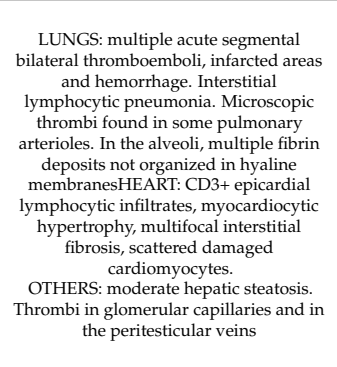 & $\mathrm{N} / \mathrm{D}$ & $\begin{array}{l}\text { Inffuenzza virus and } \\
\text { RSV test: negative }\end{array}$ & Not specified & $\begin{array}{c}\text { Positive for SARS } \\
\text { CoV-2 } \\
\text { (nasopharyngeal) }\end{array}$ \\
\hline & 48 & M & $\begin{array}{l}\text { Obesity (BMI } 35.2 \\
\left.\mathrm{Kg} / \mathrm{m}^{2}\right)\end{array}$ & N/D & N/D & N/D & $\begin{array}{l}\text { The man was found } \\
\text { dead in his residence }\end{array}$ & $\mathrm{N} / \mathrm{D}$ & 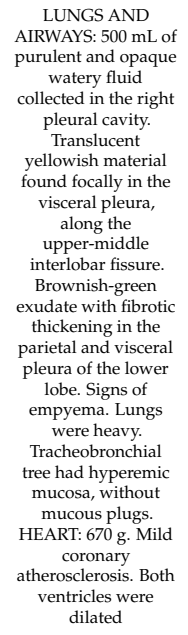 & 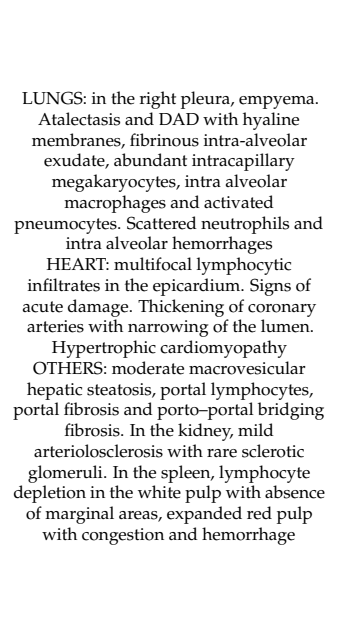 & N/D & $\begin{array}{l}\text { Influenza virus test: } \\
\text { negative }\end{array}$ & Not specified & $\begin{array}{r}\text { POST MORTEM } \\
\text { positive for SARS } \\
\text { CoV-2 } \\
\text { (nasopharyngeal) }\end{array}$ \\
\hline $\begin{array}{l}\text { Esther } \\
\text { Youd } \\
\text { et al. }\end{array}$ & 88 & $\mathrm{~F}$ & Dementia & N/D & $\mathrm{N} / \mathrm{D}$ & N/D & $\begin{array}{l}\text { Died in a nursing home. } \\
\text { No symptoms known }\end{array}$ & $\mathrm{N} / \mathrm{D}$ & $\begin{array}{c}\text { LUNGS AND } \\
\text { AIRWAYS: Heavy } \\
\text { lungs. Bilateral lobar } \\
\text { pnemoniaa. Tracheal } \\
\text { inflammation with } \\
\text { presence of } \\
\text { mucusHEART: } \\
\text { minimal } \\
\text { atheromatous } \\
\text { plaques } \\
\text { OHERSS small, } \\
\text { fibrotic kidneys. } \\
\text { Brain atrophy }\end{array}$ & $\begin{array}{l}\text { LUNGS: DAD with hyaline membranes, } \\
\text { type 2 pneumocyte hyperplasia and } \\
\text { enlargement of the alvelar walls and } \\
\text { interstitium, with lymphocytic infiltrate }\end{array}$ & N/D & $\mathrm{N} / \mathrm{D}$ & Not specified & $\begin{array}{l}\text { POST MORTEM } \\
\text { positive for SARS } \\
\text { CoV-2 (trachea } \\
\text { and lungs) }\end{array}$ \\
\hline
\end{tabular}


Table 1. Cont.

\begin{tabular}{|c|c|c|c|c|c|c|c|c|c|c|c|c|c|c|}
\hline \multirow[b]{2}{*}{ Author } & \multirow[b]{2}{*}{ A } & \multirow[b]{2}{*}{ G } & \multicolumn{5}{|c|}{ IN VIVO DATA } & \multicolumn{7}{|c|}{$\begin{array}{l}\text { POSTMORTEM DATA } \\
\end{array}$} \\
\hline & & & $\begin{array}{c}\text { Comorbidities and } \\
\text { Past Drugs }\end{array}$ & Therapy & Labor & Imaging & $\begin{array}{l}\text { Course of the } \\
\text { Disease/Circumstances } \\
\text { of Death }\end{array}$ & Imaging & $\begin{array}{c}\text { Macroscopic } \\
\text { Features }\end{array}$ & Microscopic Features & Tox & $\begin{array}{l}\text { Additional } \\
\text { Analyses }\end{array}$ & Cause of Death & Swabs \\
\hline & 86 & M & $\begin{array}{l}\text { HTN, COPD, heart } \\
\text { failure, dementia }\end{array}$ & $\mathrm{N} / \mathrm{D}$ & $\mathrm{N} / \mathrm{D}$ & N/D & $\begin{array}{l}\text { Died in a nursing home. } \\
\text { Symptoms reported } \\
\text { before death were. } \\
\text { cough, feetrer postural } \\
\text { instability }\end{array}$ & $\mathrm{N} / \mathrm{D}$ & $\begin{array}{l}\text { LUNGSS AND } \\
\text { AIRWAYS: Heavy } \\
\text { lungs, with signs of } \\
\text { consolidation. } \\
\text { Pulmonary edema, } \\
\text { anthracosis. Tracheal } \\
\text { inflammation with } \\
\text { presence of mucus } \\
\text { HEAR: 5922 g, } \\
\text { minimal } \\
\text { atheromatous } \\
\text { plaques } \\
\text { OTHERS: Chronic } \\
\text { hepatic venous } \\
\text { congestion. Fibrotic } \\
\text { kidneys. Enlarged } \\
\text { spleen with visible } \\
\text { nodules }\end{array}$ & $\begin{array}{l}\text { LUNGS: DAD with hyaline membranes, } \\
\text { type } 2 \text { pneumocyte hyperplasia and } \\
\text { enlargement of the alvelar walls and } \\
\text { interstitium, with lymphocyte infiltrate. } \\
\text { Bone marrow embolism } \\
\text { HEART: chronic ischemic changes and } \\
\text { contraction band necrosis } \\
\text { SPLEEN: B-cell lymphomoan andiagnosed } \\
\text { in vivo }\end{array}$ & $\mathrm{N} / \mathrm{D}$ & $\mathrm{N} / \mathrm{D}$ & Not specified & $\begin{array}{l}\text { POST MORTEM } \\
\text { positive for SARS } \\
\text { CoV-2 (trachea) }\end{array}$ \\
\hline & 73 & $\mathrm{~F}$ & $\begin{array}{l}\text { Obesity, DM1, } \\
\text { asthma, heart failure }\end{array}$ & $\mathrm{N} / \mathrm{D}$ & $\mathrm{N} / \mathrm{D}$ & N/D & $\begin{array}{l}\text { Died at home. Reported } \\
\text { shortness of breath } \\
\text { before death }\end{array}$ & $\mathrm{N} / \mathrm{D}$ & 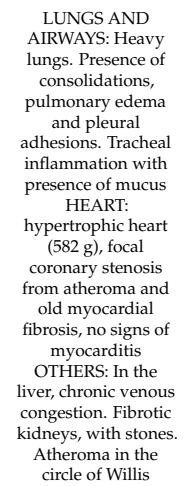 & 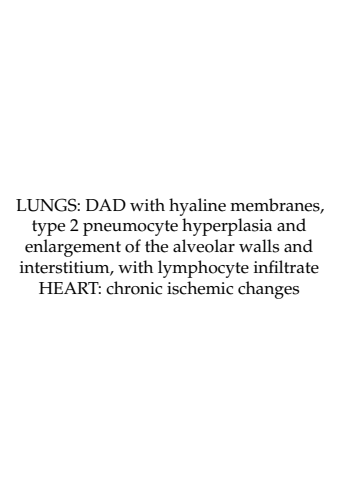 & $\mathrm{N} / \mathrm{D}$ & $\mathrm{N} / \mathrm{D}$ & Not specified & $\begin{array}{l}\text { POST MORTEM } \\
\text { positive for SARS } \\
\text { CoV-2 (trachea) }\end{array}$ \\
\hline $\begin{array}{l}\text { Lisa M. } \\
\text { Barton } \\
\text { et al. }\end{array}$ & 77 & M & $\begin{array}{l}\text { Obesity (BMI } 31.8 \\
\text { kg/m²), HTN, } \\
\text { history of DVI, } \\
\text { splenectony, history } \\
\text { of pancreatitis. } \\
\text { Positivity to ANAs }\end{array}$ & $\mathrm{N} / \mathrm{D}$ & $\mathrm{N} / \mathrm{D}$ & $\mathrm{N} / \mathrm{D}$ & $\begin{array}{l}\text { Chills and intermittent } \\
\text { fever without cough for } \\
6 \text { days. Weakness and } \\
\text { shortness of breath. } \\
\text { Cardiac arrest occurred } \\
\text { during transport to the } \\
\text { hospital }\end{array}$ & $\begin{array}{c}\text { X-ray: bilateral } \\
\text { pulmonary opacities }\end{array}$ & 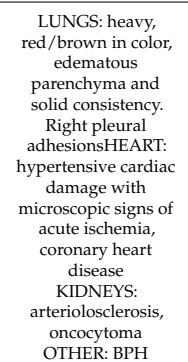 & $\begin{array}{l}\text { LUNGS: DAD in the acute phase, with } \\
\text { hyaline membranes. Scattered chronic } \\
\text { interstitial inflammation, consisting } \\
\text { mainly of lymphocytes. Thrombi in } \\
\text { small pulmonary arterial branches. } \\
\text { Congestion of alveolar septal capillaries } \\
\text { and focal edema in the air spaces. Mild } \\
\text { chronic inflammation of the bronchi and } \\
\text { bronchioles, with hedema in the bronchial } \\
\text { mulcosa. Scattered CD3 lymphocyte } \\
\text { infiltrates in the alveolar septa, with rare } \\
\text { CD20 + lymphocytes }\end{array}$ & $\mathrm{N} / \mathrm{D}$ & $\begin{array}{l}\text { Standard Panel for } \\
\text { Respiratory } \\
\text { Pathogens and swab } \\
\text { for Influenza Vivirus: } \\
\text { negative }\end{array}$ & $\begin{array}{l}\text { COVID-19, with } \\
\text { contributing } \\
\text { factors such as } \\
\text { coronary heart } \\
\text { disease }\end{array}$ & $\begin{array}{c}\text { POST MORTEM } \\
\text { Positive for SARS } \\
\text { CoV-2 } \\
\text { (nasopharyngeal } \\
\text { and lower } \\
\text { airways) }\end{array}$ \\
\hline
\end{tabular}


Table 1. Cont.

\begin{tabular}{|c|c|c|c|c|c|c|c|c|c|c|c|c|c|c|}
\hline \multirow[b]{2}{*}{ Author } & \multirow[b]{2}{*}{ A } & \multirow[b]{2}{*}{ G } & \multicolumn{5}{|c|}{ IN VIVO DATA } & \multicolumn{7}{|c|}{ POSTMORTEM DATA } \\
\hline & & & $\begin{array}{c}\text { Comorbidities and } \\
\text { Past Drugs }\end{array}$ & Therapy & Labor & Imaging & $\begin{array}{c}\text { Course of the } \\
\text { Disease/Circumstances } \\
\text { of Death }\end{array}$ & Imaging & $\begin{array}{c}\text { Macroscopic } \\
\text { Features }\end{array}$ & Microscopic Features & Tox & $\begin{array}{l}\text { Additional } \\
\text { Analyses }\end{array}$ & Cause of Death & Swabs \\
\hline \multirow[b]{2}{*}{$\begin{array}{l}\text { Miroslav } \\
\text { Sekulic } \\
\text { et al. }\end{array}$} & 42 & $\mathrm{M}$ & $\begin{array}{l}\text { Obesity (31.3 } \\
\mathrm{kg} \mathrm{m}^{2}, \text {, history of } \\
\text { myotonic dystrophy } \\
\text { and intestinal } \\
\text { obstructions }\end{array}$ & $\mathrm{N} / \mathrm{D}$ & $\mathrm{N} / \mathrm{D}$ & $\begin{array}{l}\text { Chest CT: bilateral } \\
\text { ground glasss } \\
\text { opacities bilateral } \\
\text { consolidatations }\end{array}$ & $\begin{array}{l}\text { Hospital presentation: } \\
\text { critical condition with } \\
\text { fever, cough and } \\
\text { shortness of breath, } \\
\text { abdominal pain. Death } \\
\text { due to heart failure } \\
\text { followed after a few } \\
\text { hours }\end{array}$ & $\begin{array}{c}\text { X-ray: bilateral } \\
\text { pulmonary opacities }\end{array}$ & 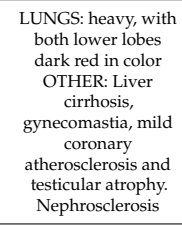 & $\begin{array}{l}\text { LUNGS: foci of acute } \\
\text { bronchopneumonia, with signs of } \\
\text { aspiration pneumonia and forieign } \\
\text { material. Neutrophils and histiocytes in } \\
\text { the peribronchiolarar air spaces. CD } 68+ \\
\text { in areas of bronchopneumonia. } \\
\text { KIDNEY: tubular crystals }\end{array}$ & $\mathrm{N} / \mathrm{D}$ & $\begin{array}{l}\text { Standard panel for } \\
\text { respiratory } \\
\text { pathogens: negative }\end{array}$ & $\begin{array}{l}\text { complications of } \\
\text { liver cirrhosis } \\
\text { with other } \\
\text { significant factors } \\
\text { (myotonic } \\
\text { dystrophy, } \\
\text { aspiration } \\
\text { pneumonia and } \\
\text { COVID-19) } \\
\end{array}$ & $\begin{array}{c}\text { POST MORTEM } \\
\text { Positive for SARS } \\
\text { CoV-2 } \\
\text { (nasopharyngeal } \\
\text { Negative for } \\
\text { SARS CV-2 } \\
\text { (lower airways) }\end{array}$ \\
\hline & 81 & M & 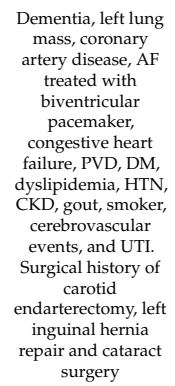 & $\mathrm{O}_{2}$ & $\begin{array}{l}\text { pancytopenia, } \\
\text { elevated } \\
\text { creatinine, } \\
\text { moderately } \\
\text { elevated urea } \\
\text { and BNP }\end{array}$ & $\begin{array}{l}\text { Chest X-ray: diffuse } \\
\text { patchy opacities in } \\
\text { the right lung and } \\
\text { subtle patchy } \\
\text { opacities in the } \\
\text { lower lobe of the left } \\
\text { lung. Chest CT: } \\
\text { multifocal bilateral } \\
\text { ground glass } \\
\text { opacities, lung mass } \\
\text { in the left lower lobe, } \\
\text { thin left pleural } \\
\text { effusion, moderate } \\
\text { cardiomegaly, } \\
\text { calcifications in the } \\
\text { coronary arteries } \\
\text { and in thoracic aorta }\end{array}$ & $\begin{array}{l}\text { Hospital presentation: } \\
\text { acute respiriatory failure } \\
\text { and fever. Cough, need } \\
\text { for oxygen support } \\
\text { until death, } 5 \text { days after } \\
\text { hospitalization }\end{array}$ & $\mathrm{N} / \mathrm{D}$ & $\begin{array}{l}\text { LUNGS: heavy } \\
\text { lungs. The } \\
\text { parenchyma was } \\
\text { congested and } \\
\text { emphysematous. } \\
\text { Mass in the lower } \\
\text { left lobe } \\
\text { HEAT: 620 g, } \\
\text { hypertrophy with } \\
\text { higns of chronic } \\
\text { ischemia, severe } \\
\text { coronary stenosis, } \\
\text { interstitial fibrosis }\end{array}$ & 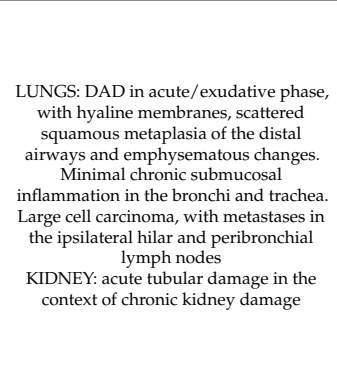 & $\mathrm{N} / \mathrm{D}$ & $\begin{array}{l}\text { Blood cultures and } \\
\text { urine cultures: } \\
\text { negative. Test for } \\
\text { Legionella, } \\
\text { pneumococcus, HIV: } \\
\text { negative. SARS } \\
\text { CoV-2 RNA found in } \\
\text { the lungs, fronchin } \\
\text { and lymph nodes. In } \\
\text { lower levels, also } \\
\text { found in spleen, } \\
\text { heart, liver, intestine } \\
\text { and skeletal muscle }\end{array}$ & $\begin{array}{l}\text { SARS CoV-2 } \\
\text { infection in a } \\
\text { setting of } \\
\text { metastatic } \\
\text { carcioma, } \\
\text { diabetes and } \\
\text { ischemic } \\
\text { cardiomyopathy, } \\
\text { leading to } \\
\text { respiratory } \\
\text { failure }\end{array}$ & $\begin{array}{c}\text { Positive for SAR } \\
\text { CoV-2 } \\
\text { (nasopharyngeal }\end{array}$ \\
\hline
\end{tabular}


Table 1. Cont.

\begin{tabular}{|c|c|c|c|c|c|c|c|c|c|c|c|c|c|c|}
\hline \multirow[b]{2}{*}{ Author } & \multirow[b]{2}{*}{ A } & \multirow[b]{2}{*}{ G } & \multicolumn{5}{|c|}{ IN VIVO DATA } & \multicolumn{7}{|c|}{ POSTMORTEM DATA } \\
\hline & & & $\begin{array}{c}\text { Comorbidities and } \\
\text { Past Drugs }\end{array}$ & Therapy & Labor & Imaging & $\begin{array}{l}\text { Course of the } \\
\text { Disease/Circumstances } \\
\text { of Death }\end{array}$ & Imaging & $\begin{array}{c}\text { Macroscopic } \\
\text { Features }\end{array}$ & Microscopic Features & Tox & $\begin{array}{c}\text { Additional } \\
\text { Analyses }\end{array}$ & Cause of Death & Swabs \\
\hline \multirow[b]{2}{*}{$\begin{array}{l}\text { Chaofu } \\
\text { Wang } \\
\text { et al. }\end{array}$} & 53 & $\mathrm{~F}$ & HTN, DM2 & Arbidol, $\mathrm{O}_{2}$ & $\begin{array}{l}\text { severe lym- } \\
\text { phocytopenia, } \\
\text { elevated IL-6 } \\
\text { and CRP }\end{array}$ & $\begin{array}{l}\text { Chest X-ray and } \\
\text { Chest CT: } \\
\text { unspecified severe } \\
\text { lung lesions }\end{array}$ & $\begin{array}{l}\text { Hospital presentation: } \\
\text { 2-day history of cough, } \\
\text { fever, and shortness of } \\
\text { breath. ARDS and died } \\
\text { of cardio-respiratory } \\
\text { failure 8 days after } \\
\text { admission }\end{array}$ & N/D & $\begin{array}{l}\text { LUNGS: moderate } \\
\text { bilateral pleural } \\
\text { effusions and fibrotic } \\
\text { pleural adhesions. } \\
\text { Hepatization of lung } \\
\text { tissue }\end{array}$ & 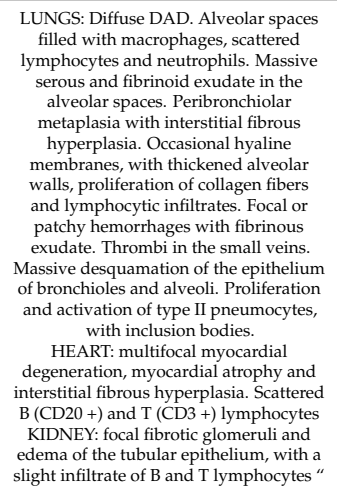 & N/D & 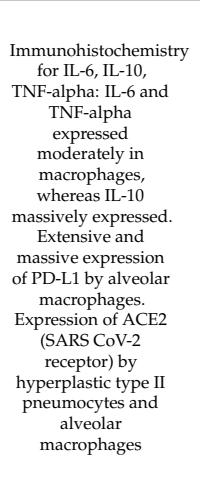 & $\begin{array}{c}\text { Cardio- } \\
\text { respiratory } \\
\text { failure }\end{array}$ & $\begin{array}{c}\text { Positive for SARS } \\
\text { CoV-2 } \\
\text { (nasopharyngeal) }\end{array}$ \\
\hline & 62 & M & N/D & $\begin{array}{c}\text { Peramivir, } \\
\text { methylpred- } \\
\text { nisolone, } \\
\mathrm{O}_{2}\end{array}$ & $\begin{array}{l}\text { severe lym- } \\
\text { phocytopenia, } \\
\text { elevated IL-6 } \\
\text { and CRP }\end{array}$ & $\begin{array}{l}\text { Chest X-ray and } \\
\text { Chest CT: } \\
\text { unspecified severe } \\
\text { lung lesions }\end{array}$ & $\begin{array}{l}\text { Hospital presentation: } \\
\text { 13-day history of cough, } \\
\text { fever, and shortness of } \\
\text { breath. ARDS and died } \\
\text { of cardio-respiratory } \\
\text { failure 10 days after } \\
\text { admission }\end{array}$ & N/D & $\begin{array}{l}\text { LUNGS: moderate } \\
\text { bilateral pleural } \\
\text { effusions and fibrotic } \\
\text { pleural adhesions. } \\
\text { Hepatization of lung } \\
\text { tissue and } \\
\text { consolidation }\end{array}$ & 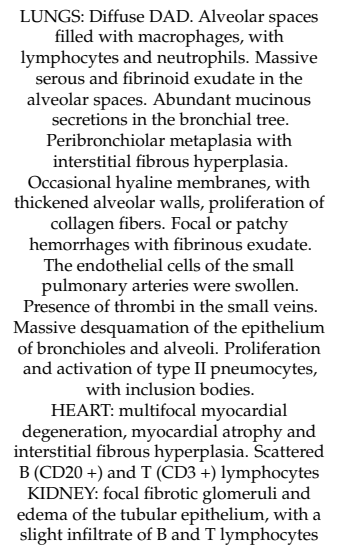 & $\mathrm{N} / \mathrm{D}$ & 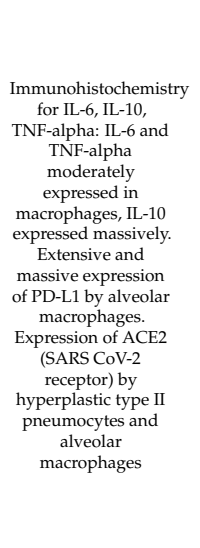 & $\begin{array}{l}\text { Cardio- } \\
\text { respiratory } \\
\text { failure }\end{array}$ & $\begin{array}{l}\text { Positive for SARS } \\
\text { CoV-2 } \\
\text { (nasopharyngeal) }\end{array}$ \\
\hline
\end{tabular}


Table 1. Cont.

\begin{tabular}{|c|c|c|c|c|c|c|c|c|c|c|c|c|c|c|}
\hline \multirow[b]{2}{*}{ Author } & \multirow[b]{2}{*}{ A } & \multirow[b]{2}{*}{ G } & \multicolumn{5}{|c|}{ IN VIVO DATA } & \multicolumn{7}{|c|}{ POSTMORTEM DATA } \\
\hline & & & $\begin{array}{c}\text { Comorbidities and } \\
\text { Past Drugs }\end{array}$ & Therapy & Labor & Imaging & $\begin{array}{l}\text { Course of the } \\
\text { Disease/Circumstances } \\
\text { of Death }\end{array}$ & Imaging & $\begin{array}{c}\text { Macroscopic } \\
\text { Features }\end{array}$ & Microscopic Features & Tox & $\begin{array}{c}\text { Additional } \\
\text { Analyses }\end{array}$ & Cause of Death & Swabs \\
\hline \multirow{2}{*}{$\begin{array}{l}\text { Zachary } \\
\text { Grimes } \\
\text { et al. }\end{array}$} & $\begin{array}{l}\text { Middle } \\
\text { age }\end{array}$ & M & $\begin{array}{l}\text { HTN with } \\
\text { anti-hypertensive } \\
\text { therapy }\end{array}$ & $\begin{array}{l}\text { Ceftriaxone, } \\
\text { azithromycin, } \\
\mathrm{O}_{2}\end{array}$ & $\begin{array}{c}\text { Elevated } \\
\text { ferritin, } \\
\text { Elevated CRP }\end{array}$ & 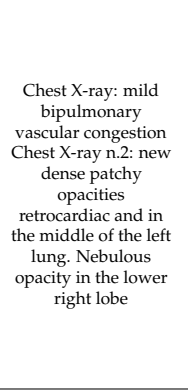 & 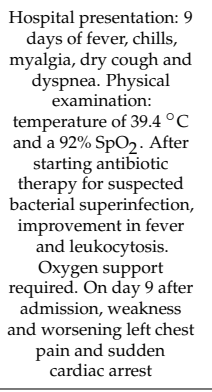 & N/D & 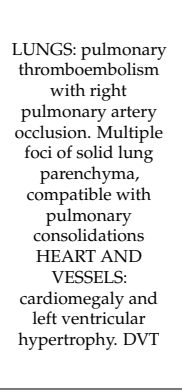 & $\begin{array}{l}\text { LUNGS: alternating light pink and red } \\
\text { areas (lines of Zahn), consistent with } \\
\text { pulmonary thromboembolism }\end{array}$ & $\mathrm{N} / \mathrm{D}$ & $\begin{array}{l}\text { ELECTRON } \\
\text { MICROSCOPY: } \\
\text { Virallike particles } \\
\text { (60-120 nm in the } \\
\text { lung, located in } \\
\text { cytoplasmic } \\
\text { vacuoles in } \\
\text { pneumocytes }\end{array}$ & $\begin{array}{l}\text { Pulmonary } \\
\text { thlombobeem- } \\
\text { bolism }\end{array}$ & $\begin{array}{r}\text { Positive for SARS } \\
\text { CoV-2 } \\
\text { (nasopharyngeal) }\end{array}$ \\
\hline & $\begin{array}{l}\text { Middle } \\
\text { age }\end{array}$ & M & $\begin{array}{l}\text { Asthma, HTN, } \\
\text { pharmacologically } \\
\text { controlled HIV } \\
\text { infection }\end{array}$ & $\begin{array}{c}\text { Broad } \\
\text { spectrum } \\
\text { antibiotics, } \\
\mathrm{O}_{2} \\
\text { vasopressors, } \\
\text { intubation }\end{array}$ & $\begin{array}{c}\text { Elevated } \\
\text { ferritin, } \\
\text { Elevated CRP }\end{array}$ & $\begin{array}{c}\text { Chest X-ray: } \\
\text { multiple bilateral } \\
\text { pulmonary opacities }\end{array}$ & 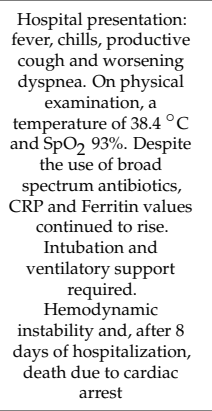 & N/D & $\begin{array}{l}\text { LUNGS: pulmonary } \\
\text { thrombeombolism } \\
\text { with occlusion of the } \\
\text { right and left } \\
\text { pulmonary arteries. } \\
\text { Multiple foc of of solid } \\
\text { lung parenchyma, } \\
\text { compatible with } \\
\text { pulmonary } \\
\text { consolidations } \\
\text { HEARTAND } \\
\text { VESESES: } \\
\text { cardiomegaly and } \\
\text { left ventricular } \\
\text { hypertrophy. DVV }\end{array}$ & $\begin{array}{l}\text { LUNGS: alternating light pink and red } \\
\text { areas (lines of Zahn), consistent with } \\
\text { pulmonary thromboembolism }\end{array}$ & $\mathrm{N} / \mathrm{D}$ & $\begin{array}{l}\text { ELECTRON } \\
\text { MICROSCOPY: } \\
\text { Viral-1ike particles } \\
\text { (60-120 nmm in the } \\
\text { lung, } \\
\text { located in } \\
\text { cytoplasmic } \\
\text { vacuoles in } \\
\text { pneumocytes }\end{array}$ & $\begin{array}{l}\text { Pulmonary } \\
\text { thromboem- } \\
\text { bolism }\end{array}$ & $\begin{array}{r}\text { Positive for SARS } \\
\text { CoV-2 } \\
\text { (nasopharyngeal) }\end{array}$ \\
\hline $\begin{array}{l}\text { Kristine } \\
\text { E. } \\
\text { Konopka } \\
\text { et al. }\end{array}$ & 37 & M & $\begin{array}{l}\text { Asthma, DM2, in } \\
\text { therapy vith } \\
\text { ipratropium } \\
\text { bromide, alluterol, } \\
\text { sitagliptin }\end{array}$ & $\begin{array}{c}\text { HCQ, } \\
\text { piperacillin/tazobacta } \\
\text { vancomycin, } \\
\text { CS, ECMO, } \\
\text { dialysis, } \\
\text { intubation }\end{array}$ & N/D & $\begin{array}{l}\text { Chest CT: multifocal } \\
\text { ground glass } \\
\text { opacities }\end{array}$ & $\begin{array}{l}\text { Hospital presentation: } \\
\text { 1-day history of fever, } \\
\text { non-productive cught } \\
\text { and myalgia. } \\
\text { Worsening hypoxiania } \\
\text { and, intubated, died } \\
\text { after 9 days of } \\
\text { hospitalization }\end{array}$ & $\mathrm{N} / \mathrm{D}$ & $\begin{array}{l}\text { LUNGS: heavy } \\
\text { lungs, consolidation } \\
\text { of the lung } \\
\text { parenchyma } \\
\text { AIRWASYm mucous } \\
\text { plugs in the } \\
\text { conduction ways }\end{array}$ & 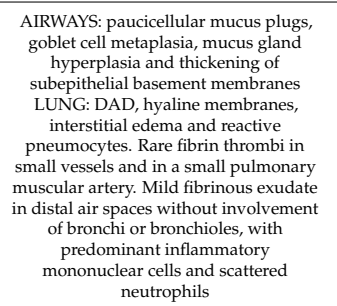 & $\mathrm{N} / \mathrm{D}$ & $\mathrm{N} / \mathrm{D}$ & $\begin{array}{l}\text { ARDS due to } \\
\text { SARS CoV-2 }\end{array}$ & $\begin{array}{c}\text { Positive for SARS } \\
\text { CoV-2 } \\
\text { (not specified) }\end{array}$ \\
\hline
\end{tabular}


Table 1. Cont.

\begin{tabular}{|c|c|c|c|c|c|c|c|c|c|c|c|c|c|c|}
\hline \multirow[b]{2}{*}{ Author } & \multirow[b]{2}{*}{ A } & \multirow[b]{2}{*}{ G } & \multicolumn{5}{|c|}{ IN VIVO DATA } & \multicolumn{7}{|c|}{ POSTMORTEM DATA } \\
\hline & & & $\begin{array}{c}\text { Comorbidities and } \\
\text { Past Drugs }\end{array}$ & Therapy & Labor & Imaging & $\begin{array}{l}\text { Course of the } \\
\text { Disease/Circumstances } \\
\text { of Death }\end{array}$ & Imaging & $\begin{array}{c}\text { Macroscopic } \\
\text { Features }\end{array}$ & Microscopic Features & Tox & $\begin{array}{l}\text { Additional } \\
\text { Analyses }\end{array}$ & Cause of Death & Swabs \\
\hline $\begin{array}{l}\text { Randall } \\
\text { Craver } \\
\text { et al. }\end{array}$ & 17 & M & $\mathrm{N}$ & N/D & N/D & N/D & $\begin{array}{l}\text { Collapsed after } 2 \text { days } \\
\text { of severe headache, } \\
\text { dizziness, nausease and } \\
\text { vomiting. } \\
\text { It was later reported } \\
\text { that he had complained } \\
\text { of flu-like symptoms } \\
\text { and a dry cough } \\
\text { without fever, uut both } \\
\text { the PCR for rnfluenza A } \\
\text { and Band the throat } \\
\text { cultures performed at } \\
\text { the time were negative }\end{array}$ & N/D & $\begin{array}{l}\text { LUNGS: heavy and } \\
\text { congested } \\
\text { HEATR: } \\
\text { hypertrophic heart } \\
\text { hyog g, soft and with } \\
\text { mottled parenchyma. } \\
\text { got mL of pericardial } \\
\text { fluid in the cavity }\end{array}$ & 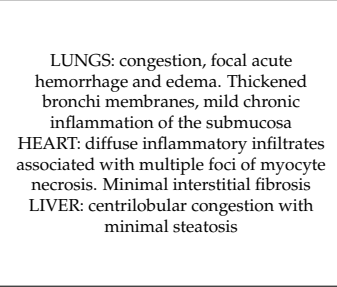 & negative & $\begin{array}{l}\text { Tests for influenza A } \\
\text { and B, parainfluenza } \\
\text { and RSV: negative }\end{array}$ & $\begin{array}{l}\text { Fulminant } \\
\text { eosinophilic } \\
\text { myocarditis }\end{array}$ & $\begin{array}{c}\text { POST MORTEM } \\
\text { positive for SARS } \\
\text { CoV-2 } \\
\text { (nasopharyngeal) }\end{array}$ \\
\hline $\begin{array}{l}\text { Lei Yan } \\
\text { et al. }\end{array}$ & 44 & $\mathrm{~F}$ & $\begin{array}{l}\text { Obesity (BMI } 41.5 \\
\left.\quad \mathrm{Kg} / \mathrm{m}^{2}\right)\end{array}$ & $\begin{array}{c}\mathrm{O}_{2}, \\
\text { intubation, } \\
\text { vasopressors, } \\
\text { HCQ, } \\
\text { azithromycin, } \\
\text { tocilizumab }\end{array}$ & $\begin{array}{l}\text { Lymphocytopenia, } \\
\text { elevated CRR, } \\
\text { elevated ESR, } \\
\text { elevated } \\
\text { Tloponin I, } \\
\text { elevated } \\
\text { - D-dimer, } \\
\text { elevated IL-6 }\end{array}$ & $\begin{array}{l}\text { Chest X-ray: } \\
\text { irregular bilateral } \\
\text { peripheral opacities } \\
\text { Echocardiography: } \\
\text { severe hypokinesias } \\
\text { with mild EF } \\
\text { reduction }\end{array}$ & 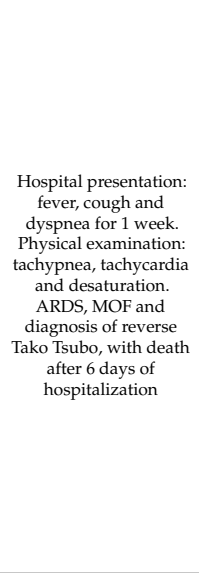 & N/D & 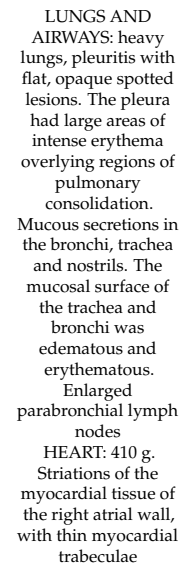 & 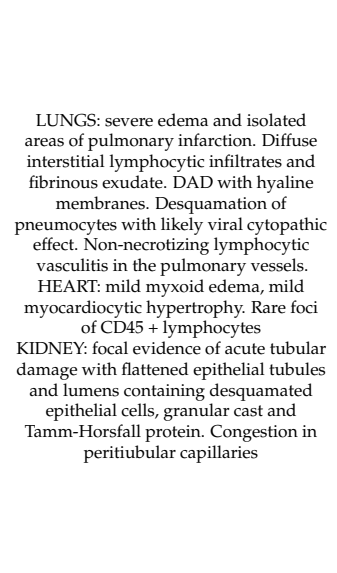 & $\mathrm{N} / \mathrm{D}$ & 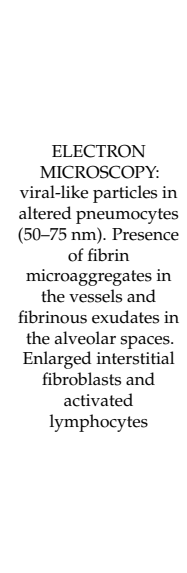 & $\begin{array}{l}\text { ARDS, MOF, } \\
\text { reverse Tako } \\
\text { tsubo } \\
\text { cardiomyopathy }\end{array}$ & $\begin{array}{c}\text { Positive for SARS } \\
\text { CoV-2 } \\
\text { (nasopharyngeal) }\end{array}$ \\
\hline
\end{tabular}


Table 1. Cont.

\begin{tabular}{|c|c|c|c|c|c|c|c|c|c|c|c|c|c|c|}
\hline \multirow[b]{2}{*}{ Author } & \multirow[b]{2}{*}{ A } & \multirow[b]{2}{*}{ G } & \multicolumn{5}{|c|}{ IN VIVO DATA } & \multicolumn{7}{|c|}{ POSTMORTEM DATA } \\
\hline & & & $\begin{array}{c}\text { Comorbidities and } \\
\text { Past Drugs }\end{array}$ & Therapy & Labor & Imaging & $\begin{array}{l}\text { Course of the } \\
\text { Disease/Circumstances } \\
\text { of Death }\end{array}$ & Imaging & $\begin{array}{c}\text { Macroscopic } \\
\text { Features }\end{array}$ & Microscopic Features & Tox & $\begin{array}{l}\text { Additional } \\
\text { Analyses }\end{array}$ & Cause of Death & Swabs \\
\hline $\begin{array}{l}\text { J. } \\
\text { Matthew } \\
\text { Lacy } \\
\text { et al. }\end{array}$ & 58 & $\mathrm{~F}$ & $\begin{array}{l}\text { DM2, obesity (BMI: } \\
3 \mathrm{~kg} / \mathrm{m}^{2} \text { ), } \\
\text { dyslipidemia, } \\
\text { asthma, ulceration of } \\
\text { the lower limbs }\end{array}$ & N/D & N/D & N/D & $\begin{array}{l}\text { After } 7 \text { days of fever } \\
\text { and respiratory distress, } \\
\text { found dead at home } \\
\text { during quarantine }\end{array}$ & N/D & 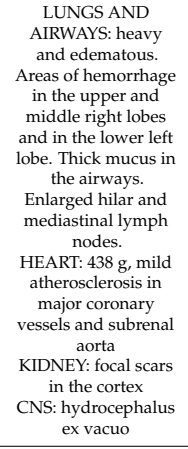 & 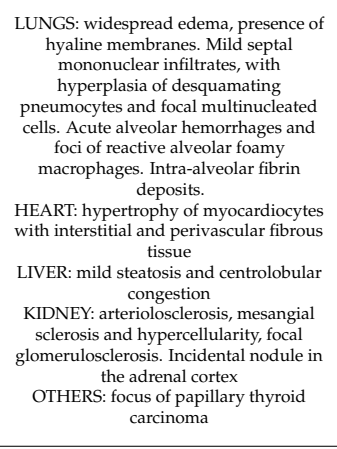 & N/D & $\begin{array}{l}\text { Influenzza virus test: } \\
\text { negative. Positive } \\
\text { bacterial cultures for } \\
\text { Staphylococus } \\
\text { aureus and } \\
\text { Streptococcus } \\
\text { viridans, interpreted } \\
\text { as contamination or } \\
\text { post-mortem } \\
\text { artififacts }\end{array}$ & $\begin{array}{l}\text { ARDS due to } \\
\text { SARS CoV-2 }\end{array}$ & $\begin{array}{l}\text { POST MORTEM } \\
\text { positive for SARS } \\
\text { CoV-2( (lower } \\
\text { airways) }\end{array}$ \\
\hline $\begin{array}{l}\text { Evan A. } \\
\text { Farkash } \\
\text { et al. }\end{array}$ & 53 & M & $\begin{array}{l}\text { Obesity, } \\
\text { dyslipidemia }\end{array}$ & $\begin{array}{l}\mathrm{HCQ}, \mathrm{O}_{2}, \\
\text { furosemide, } \\
\text { metolazone, } \\
\text { intubation }\end{array}$ & $\begin{array}{l}\text { Leukocytosis, } \\
\text { reduced GFR }\end{array}$ & $\begin{array}{l}\text { Chest X-ray: } \\
\text { bilateral patchy } \\
\text { opacities }\end{array}$ & $\begin{array}{l}\text { Hospitalized for aortic } \\
\text { dissection, which was } \\
\text { surically repaired } \\
\text { Re-intubation on day } 6 \\
\text { due to hypoxemia. } \\
\text { MOF and cardiac arrest, } \\
\text { with death or on } \\
\text { postoperative day } 12\end{array}$ & $\mathrm{~N} / \mathrm{D}$ & $\begin{array}{l}\text { LUNGS: widespread } \\
\text { signs of DAD, } \\
\text { edema and acute } \\
\text { bronchopneumonia }\end{array}$ & $\begin{array}{l}\text { LUNGS: DAD, hyaline membranes and } \\
\text { edemaKIDNEY: mild autolysis }\end{array}$ & N/D & $\begin{array}{l}\text { Respiratory } \\
\text { Pathogen Standard } \\
\text { Panel with swab for } \\
\text { Influenza Virus: } \\
\text { Negativive. } \\
\text { ELECTRON } \\
\text { MICROSCOOPY: } \\
\text { abundant virallike } \\
\text { particles } 65-91 \\
\text { nanometers) inside } \\
\text { tubular peithelial } \\
\text { cells, in areas of } \\
\text { issometric } \\
\text { vacuolation } \\
\end{array}$ & MOF, AKI & $\begin{array}{c}\text { Positive for SARS } \\
\text { CoV-2 } \\
\text { (not specified) }\end{array}$ \\
\hline $\begin{array}{l}\text { Diego } \\
\text { Agumiar } \\
\text { et al. }\end{array}$ & 31 & $\mathrm{~F}$ & $\begin{array}{l}\text { Obesity (BMI } 61.2 \\
\left.\mathrm{~kg} / \mathrm{m}^{2}\right)\end{array}$ & N/D & Elevated CRP & $\mathrm{N} / \mathrm{D}$ & 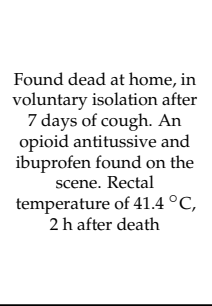 & $\begin{array}{l}\text { CT: diffuse bilateral } \\
\text { ground glasss opacities } \\
\text { associate with } \\
\text { panlobar consolidations } \\
\text { and air bronchograms }\end{array}$ & 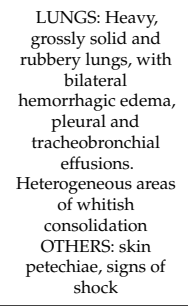 & $\begin{array}{l}\text { LUNGS: alveolar damage and edema, } \\
\text { DAD in the exudatative phase with the } \\
\text { presence of hyaline membranes, fibrin } \\
\text { deposits and moderate activated and } \\
\text { desquamated pneumocytes. Alveolar } \\
\text { exudate, moderate increase in } \\
\text { intra-alveolar macrophages. Focal areas } \\
\text { of intra alveolar hemorrhage and } \\
\text { bacterial profilefration. Abundant septal } \\
\text { and capillaries polymorphonuclear cells } \\
\text { OTHER Chronic tracheitis and } \\
\text { microabscesses in the liver parenchyma }\end{array}$ & $\begin{array}{l}\text { dextrometh- } \\
\text { orphan } \\
\text { found in } \\
\text { the } \\
\text { patient's } \\
\text { blood }\end{array}$ & $\begin{array}{l}\text { Panel for influenza } \\
\text { viruses Aand B, RSV } \\
\text { A and B, adenovirus, } \\
\text { rhinoviruses, } \\
\text { bocavirus, } \\
\text { metachenumovirus, } \\
\text { other coronaviruses } \\
\text { and parainfluenza } \\
\text { viruses } 1-4: \text { : negative }\end{array}$ & $\begin{array}{l}\text { Lung changes } \\
\text { related to SARS } \\
\text { CoV-2 }\end{array}$ & $\begin{array}{c}\text { POST MORTEM } \\
\text { positive for SARS } \\
\text { CoV-2 (lower } \\
\text { airways) }\end{array}$ \\
\hline
\end{tabular}


Table 1. Cont.

\begin{tabular}{|c|c|c|c|c|c|c|c|c|c|c|c|c|c|c|}
\hline \multirow[b]{2}{*}{ Author } & \multirow[b]{2}{*}{ A } & \multirow[b]{2}{*}{ G } & \multicolumn{5}{|c|}{ IN VIVO DATA } & \multicolumn{7}{|c|}{ POSTMORTEM DATA } \\
\hline & & & $\begin{array}{c}\text { Comorbidities and } \\
\text { Past Drugs }\end{array}$ & Therapy & Labor & Imaging & $\begin{array}{l}\text { Course of the } \\
\text { Disease/Circumstances } \\
\text { of Death }\end{array}$ & Imaging & $\begin{array}{l}\text { Macroscopic } \\
\text { Features }\end{array}$ & Microscopic Features & Tox & $\begin{array}{l}\text { Additional } \\
\text { Analyses }\end{array}$ & Cause of Death & Swabs \\
\hline $\begin{array}{l}\text { Takuya } \\
\text { Adachi. } \\
\text { et al. }\end{array}$ & 84 & F & $\mathrm{N}$ & $\begin{array}{l}\text { Ampicillin/sulbactan } \\
\text { lopinavir/ritonavir, } \\
\text { morphine, } \mathrm{O}_{2}\end{array}$ & r, $\quad$ N/D & $\begin{array}{l}\text { Chest X-ray: } \\
\text { bilateral opacities } \\
\text { Chest CT: iground } \\
\text { glass opacities and } \\
\text { consolidations, } \\
\text { especially in the } \\
\text { lower lobes }\end{array}$ & $\begin{array}{l}\text { Fever, diarrhea and } \\
\text { shortness of breasth } \\
\text { while on cruise, } \\
\text { Admitted to the hospital } \\
\text { with dysprea and fever. } \\
\text { ARDS and hypoxemia, } \\
\text { died after 16 days }\end{array}$ & N/D & 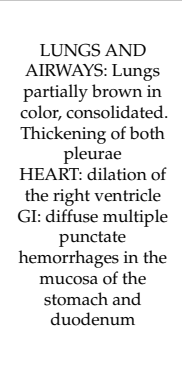 & 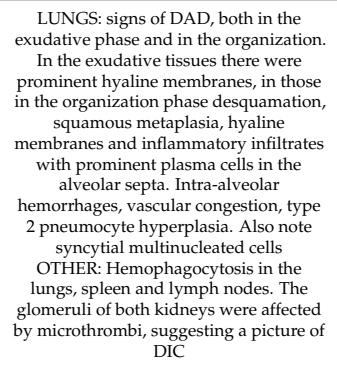 & $\mathrm{N} / \mathrm{D}$ & 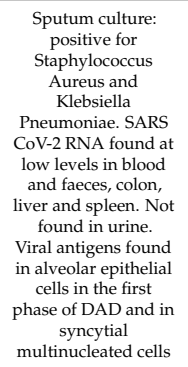 & $\begin{array}{l}\text { Respiratory } \\
\text { failure due to } \\
\text { SARS CoV-2 }\end{array}$ & $\begin{array}{c}\text { Positive for SARS } \\
\text { CoV-2 } \\
\text { (nasopharyngeal) } \\
\text { POST MORTEM } \\
\text { Positive in both } \\
\text { lower airways } \\
\text { and upper } \\
\text { airways, with } \\
\text { muore copies of } \\
\text { viral RNA in } \\
\text { lower airways } \\
\text { (bronchi) }\end{array}$ \\
\hline $\begin{array}{l}\text { Parisa } \\
\text { Karami } \\
\text { et al. }\end{array}$ & 27 & $\mathrm{~F}$ & $\mathrm{~N}$ & $\begin{array}{l}\text { Azithromycin, } \\
\text { ceftriaxone, } \\
\text { oseltamivir, } \\
\text { lopinavir ritonavir, } \\
\text { HCQ, } \\
\text { meropene, } \\
\text { vancomycin, } \\
\text { methylpred- } \\
\text { nisiolone, } \mathrm{O}_{2,} \\
\text { intubations }\end{array}$ & $\begin{array}{l}\text { Leukopenia, } \\
\text { trombocy- } \\
\text { topenia, } \\
\text { elevated CRP, } \\
\text { elevated LDH, } \\
\text { elevated } \\
\text { D-dimer }\end{array}$ & 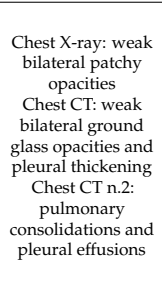 & 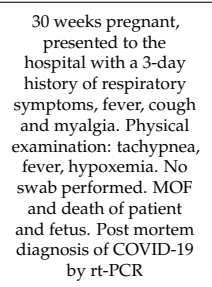 & $\mathrm{N} / \mathrm{D}$ & N/D & $\begin{array}{l}\text { LUNGS: focal hyaline membranes, } \\
\text { pneumocytes proliferation and } \\
\text { metaplastic changes. Cytopathic effects } \\
\text { from viral infection. Lymphocytes and } \\
\text { macrophages }\end{array}$ & $\mathrm{N} / \mathrm{D}$ & $\mathrm{N} / \mathrm{D}$ & MOF & $\begin{array}{c}\text { Positive for SARS } \\
\text { CoV-2 } \\
\text { (not specified) }\end{array}$ \\
\hline
\end{tabular}


Table 1. Cont.

\begin{tabular}{|c|c|c|c|c|c|c|c|c|c|c|c|c|c|c|}
\hline \multirow[b]{2}{*}{ Author } & \multirow[b]{2}{*}{ A } & \multirow[b]{2}{*}{ G } & \multicolumn{5}{|c|}{ IN VIVO DATA } & \multicolumn{7}{|c|}{ POSTMORTEM DATA } \\
\hline & & & $\begin{array}{l}\text { Comorbidities and } \\
\text { Past Drugs }\end{array}$ & Therapy & Labor & Imaging & $\begin{array}{l}\text { Course of the } \\
\text { Disease/Circumstances } \\
\text { of Death }\end{array}$ & Imaging & $\begin{array}{c}\text { Macroscopic } \\
\text { Features }\end{array}$ & Microscopic Features & Tox & $\begin{array}{l}\text { Additional } \\
\text { Analyses }\end{array}$ & Cause of Death & Swabs \\
\hline $\begin{array}{l}\text { Monique } \\
\text { Freire } \\
\text { Santana } \\
\text { et al. }\end{array}$ & 71 & M & HTN, DM2, CKD & $\begin{array}{c}\mathrm{O}_{2}, \\
\text { vasopressors, } \\
\text { oseltamivir, } \\
\text { HCQ, } \\
\text { azithromycin, } \\
\text { ceftriaxone, } \\
\text { furosemide, } \\
\text { heparin, } \\
\text { intubation }\end{array}$ & $\begin{array}{l}\text { Elevated urea, } \\
\text { elevated } \\
\text { creatinine and } \\
\text { CRP, lympho- } \\
\text { cytopenia, } \\
\text { neutrophilia }\end{array}$ & $\begin{array}{l}\text { Chest X-ray: } \\
\text { infiltrates and } \\
\text { nodular } \\
\text { consolidation in the } \\
\text { lower right lobe }\end{array}$ & $\begin{array}{l}\text { Transferred to a } \\
\text { COVID-19 dedicated } \\
\text { facility, required } \\
\text { orotracheal intubation } \\
\text { and pharmacological } \\
\text { support. After 4 days of } \\
\text { hospitalization, } \\
\text { hemodynamic } \\
\text { worsening, up to shock } \\
\text { with irreversible } \\
\text { hypotension, } \\
\text { bradycardia and death }\end{array}$ & $\mathrm{N} / \mathrm{D}$ & $\begin{array}{l}\text { LUNGS: focal areas } \\
\text { of of onsolidation in } \\
\text { the right lower lobe }\end{array}$ & $\begin{array}{l}\text { LUNGS: presence of well-defined } \\
\text { Aspergillus structuruse, with hyphae and } \\
\text { spores. Snoring pneumonia, fibrin } \\
\text { thrombi occluding an artery, and } \\
\text { squamous metaplasia were also present. } \\
\text { Aspergillus was also in the pulmonary } \\
\text { vessels }\end{array}$ & $\mathrm{N} / \mathrm{D}$ & $\begin{array}{c}\text { blood culture: } \\
\text { negative for bacterial } \\
\text { growth } \\
\text { Detection of GM } \\
\text { antigen in peripheral } \\
\text { blood: positive } \\
\text { PCR for aspergillus: } \\
\text { positive }\end{array}$ & Shock & $\begin{array}{c}\text { Positive for SARS } \\
\text { CoV-2 } \\
\text { (not specified) }\end{array}$ \\
\hline $\begin{array}{l}\text { James } \\
\text { R. } \\
\text { Stone } \\
\text { et al. }\end{array}$ & 76 & $\mathrm{~F}$ & 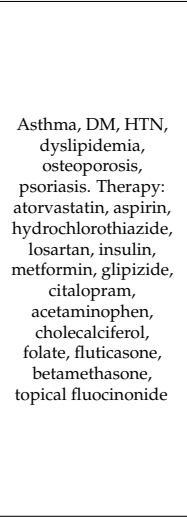 & $\begin{array}{c}\text { Paracetamol, } \\
\text { ceftrixone, } \\
\text { azithromycin, } \\
\text { HCQ, } \\
\text { metroprolol, } \\
\text { furosemide, } \\
\mathrm{O}_{2}\end{array}$ & $\begin{array}{l}\text { hyperglycemia, } \\
\text { elevated } \\
\text { creatine } \\
\text { kinase, } \\
\text { elevated LDH, } \\
\text { elevated } \\
\text { Ferritin, } \\
\text { elevated } \\
\text { D-dimer }\end{array}$ & $\begin{array}{l}\text { Chest X-ray: patchy } \\
\text { opacities in the } \\
\text { upper left lobe and } \\
\text { near the hilum } \\
\text { Chest T with } \\
\text { contrats ground } \\
\text { glass opacities and } \\
\text { bilateral multifiocal } \\
\text { consolidations }\end{array}$ & 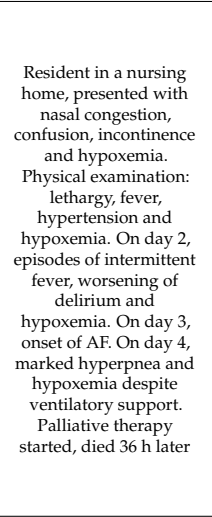 & $\mathrm{N} / \mathrm{D}$ & $\begin{array}{l}\text { LUNGS: areas of } \\
\text { pulmonary } \\
\text { consolidation } \\
\text { HEART: } \\
\text { hypertrophic heart, } \\
\text { dilation of the left } \\
\text { ventricle Mild } \\
\text { coronary } \\
\text { atherosclerosis }\end{array}$ & 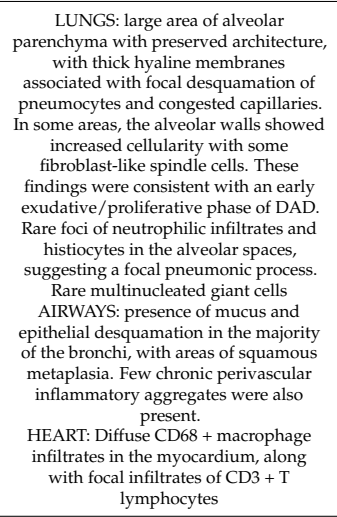 & $\mathrm{N} / \mathrm{D}$ & $\begin{array}{l}\text { Influenza A, B and } \\
\text { RSV tetsts negative. } \\
\text { Immunohistochemistry } \\
\text { for SARS CoV 1-2 } \\
\text { (nucleocapsid } \\
\text { protein) positive in } \\
\text { alveolar } \\
\text { macrophages and } \\
\text { scattered } \\
\text { pneumocytes }\end{array}$ & $\begin{array}{l}\text { ARDS due to } \\
\text { SARS CoV-2 }\end{array}$ & $\begin{array}{c}\text { Positive for SARS } \\
\text { CoV-2 } \\
\text { (nasopharyngeal) }\end{array}$ \\
\hline $\begin{array}{l}\text { Sociedad } \\
\text { Es- } \\
\text { panola } \\
\text { de } \\
\text { Anatomia } \\
\text { Patolog- } \\
\text { ica }\end{array}$ & 54 & M & $\begin{array}{c}\text { HTN, gout, } \\
\text { migraine, OSAS, } \\
\text { obesity (BMI: 30.9.) } \\
\text { Therapy with C-PAP }\end{array}$ & $\begin{array}{l}\text { CS, } \\
\text { lopinavir/ritonavir, } \\
\text { HCQ, } \\
\text { azithromycin, } \\
\text { tocilizumab, } \\
\text { enoxaparin, } \\
\text { intubation, } \\
\text { dialysis }\end{array}$ & $\begin{array}{l}\text { Lymphocytopenia, } \\
\text { r, elevated } \\
\text { D-dimer, } \\
\text { elevated LDH } \\
\text { elevated L-6, } \\
\text { elevated CRP, } \\
\text { eleated } \\
\text { ferritin }\end{array}$ & $\begin{array}{c}\text { Chest X-ray: } \\
\text { bilateral pulmonary } \\
\text { opacities }\end{array}$ & $\begin{array}{l}\text { Hospital presentation: } \\
\text { 8-day history of chills, } \\
\text { fever and cough. } \\
\text { Steroid treatment, } \\
\text { intubation. AKI and } \\
\text { progressive } \\
\text { desaturations, requiring } \\
\text { tracheostomy and } \\
\text { hemodialysis. Death } \\
\text { after } 25 \text { days in ICU, } \\
\text { due to pulmonary } \\
\text { thromboembolism }\end{array}$ & $\mathrm{N} / \mathrm{D}$ & $\begin{array}{l}\text { LUNGS: heavy, hard } \\
\text { and congested. Red } \\
\text { and rubbery cut } \\
\text { surface cut }\end{array}$ & 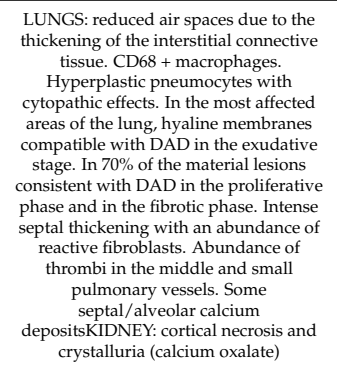 & $\mathrm{N} / \mathrm{D}$ & $\begin{array}{l}\text { Histochemical and } \\
\text { immunohistochemi- } \\
\text { cal tests for other } \\
\text { pathogens: negative }\end{array}$ & $\begin{array}{l}\text { Pulmonary } \\
\text { thromboem- } \\
\text { bolism }\end{array}$ & $\begin{array}{c}\text { Positive for SARS } \\
\text { CoV-2 } \\
\text { (nasopharyngeal) }\end{array}$ \\
\hline
\end{tabular}


Table 1. Cont.

\begin{tabular}{|c|c|c|c|c|c|c|c|c|c|c|c|c|c|c|}
\hline \multirow[b]{2}{*}{ Author } & \multirow[b]{2}{*}{ A } & \multirow[b]{2}{*}{ G } & \multicolumn{5}{|c|}{ IN VIVO DATA } & \multicolumn{7}{|c|}{ POSTMORTEM DATA } \\
\hline & & & $\begin{array}{c}\text { Comorbidities and } \\
\text { Past Drugs }\end{array}$ & Therapy & Labor & Imaging & $\begin{array}{l}\text { Course of the } \\
\text { Disease/Circumstances } \\
\text { of Death }\end{array}$ & Imaging & $\begin{array}{c}\text { Macroscopic } \\
\text { Features }\end{array}$ & Microscopic Features & Tox & $\begin{array}{l}\text { Additional } \\
\text { Analyses }\end{array}$ & Cause of Death & Swabs \\
\hline $\begin{array}{l}\text { Pedro } \\
\text { Navarro } \\
\text { Conde } \\
\text { et al. }\end{array}$ & 69 & M & $\begin{array}{c}\text { Low-grade } \\
\text { non-invasive } \\
\text { urothelial carcinoma } \\
\text { of the bladder }\end{array}$ & $\begin{array}{l}\text { Levofloxacin, } \\
\text { ceftriaxone, } \\
\mathrm{O}_{2}\end{array}$ & $\mathrm{~N} / \mathrm{D}$ & $\begin{array}{l}\text { Chest X-ray: } \\
\text { bilateral ground } \\
\text { glass interstitial } \\
\text { infiltrate in the lower } \\
\text { lobes } \\
\text { CT: negative for } \\
\text { pulmonary } \\
\text { thromboembolism }\end{array}$ & 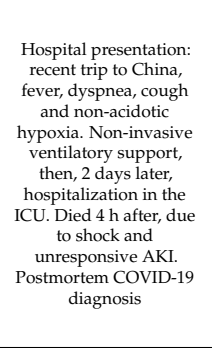 & $\mathrm{N} / \mathrm{D}$ & $\begin{array}{l}\text { LUNGS: dark red in } \\
\text { color increased in } \\
\text { weight and density. } \\
\text { Pleural posterior } \\
\text { adhesions } \\
\text { HEART: mild } \\
\text { stenosis of the aortic } \\
\text { valve, slight } \\
\text { thickening of the left } \\
\text { ventricle and } \\
\text { dilation of both } \\
\text { ventricles } \\
\text { OTHER } \\
\text { conges generaized } \\
\text { congion of other } \\
\text { organs }\end{array}$ & $\begin{array}{l}\text { LUNGS: edema and intra alveolar } \\
\text { hemomorhage. DAD with desquamation } \\
\text { of type II Pneumocytes, and hyaline } \\
\text { membranes, sometimes in the in the } \\
\text { proliferative phase. Thrombi in the } \\
\text { pulmonary vessels of medium caliber. } \\
\text { Abundant intralveolar macrophages } \\
\text { Cybopathic changes in pneumocytes and } \\
\text { macrophages. Cells with large and } \\
\text { hyperchromatic nuclei, similiar to the } \\
\text { smudge cells described in adenovirus } \\
\text { pneumonia. SGuamous metaplasia of } \\
\text { pneumocytes. Inflammatory infiltrate } \\
\text { with few lymphocytes and abundant } \\
\text { macrophages. Emphysematous areas }\end{array}$ & $\mathrm{N} / \mathrm{D}$ & 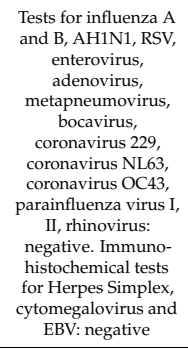 & $\begin{array}{l}\text { CLINICAL: } \\
\text { severe bilateral } \\
\text { CAP } \\
\text { PATHOLOGICAL: } \\
\text { SARS CoV-2 } \\
\text { pneumonia }\end{array}$ & $\begin{array}{c}\text { Positive for SARS } \\
\text { CoV-2 } \\
\text { (nasopharyngeal) }\end{array}$ \\
\hline $\begin{array}{l}\text { Fabian } \\
\text { Hein- } \\
\text { rich } \\
\text { et al. }\end{array}$ & 59 & M & $\begin{array}{l}\text { Obesity (BMI: 32.8), } \\
\text { HTN }\end{array}$ & $\mathrm{N} / \mathrm{D}$ & $\mathrm{N} / \mathrm{D}$ & N/D & $\begin{array}{c}\text { Systemic symptoms } \\
\text { during a cruise, with } \\
\text { dyspnea. Hospitalized, } \\
\text { developed fever and } \\
\text { productive cough. Died } \\
\text { after } 6 \text { days of } \\
\text { hospitalization }\end{array}$ & $\begin{array}{l}\text { CT: Moderate bilateral } \\
\text { pleural effusions. } \\
\text { Subpleural ground glass } \\
\text { opacities and ground } \\
\text { glass nodules in the } \\
\text { center of the lungs. } \\
\text { Multifocal reticular } \\
\text { consolidations, } \\
\text { especially in the central } \\
\text { areas of both lungs }\end{array}$ & 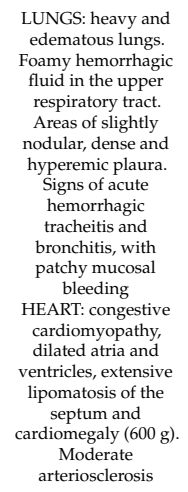 & 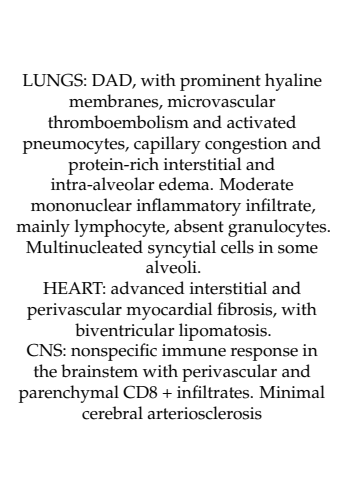 & $\mathrm{N} / \mathrm{D}$ & $\begin{array}{l}\text { Several SARS CoV-2 } \\
\text { copies in the lungs }\end{array}$ & $\begin{array}{l}\text { Respiratory } \\
\text { failure due to } \\
\text { SARS CoV-2 }\end{array}$ & $\begin{array}{c}\text { POST MORTEM } \\
\text { Positive for rARS } \\
\text { CoV-2 } \\
\text { (nasopharyngeal } \\
\text { and } \\
\text { oropharyngeal) }\end{array}$ \\
\hline $\begin{array}{l}\text { Inga- } \\
\text { Marie } \\
\text { Schae- } \\
\text { fer } \\
\text { et al. }\end{array}$ & 66 & $\mathrm{~F}$ & $\begin{array}{l}\text { SLE, RA, Pulmonary } \\
\text { fibrosis, CKD, } \\
\text { interstitial lung } \\
\text { disease, } M \text { GUS, } \\
\text { coronary heart } \\
\text { disease, HTN }\end{array}$ & HCQ & $\mathrm{N} / \mathrm{D}$ & 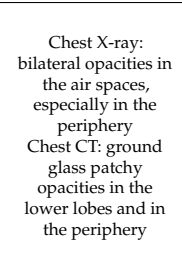 & $\begin{array}{l}\text { Hospital presentation: } \\
\text { 2-week history of cough } \\
\text { and fever. Died after 7 } \\
\text { days }\end{array}$ & $\mathrm{N} / \mathrm{D}$ & $\mathrm{N} / \mathrm{D}$ & $\begin{array}{l}\text { LUNGS: acute DAD, scattered foci in the } \\
\text { organization phase and prominent } \\
\text { hyaline membranes. Interstitial lung } \\
\text { disease with bronchiectasis. Pulmonary } \\
\text { thromboembolism. Diffuse interstitial } \\
\text { and peribronchial lymphocytic } \\
\text { inflammatory infiltrates, with } \\
\text { intra-alveolar macrophages } \\
\text { AIRWAYSS: reactive squamous } \\
\text { metaplasiai. Minimal lymphocytic } \\
\text { infiltrate in the edematous connective } \\
\text { tissue of the airway walls }\end{array}$ & $\mathrm{N} / \mathrm{D}$ & $\begin{array}{l}\text { Post mortem im- } \\
\text { munohistochemistry } \\
\text { for SARS CoV-2: } \\
\text { positive in } \\
\text { pneumocytes }(<5 \\
\left.\text { cells } \times 4 \mathrm{~mm}^{2}\right)\end{array}$ & $\begin{array}{l}\text { SARS CoV-2 } \\
\text { preumonia } \\
\text { resulting in } \\
\text { respiratory } \\
\text { failure }\end{array}$ & $\begin{array}{c}\text { Positive for SARS } \\
\text { CoV-2 } \\
\text { (nasopharyngeal) }\end{array}$ \\
\hline
\end{tabular}


Table 1. Cont.

\begin{tabular}{|c|c|c|c|c|c|c|c|c|c|c|c|c|c|c|}
\hline \multirow[b]{2}{*}{ Author } & \multirow[b]{2}{*}{ A } & \multirow[b]{2}{*}{ G } & \multicolumn{5}{|c|}{ IN VIVO DATA } & \multicolumn{7}{|c|}{ POSTMORTEM DATA } \\
\hline & & & $\begin{array}{c}\text { Comorbbidities and } \\
\text { Past Drugs }\end{array}$ & Therapy & Labor & Imaging & $\begin{array}{l}\text { Course of the } \\
\text { Disease/Circumstances } \\
\text { of Death }\end{array}$ & Imaging & $\begin{array}{l}\text { Macroscopic } \\
\text { Features }\end{array}$ & Microscopic Features & Tox & $\begin{array}{l}\text { Additional } \\
\text { Analyses }\end{array}$ & Cause of Death & Swabs \\
\hline & 57 & M & $\begin{array}{l}\text { HTN, DM, } \\
\text { neurological } \\
\text { impairment }\end{array}$ & $\mathrm{N} / \mathrm{D}$ & $\mathrm{N} / \mathrm{D}$ & $\begin{array}{l}\text { Chest } X \text {-ray: Diffuse, } \\
\text { bilateral opacities in } \\
\text { the air spaces }\end{array}$ & $\begin{array}{l}\text { Hospital presentation: } \\
\text { cough, dyspnea and } \\
\text { cardiac arrest. Died } \\
\text { after } 1 \text { day }\end{array}$ & $\mathrm{N} / \mathrm{D}$ & N/D & 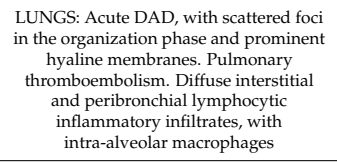 & N/D & $\begin{array}{c}\text { Post mortem im- } \\
\text { munohistochemistry } \\
\text { for SARS CoV-2: } \\
\text { positivin in } \\
\text { preumocyes }(<5 \\
\left.\text { cells } \times 4 \mathrm{~mm}^{2}\right) \\
\end{array}$ & $\begin{array}{l}\text { SARS CoV-2 } \\
\text { preumonia } \\
\text { resulting in } \\
\text { respiratory } \\
\text { failure }\end{array}$ & $\begin{array}{l}\text { Positive for SARS } \\
\text { CoV-2 } \\
\text { (nasopharyngeal) }\end{array}$ \\
\hline & 77 & M & $\begin{array}{l}\text { CKD, cardiomegaly, } \\
\text { atherosclerosis, DM, } \\
\text { dementialimb } \\
\text { amputation }\end{array}$ & $\mathrm{N} / \mathrm{D}$ & $\mathrm{N} / \mathrm{D}$ & $\begin{array}{l}\text { Chest X-ray: diffuse } \\
\text { bilateral opacities in } \\
\text { the pulmonary air } \\
\text { spaces and } \\
\text { interstitium }\end{array}$ & $\begin{array}{c}\text { Hospital presentation: } \\
\text { cough, fever, dyspnea } \\
\text { for 3 days and } \\
\text { hypoxemic respiratory } \\
\text { failure. Died after 3 } \\
\text { days }\end{array}$ & $\mathrm{N} / \mathrm{D}$ & N/D & 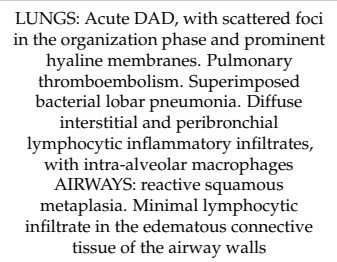 & N/D & $\begin{array}{l}\text { post mortem im- } \\
\text { munohistochemistry } \\
\text { for SARS CoV-2: } \\
\text { positivin in } \\
\text { pneumocytes }(<5 \\
\left.\text { cells } \times 4 \mathrm{~mm}^{2}\right)\end{array}$ & $\begin{array}{l}\text { SARS CoV-2 } \\
\text { preumonia } \\
\text { resulting in } \\
\text { respiratory } \\
\text { failure }\end{array}$ & $\begin{array}{c}\text { Positive for SARS } \\
\text { CoV-2 } \\
\text { (nasopharyngeal) }\end{array}$ \\
\hline & 50 & M & $\begin{array}{l}\text { Former smoker, UTI, } \\
\text { aspergillus Un } \\
\text { pneumonia, febrile } \\
\text { neutropenial } \\
\text { relapping -cell } \\
\text { acute lymphoblastic } \\
\text { leukemia }\end{array}$ & $\mathrm{N} / \mathrm{D}$ & $\mathrm{N} / \mathrm{D}$ & $\begin{array}{l}\text { Chest } X \text {-ray: Diffuse, } \\
\text { bilateral opacities in } \\
\text { the air spaces }\end{array}$ & $\begin{array}{l}\text { Hospitalization for } \\
\text { other reasons, } \\
\text { developed cough, fever, } \\
\text { hypoxemic respiratory } \\
\text { failure and hematuria. } \\
\text { Died after } 11 \text { days }\end{array}$ & $\mathrm{N} / \mathrm{D}$ & $\mathrm{N} / \mathrm{D}$ & 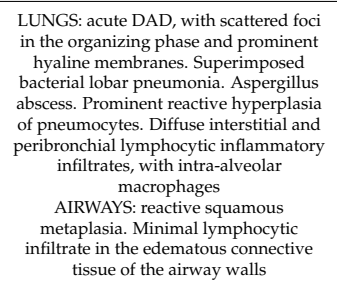 & $\mathrm{N} / \mathrm{D}$ & $\begin{array}{l}\text { post mortem im- } \\
\text { munohistochemistry } \\
\text { for AARS Cov-2: } \\
\text { positive in trachea } \\
\left(<5 \text { cells } \times 4 \mathrm{~mm}^{2}\right) \\
\text { and in pneumocytes } \\
\left(5-50 \text { cells } \times 4 \mathrm{~mm}^{2}\right)\end{array}$ & $\begin{array}{l}\text { SARS CoV-2 } \\
\text { peumonia } \\
\text { resulting in } \\
\text { respiratory } \\
\text { failure }\end{array}$ & $\begin{array}{c}\text { Positive for SARS } \\
\text { CoV-2 } \\
\text { (nasopharyngeal) }\end{array}$ \\
\hline & 68 & $\mathrm{~F}$ & $\begin{array}{l}\text { Smoker, } \\
\text { atherosclersis, } \\
\text { HTN, DM, COP }\end{array}$ & $\mathrm{N} / \mathrm{D}$ & $\mathrm{N} / \mathrm{D}$ & $\begin{array}{l}\text { Chest X-ray: diffuse } \\
\text { bilateral opacities of } \\
\text { the pulmonary air } \\
\text { spaces and } \\
\text { interstitum } \\
\text { Chest CTium wide, } \\
\text { subpleural sparing, } \\
\text { bilateral ground } \\
\text { glass opacities and } \\
\text { consolidations }\end{array}$ & $\begin{array}{l}\text { Hospital presentation: } \\
\text { 7-dan history of hhest } \\
\text { pain, fatigue and altered } \\
\text { mental status. Died } \\
\text { after 1 day }\end{array}$ & $\mathrm{N} / \mathrm{D}$ & $\mathrm{N} / \mathrm{D}$ & 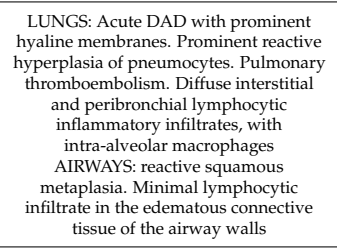 & $\mathrm{N} / \mathrm{D}$ & 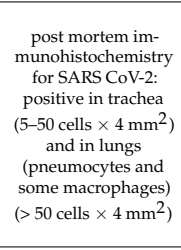 & $\begin{array}{l}\text { SARS CoV-2 } \\
\text { pneumonia } \\
\text { resulting in } \\
\text { respiratory } \\
\text { failure, } \\
\text { complicating a } \\
\text { recent } \\
\text { myocardial } \\
\text { infarction }\end{array}$ & $\begin{array}{c}\text { Positive for SARS } \\
\text { CoV-2 } \\
\text { (nasopharyngeal) }\end{array}$ \\
\hline & 66 & M & $\begin{array}{l}\text { Former smoker, } \\
\text { HTN, DM }\end{array}$ & HCQ & $\mathrm{N} / \mathrm{D}$ & $\begin{array}{l}\text { Chest X-ray: } \\
\text { bilateral opacitites in } \\
\text { the air saces, } \\
\text { especially in the } \\
\text { periphery }\end{array}$ & $\begin{array}{l}\text { Hospital presentation: } \\
\text { 7-day history of cough, } \\
\text { fever and diarrha.. } \\
\text { Died after } 16 \text { days }\end{array}$ & $\mathrm{N} / \mathrm{D}$ & $\mathrm{N} / \mathrm{D}$ & $\begin{array}{l}\text { LUNGS: DAD and organizing lung } \\
\text { injury. Diffuse interstitial and } \\
\text { peribronchial lymphocyticin inflammatory } \\
\text { infiltrates, whith intra-alveolar } \\
\text { macrophages } \\
\text { AIRWWAYS: reactive squamous } \\
\text { metaplasia. Minimal lymphocytic } \\
\text { infilitrate in the edematous connective } \\
\text { tissue of the airway walls }\end{array}$ & $\mathrm{N} / \mathrm{D}$ & $\begin{array}{l}\text { post mortem im- } \\
\text { munohihtscochemistry } \\
\text { for ARS CoV-2: } \\
\text { negative in lung and } \\
\text { trachea }\end{array}$ & $\begin{array}{l}\text { SARS CoV-2 } \\
\text { peumonia } \\
\text { resulting in } \\
\text { respiratory } \\
\text { failure }\end{array}$ & $\begin{array}{c}\text { Positive for SARS } \\
\text { CoV-2 } \\
\text { (nasopharyngeal) }\end{array}$ \\
\hline
\end{tabular}


Table 1. Cont.

\begin{tabular}{|c|c|c|c|c|c|c|c|c|c|c|c|c|c|c|}
\hline \multirow[b]{2}{*}{ Author } & \multirow[b]{2}{*}{ A } & \multirow[b]{2}{*}{ G } & \multicolumn{5}{|c|}{ IN VIVO DATA } & \multicolumn{7}{|c|}{ POSTMORTEM DATA } \\
\hline & & & $\begin{array}{c}\text { Comorbidities and } \\
\text { Past Drugs }\end{array}$ & Therapy & Labor & Imaging & $\begin{array}{l}\text { Course of the } \\
\text { Disease/Circumstances } \\
\text { of Death }\end{array}$ & Imaging & $\begin{array}{c}\text { Macroscopic } \\
\text { Features }\end{array}$ & Microscopic Features & Tox & $\begin{array}{l}\text { Additional } \\
\text { Analyses }\end{array}$ & Cause of Death & Swabs \\
\hline & 53 & M & $\begin{array}{l}\text { HTN, DM, CKD, } \\
\text { NASH }\end{array}$ & Remdesivir & $\mathrm{N} / \mathrm{D}$ & $\begin{array}{l}\text { Chest X-ray: diffuse } \\
\text { bilateral opacities in } \\
\text { the pulmonary air } \\
\text { spaces. Pneumomome- } \\
\text { diastinum }\end{array}$ & $\begin{array}{l}\text { Hospital presentation: } \\
\text { 8-day history of cough, } \\
\text { fever, and dyspnea. } \\
\text { Died after } 21 \text { days }\end{array}$ & $\mathrm{N} / \mathrm{D}$ & $\mathrm{N} / \mathrm{D}$ & 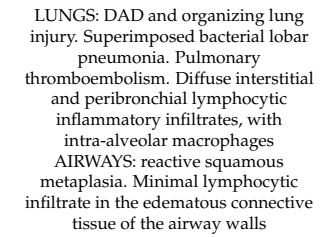 & $\mathrm{N} / \mathrm{D}$ & 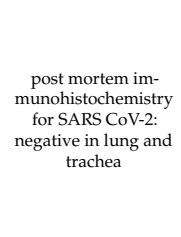 & $\begin{array}{l}\text { SARS CoV-2 } \\
\text { preumonia } \\
\text { resulling in } \\
\text { respinatory } \\
\text { failure }\end{array}$ & $\begin{array}{c}\text { Positive for SARS } \\
\text { CoV-2 } \\
\text { (nasopharyngeal) }\end{array}$ \\
\hline \multirow{3}{*}{$\begin{array}{l}\text { Mohammad } \\
\text { Taghi } \\
\text { Beigmo- } \\
\text { ham- } \\
\text { madi } \\
\text { et al. }\end{array}$} & 84 & $\mathrm{~F}$ & $\begin{array}{l}\text { HTN. Therapy: } \\
\text { amlodipine, aspirin, } \\
\text { citalopram }\end{array}$ & $\begin{array}{l}\text { HCQ, } \\
\text { lopinavir/oseltamivir, } \\
\text { intubation }\end{array}$ & $\mathrm{N} / \mathrm{D}$ & $\begin{array}{l}\text { Chest CT: bilateral } \\
\text { peripheral round } \\
\text { glass opacities } \\
\text { especially along the } \\
\text { basal segments }\end{array}$ & $\begin{array}{l}\text { Hospital presentation: } \\
\text { fever, dyspnea and } \\
\text { myalial Intubation, } \\
\text { died } 3 \text { dayys after } \\
\text { hospitalization }\end{array}$ & $\mathrm{N} / \mathrm{D}$ & N/D & $\begin{array}{l}\text { LUNGS: pulmonary edema, hyaline } \\
\text { membranes, fifrinous exudate, } \\
\text { inflammation in the alveolar walls, } \\
\text { alveolar macrophages, fibrinoidd material } \\
\text { in the vessel walls } \\
\text { LIVER: minimial portal inflammation, } \\
\text { severe congestion, mild macrovesicular } \\
\text { and microvesicular steatosis, mild } \\
\text { ballooning degeneration }\end{array}$ & $\mathrm{N} / \mathrm{D}$ & $\mathrm{N} / \mathrm{D}$ & Not specified & $\begin{array}{c}\text { Positive for SARS } \\
\text { CoV-2 } \\
\text { (not specified) }\end{array}$ \\
\hline & 72 & $\mathrm{~F}$ & $\begin{array}{l}\text { RA. Therapy: } \\
\text { sulfasalazine, } \\
\text { prednisolone, MTX }\end{array}$ & $\begin{array}{c}\text { HCQ, } \\
\text { levofloxacin, } \\
\text { intubation }\end{array}$ & $\mathrm{N} / \mathrm{D}$ & $\begin{array}{l}\text { Chest CT: bilateral } \\
\text { peripheral round } \\
\text { glass opacities, } \\
\text { especially along the } \\
\text { basal segments }\end{array}$ & $\begin{array}{l}\text { Hospital presentation: } \\
\text { fever, headache, nausea } \\
\text { and vomiting. } \\
\text { Intubated, died } 15 \text { days } \\
\text { after hospitalization }\end{array}$ & $\mathrm{N} / \mathrm{D}$ & N/D & 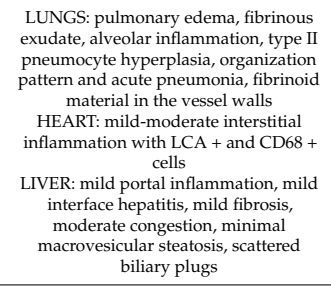 & $\mathrm{N} / \mathrm{D}$ & $\mathrm{N} / \mathrm{D}$ & Not specified & $\begin{array}{c}\text { Positive for SARS } \\
\text { CoV-2 } \\
\text { (not specified) }\end{array}$ \\
\hline & 72 & $\mathrm{M}$ & $\begin{array}{l}\text { HTN, DM with } \\
\text { insulin treatment }\end{array}$ & $\begin{array}{c}\text { HCQ, } \\
\text { oseltamivir, } \\
\text { atazanavir, } \\
\text { levofloxacin, } \\
\text { intubation }\end{array}$ & $\mathrm{N} / \mathrm{D}$ & $\begin{array}{l}\text { Chest CT: bilateral } \\
\text { peripheral ground } \\
\text { glass opacities, } \\
\text { especially along the } \\
\text { basal segments }\end{array}$ & $\begin{array}{l}\text { Hospital presentation: } \\
\text { fever, dyspnea and } \\
\text { diarhea. Intubation, } \\
\text { died } 4 \text { days after } \\
\text { hospitalization }\end{array}$ & $\mathrm{N} / \mathrm{D}$ & N/D & $\begin{array}{l}\text { LUNGS: pulmonary edema, hyaline } \\
\text { membranes, inflammation in the } \\
\text { alvelar walls } \\
\text { LIVER: mild portal inflammation, mild } \\
\text { congestion, minimal macrovesicular and } \\
\text { microvescicular steatosis }\end{array}$ & $\mathrm{N} / \mathrm{D}$ & $\mathrm{N} / \mathrm{D}$ & Not specified & $\begin{array}{c}\text { Positive for SARS } \\
\text { CoV-2 } \\
\text { (not specified) }\end{array}$ \\
\hline
\end{tabular}


Table 1. Cont.

\begin{tabular}{|c|c|c|c|c|c|c|c|c|c|c|c|c|c|c|}
\hline \multirow[b]{2}{*}{ Author } & \multirow[b]{2}{*}{ A } & \multirow[b]{2}{*}{ G } & \multicolumn{5}{|c|}{ IN VIVO DATA } & \multicolumn{7}{|c|}{ POSTMORTEM DATA } \\
\hline & & & $\begin{array}{c}\text { Comorbidities and } \\
\text { Past Drugs }\end{array}$ & Therapy & Labor & Imaging & $\begin{array}{l}\text { Course of the } \\
\text { Disease/Circumstances } \\
\text { of Death }\end{array}$ & Imaging & $\begin{array}{c}\text { Macroscopic } \\
\text { Features }\end{array}$ & Microscopic Features & Tox & $\begin{array}{l}\text { Additional } \\
\text { Analyses }\end{array}$ & Cause of Death & Swabs \\
\hline & 68 & $\mathrm{M}$ & $\begin{array}{l}\text { HTN, valuvular } \\
\text { regurgitation. } \\
\text { Therapy: losatan, } \\
\text { propranolol }\end{array}$ & $\begin{array}{c}\text { HC, } \\
\text { oseltamivir, } \\
\text { intubation }\end{array}$ & N/D & $\begin{array}{l}\text { Chest CT: bilateral } \\
\text { peripheral rround } \\
\text { glass opacities } \\
\text { especially along the } \\
\text { basal segments }\end{array}$ & $\begin{array}{l}\text { Hospital presentation: } \\
\text { fever and dysprea. } \\
\text { Endocarditis and valve } \\
\text { surgery. Developpment } \\
\text { of respiratory } \\
\text { symptoms, intubated, } \\
\text { died after 19 days of } \\
\text { hospitalization }\end{array}$ & N/D & $\mathrm{N} / \mathrm{D}$ & 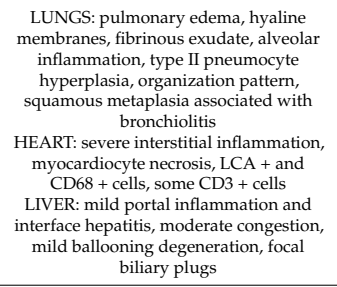 & $\mathrm{N} / \mathrm{D}$ & $\mathrm{N} / \mathrm{D}$ & Not specified & $\begin{array}{c}\text { Positive for SARS } \\
\text { CoV-2 } \\
\text { (not specified) }\end{array}$ \\
\hline & 46 & $\mathrm{M}$ & $\begin{array}{l}\text { Peptic ulcer disease. } \\
\text { Therapy= } \\
\text { chlordiazepoxide, } \\
\text { clidinium }\end{array}$ & $\begin{array}{l}\text { HCQ, } \\
\text { remedesivir, } \\
\text { naproxen, } \\
\text { cefepepime, } \\
\text { intubation }\end{array}$ & $\mathrm{N} / \mathrm{D}$ & $\begin{array}{l}\text { Chest CT: bilateral } \\
\text { peripheral ground } \\
\text { glass opacities } \\
\text { especially along the } \\
\text { basal segments }\end{array}$ & $\begin{array}{l}\text { Hospital presentation: } \\
\text { fever, dyspnea, myalgia } \\
\text { and pharyngodynia. } \\
\text { Intubation, nied after } 16 \\
\text { days }\end{array}$ & $\mathrm{N} / \mathrm{D}$ & $\mathrm{N} / \mathrm{D}$ & $\begin{array}{l}\text { LUNGS: pulmonary edema, fibrinous } \\
\text { exudate, inflammation in alveolar } \\
\text { spaces and walls, type II pneumocyte } \\
\text { hyperplasia, organization pattern and } \\
\text { acute pneumonia, hemorrhagic areas } \\
\text { LIVER: minimal portal inflammation, } \\
\text { moderate to severe congestion, mild } \\
\text { macrovesicular and microvesciular } \\
\text { steatosis, mild ballooning degeneration }\end{array}$ & $\mathrm{N} / \mathrm{D}$ & N/D & Not specified & $\begin{array}{c}\text { Positive for SARS } \\
\text { CoV-2 } \\
\text { (not specified) }\end{array}$ \\
\hline & 75 & M & $\mathrm{N}$ & $\begin{array}{c}\mathrm{HCQ}, \\
\text { oseltamivir, } \\
\text { intubation }\end{array}$ & $\mathrm{N} / \mathrm{D}$ & $\begin{array}{l}\text { Chest CT: bilateral } \\
\text { peripheral ground } \\
\text { glass opacities, } \\
\text { especially along the } \\
\text { basal segments }\end{array}$ & $\begin{array}{l}\text { Hospital presentation: } \\
\text { fever, dyspnea and } \\
\text { anorexia. Intubation, } \\
\text { died after } 6 \text { days }\end{array}$ & $\mathrm{N} / \mathrm{D}$ & N/D & 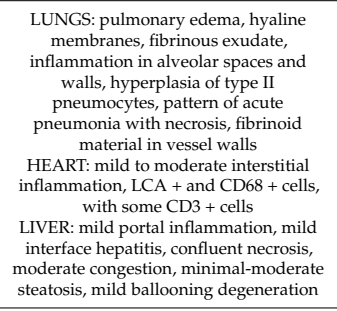 & $\mathrm{N} / \mathrm{D}$ & $\mathrm{N} / \mathrm{D}$ & Not specified & $\begin{array}{l}\text { Positive for SARS } \\
\text { CoV-2(not } \\
\text { specified) }\end{array}$ \\
\hline $\begin{array}{l}\text { Sufang } \\
\text { Tian } \\
\text { et al. }\end{array}$ & 78 & $\mathrm{~F}$ & $\begin{array}{l}\text { Chronic lymphocytic } \\
\text { leukemia }\end{array}$ & $\begin{array}{l}\text { Antibiotics, } \\
\text { antivirals, } \mathrm{O}_{2}\end{array}$ & $\begin{array}{l}\text { elevated } \\
\text { pro-BNP, } \\
\text { elevated } \\
\text { troponin, } \\
\text { elevated LDH, } \\
\text { leukocytosis }\end{array}$ & 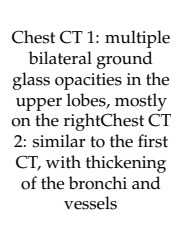 & $\begin{array}{l}\text { Hospitalized for } \\
\text { COVID-19 preumonia } \\
\text { at Wuhan University } \\
\text { Zhongnnan Hospital. } \\
\text { Died after } 22 \text { days }\end{array}$ & $\mathrm{N} / \mathrm{D}$ & N/D & 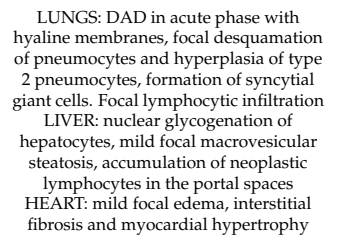 & $\mathrm{N} / \mathrm{D}$ & $\begin{array}{l}\text { RT-PCR for viral } \\
\text { RNA in heart and } \\
\text { liver samples: } \\
\text { positive }\end{array}$ & $\begin{array}{l}\text { SARS CoV-2 } \\
\text { pneumonia }\end{array}$ & $\begin{array}{c}\text { Positive for SARS } \\
\text { CoV-2 } \\
\text { (nasopharyngeal) }\end{array}$ \\
\hline
\end{tabular}


Table 1. Cont.

\begin{tabular}{|c|c|c|c|c|c|c|c|c|c|c|c|c|c|c|}
\hline \multirow[b]{2}{*}{ Author } & \multirow[b]{2}{*}{ A } & \multirow[b]{2}{*}{ G } & \multicolumn{5}{|c|}{ IN VIVO DATA } & \multicolumn{7}{|c|}{ POSTMORTEM DATA } \\
\hline & & & $\begin{array}{c}\text { Comorbiditites and } \\
\text { Past Drugs }\end{array}$ & Therapy & Labor & Imaging & $\begin{array}{l}\text { Course of the } \\
\text { Disease/Circumstances } \\
\text { of Death }\end{array}$ & Imaging & $\begin{array}{c}\text { Macroscopic } \\
\text { Features }\end{array}$ & Microscopic Features & Tox & $\begin{array}{c}\text { Additional } \\
\text { Analyses }\end{array}$ & Cause of Death & Swabs \\
\hline & 74 & M & $\begin{array}{c}\text { Cirrhosis, variceal } \\
\text { bleeding }\end{array}$ & $\begin{array}{l}\text { Antibiotics, } \\
\text { antivirals, } \mathrm{O}_{2}\end{array}$ & $\begin{array}{l}\text { mildly, } \\
\text { elevated } \\
\text { troponin, } \\
\text { elevated LDH, } \\
\text { leukoctosisi, } \\
\text { lymphocy- } \\
\text { topenia }\end{array}$ & $\begin{array}{l}\text { Chest CT 1: patchy } \\
\text { ground dlass } \\
\text { opacities } \\
\text { consolidations, air } \\
\text { bronchogram } \\
\text { Chest CT2 2: } \\
\text { additional } \\
\text { consolidation in the } \\
\text { left upper lobe }\end{array}$ & 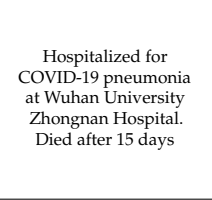 & $\mathrm{N} / \mathrm{D}$ & N/D & $\begin{array}{l}\text { LUNGS: DAD in the acute phase, } \\
\text { formation of hyyline membranes } \\
\text { LIVER: pre-existing cirrosis }\end{array}$ & $\mathrm{N} / \mathrm{D}$ & $\begin{array}{l}\text { RT-PCR for viral } \\
\text { RNA in lung } \\
\text { samples: positive }\end{array}$ & $\begin{array}{l}\text { SARS CoV-2 } \\
\text { pneumonia }\end{array}$ & $\begin{array}{c}\text { Positive for SARS } \\
\text { CoV-2 } \\
\text { (nasopharyngeal) }\end{array}$ \\
\hline & 81 & M & DM, HTN & $\begin{array}{l}\text { Antibiotics, } \\
\text { antivirals, } \mathrm{O}_{2}\end{array}$ & $\begin{array}{l}\text { elevated } \\
\text { troponin, } \\
\text { elevated LDH, } \\
\text { leukocytosis, } \\
\text { lymphocy- } \\
\text { topenia }\end{array}$ & $\begin{array}{l}\text { Chest X-ray 1: } \\
\text { patchy opaciciein in } \\
\text { both ungs, } \\
\text { especillly in the } \\
\text { lower lobes } \\
\text { Chest - -ray } \\
\text { worsening of the } \\
\text { previous picture }\end{array}$ & $\begin{array}{l}\text { Hospitalized for } \\
\text { COVID-19 preumonia } \\
\text { at Wunhn University } \\
\text { Zhongnan Hospital. } \\
\text { Died after } 23 \text { days }\end{array}$ & $\mathrm{N} / \mathrm{D}$ & N/D & $\begin{array}{l}\text { LUNGS: Acute DAD with hyaline } \\
\text { membranes, focal interstitial thickening, } \\
\text { vascular congestion, mild interstitial } \\
\text { inflammantory infiltrate } \\
\text { LIVER: mild sinusoidal dilation, liver } \\
\text { plaque necrosis, mald inicrease in } \\
\text { sinusoidal lymphocytes }\end{array}$ & $\mathrm{N} / \mathrm{D}$ & $\begin{array}{l}\text { RT-PCR for viral } \\
\text { RNA in liver } \\
\text { samples: negative }\end{array}$ & $\begin{array}{l}\text { SARS CoV-2 } \\
\text { pneumonia }\end{array}$ & $\begin{array}{c}\text { Positive for SARS } \\
\text { CoV-2 } \\
\text { (nasopharyngeal) }\end{array}$ \\
\hline & 59 & M & $\begin{array}{l}\text { Kidney transplant } \\
\text { performed } 3 \text { months } \\
\text { earlier }\end{array}$ & $\begin{array}{l}\text { Antibiotics, } \\
\text { antivirals, } \mathrm{O}_{2}\end{array}$ & 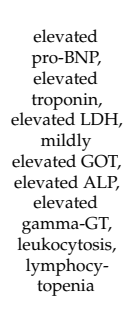 & $\begin{array}{l}\text { Chest CT 1: diffuse } \\
\text { ground glass } \\
\text { opacites, } \\
\text { consolidation in the } \\
\text { posterior segment } \\
\text { Chest CT2 } \\
\text { additional visible air } \\
\text { bronchogram }\end{array}$ & 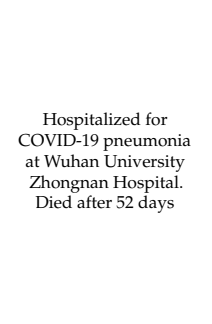 & $\mathrm{N} / \mathrm{D}$ & N/D & 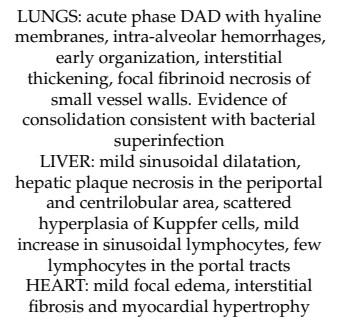 & $\mathrm{N} / \mathrm{D}$ & $\begin{array}{l}\text { RT-PCR for viral } \\
\text { RNA in heart and } \\
\text { liver samples: } \\
\text { negative }\end{array}$ & $\begin{array}{l}\text { SARS CoV-2 } \\
\text { pneumonia }\end{array}$ & $\begin{array}{c}\text { Positive for SARS } \\
\text { CoV-2 } \\
\text { (nasopharyngeal) }\end{array}$ \\
\hline $\begin{array}{l}\text { Zsuzsanna } \\
\text { Varga } \\
\text { et al. }\end{array}$ & 71 & M & $\begin{array}{l}\text { Kidney transplant, } \\
\text { coronary heart } \\
\text { disease, HNN }\end{array}$ & Intubation & N/D & N/D & $\begin{array}{l}\text { Hospitalized with a } \\
\text { diagnosis of COVIID-19, } \\
\text { mechanical ventilation. } \\
8 \text { days later died due to } \\
\text { MOF }\end{array}$ & $\mathrm{N} / \mathrm{D}$ & N/D & $\begin{array}{l}\text { LUNGS: concentration of mononuclear } \\
\text { cells, with congestion of many of the } \\
\text { small pulmonary vessels } \\
\text { OTHERS: Apoptotic bodies in the heart, } \\
\text { small intestine and lung }\end{array}$ & $\mathrm{N} / \mathrm{D}$ & $\begin{array}{l}\text { ELECTRON } \\
\text { MICROSCOY: in } \\
\text { the transplanted } \\
\text { kindey, viral } \\
\text { inclusions in } \\
\text { endothelial cells }\end{array}$ & MOF & $\begin{array}{l}\text { Positive for SARS } \\
\text { CoV-2(not } \\
\text { specified) }\end{array}$ \\
\hline
\end{tabular}


Table 1. Cont.

\begin{tabular}{|c|c|c|c|c|c|c|c|c|c|c|c|c|c|c|}
\hline \multirow[b]{2}{*}{ Author } & \multirow[b]{2}{*}{ A } & \multirow[b]{2}{*}{ G } & \multicolumn{5}{|c|}{ IN VIVO DATA } & \multicolumn{7}{|c|}{ POSTMORTEM DATA } \\
\hline & & & $\begin{array}{c}\text { Comorbidities and } \\
\text { Past Drugs }\end{array}$ & Therapy & Labor & Imaging & $\begin{array}{l}\text { Course of the } \\
\text { Disease/Circumstances } \\
\text { of Death }\end{array}$ & Imaging & $\begin{array}{l}\text { Macroscopic } \\
\text { Features }\end{array}$ & Microscopic Features & Tox & $\begin{array}{l}\text { Additional } \\
\text { Analyses }\end{array}$ & Cause of Death & Swabs \\
\hline & 58 & F & $\mathrm{DM}, \mathrm{HTN}$, obesity & Dialysis & N/D & N/D & $\begin{array}{l}\text { Progressive respiratory } \\
\text { failure due to to } \\
\text { COVIID-19, MOF, } \\
\text { dialysis required. On } \\
\text { day } 16 \text { of admission, } \\
\text { mesenteric ischemia } \\
\text { requiring surgeryy. } \\
\text { STEMI infarction, } \\
\text { circulatory failure and } \\
\text { cardiac arrest }\end{array}$ & $\mathrm{N} / \mathrm{D}$ & N/D & $\begin{array}{l}\text { LUNGS: Iymphocytic endothelitis } \\
\text { KIDNEY: Iymphocytic endothelitis } \\
\text { LIVR: hepatocyte necrosis, } \\
\text { lymphocytic endothelitis } \\
\text { HEART: myocardial infarction, } \\
\text { lymphoytic endothelitis } \\
\text { GI: endothelitis of the submucosal } \\
\text { vessels }\end{array}$ & $\mathrm{N} / \mathrm{D}$ & $\mathrm{N} / \mathrm{D}$ & Cardiac arrest & $\begin{array}{l}\text { Positive for SARS } \\
\text { CoV-2(not } \\
\text { specified) }\end{array}$ \\
\hline $\begin{array}{l}\text { Zhe Xu } \\
\text { et al. }\end{array}$ & 50 & M & N/D & $\begin{array}{l}\mathrm{O}_{2}, \text { interferon } \\
\text { alfa-2b, } \\
\text { lopinavir, } \\
\text { ritonavir, } \\
\text { moxifloxacin, } \\
\text { methylpred- } \\
\text { nisolone }\end{array}$ & lymphocytopenia & 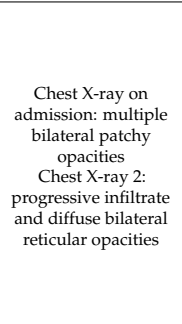 & $\begin{array}{l}\text { Hospital presentation: } \\
\text { fever, chills, cough, } \\
\text { fatiguea and shortness of } \\
\text { breath, recent trip to } \\
\text { Wuhan. On day 14 after } \\
\text { the onset, hypoxemia } \\
\text { and worsened dyspnea } \\
\text { died due to cardiac } \\
\text { arrest }\end{array}$ & $\mathrm{N} / \mathrm{D}$ & N/D & $\begin{array}{l}\text { LUNGS: Bilateral DAD with } \\
\text { fibromyxoid cellexudate. Desquamation } \\
\text { of the preumocytes and hyaline } \\
\text { membranes,s suggestive of ARDS. } \\
\text { Pulmonary edema, interstitial } \\
\text { inflammatory infiltrates, dominated by } \\
\text { lymphocytes. Multinclear syncytial } \\
\text { cells with enlarged atypicyl } \\
\text { pneumocytes and viral cytopathic } \\
\text { changes } \\
\text { LIVERR: moderate microvesicular } \\
\text { steatosis and mild lobular and portal } \\
\text { activity } \\
\text { HEART: slight mononuclear interstitial } \\
\text { infiltrate }\end{array}$ & $\mathrm{N} / \mathrm{D}$ & $\begin{array}{l}\text { Cytometric analyzes: } \\
\text { lymphocytopeneina, } \\
\text { lymphocte } \\
\text { hyperactivation }\end{array}$ & Cardiac arrest & $\begin{array}{c}\text { Positive for SARS } \\
\text { CoV-2 } \\
\text { (pharyngeal) }\end{array}$ \\
\hline $\begin{array}{l}\text { Christine } \\
\text { M. } \\
\text { Lovly } \\
\text { et al. }\end{array}$ & 56 & M & $\begin{array}{l}\text { DM2, smoker, } \\
\text { COPD, small cell } \\
\text { lung cancer. } \\
\text { Therapy: } \\
\text { doxycyline for } \\
\text { possible pheumonia } \\
\text { before diagnosis of } \\
\text { carinoma, then } \\
\text { carboplatin, } \\
\text { etoposide, } \\
\text { atezolizumab }\end{array}$ & $\begin{array}{l}\text { Methylprednisolone } \\
\text { infliximab, } \\
\text { O}_{2}, \\
\text { vancomyin } \\
\text { and } \\
\text { and } \\
\text { pipacailin/tazo- } \\
\text { bactam, } \\
\text { vasoressors, } \\
\text { intubation, }\end{array}$ & $\begin{array}{l}\text { e, } \\
\text { High ferritin, } \\
\text { high LDH }\end{array}$ & 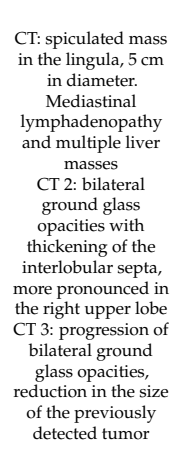 & 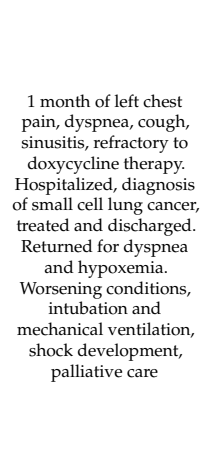 & $\mathrm{N} / \mathrm{D}$ & $\mathrm{N} / \mathrm{D}$ & 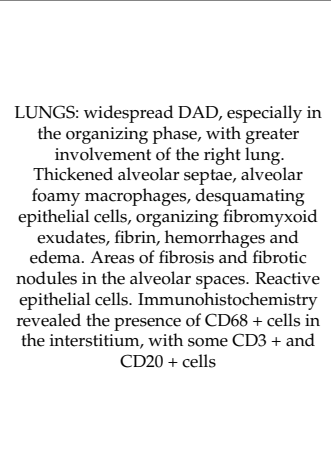 & $\mathrm{N} / \mathrm{D}$ & 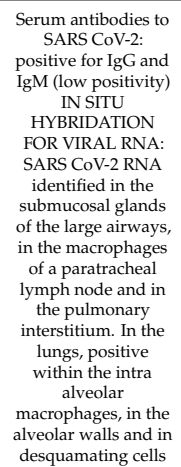 & Shock & $\begin{array}{c}\text { Positive for SARS } \\
\text { CoV-2 } \\
\text { (nasopharyngeal) }\end{array}$ \\
\hline
\end{tabular}

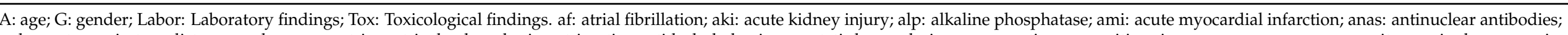

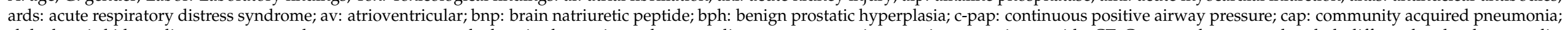

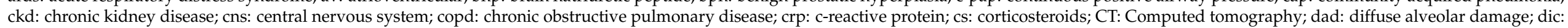

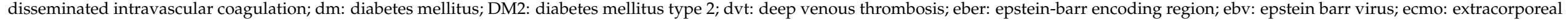

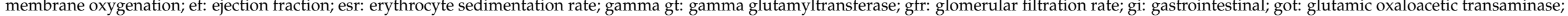

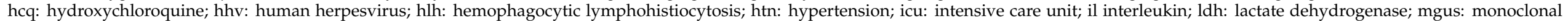

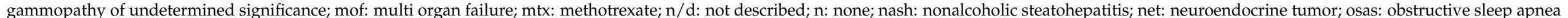

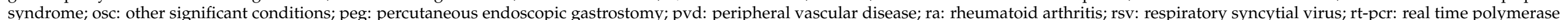
chain reaction; sle: systemic lupus erythematosus; uc: ulcerative colitis; uti: urinary tract infection. 
Victims were mostly male (58 cases), with a mean age of 65.3 years (median: 70.5, lower limit: 17, 25\% percentile: 55.5; 75\% percentile: 76.0; upper limit: 91 ). Since the exact age was not reported in two cases, defined as "middle aged", in the mean calculation they were both considered to be 55 years old. All the cases tested positive for SARS CoV2 RNA, with swabs performed in vivo and/or post-mortem. Seventy-four victims had comorbidities, though no information was reported in 5 cases, and of these, the majority (56 cases) had 2 or more diseases, up to a maximum of 14 . The most frequently reported were: arterial hypertension (in 41 cases, 55\%), diabetes mellitus (in 28 cases, $37.8 \%$ ) and obesity (in 24 cases, $32.4 \%$ ).

Signs and symptoms of SARS Cov- 2 infection were reported in 65 out of 84 cases. Respiratory symptoms were described in 50 cases, fever in 47 , cough in 34 . Fatigue/myalgia (11 times), gastrointestinal symptoms (10 times), alterations of consciousness, e.g., delirium/confusion/syncope (8 times), chills (6 times), tachycardia (5 times) and headache (4 times) were less common. Even more rarely hypotension, incontinence, chest pain and balance disorders (like dizziness/postural instability), described each in 2 cases, were reported. Acute kidney injury, acute cardiomyopathy, bradycardia, atrioventricular block, cardiac arrest, hemoptysis, hematuria, sore throat, sinusitis and anorexia were reported only one 1 time. In one case, unspecified systemic symptoms were described. Among the 49 cases whose laboratory abnormalities were reported, the most frequently encountered changes were elevated c-reactive protein (CRP) (51\%), lymphocytopenia $(46.9 \%)$, elevated lactate dehydrogenase (LDH) (38.7\%), elevated creatinine (26.5\%), elevated D-dimer $(24.4 \%)$, leukocytosis $(22.4 \%)$. Other alterations, such as in the values of fibrinogen, troponins, ferritin and Il-6, were rarely found.

Data on medications were available in 13 patients, 12 of whom were taking therapy for their previous conditions, while drugs administered during COVID-19 were reported in 55 out of 84 cases. The most common drugs included antibiotics $(52.7 \%)$, antivirals $(34.5 \%)$, hydroxychloroquine $(32.7 \%)$, vasopressors $(10,18.1 \%)$, corticosteroids $(12.7 \%)$, anticoagulants and heparins (12.7\%) and biologics (10.9\%). Diuretics, pain relievers and other medications were used in less than 5 patients $(9 \%)$. The use of non-invasive ventilatory support was specified in 21 patients (38.1\%), while 33 cases $(60 \%)$ required intubation during hospitalization for COVID-19. Finally, 6 patients underwent hemodialysis (10.9\%), while extracorporeal membrane oxygenation (ECMO) was used in 2 of them (3.6\%).

The majority (73) of the deaths occurred in a hospital setting, i.e., intensive care or other wards, while among the 11 out of the hospital cases, 3 occurred in nursing homes, 5 patients were found dead in their homes, 1 in his car, while in 2 cases the data were not extractable. Post mortem examinations performed included complete autopsies (29 cases), partial autopsies (33 cases) and post mortem histology (22 cases). The histological samples involved the lung in all the 22 cases, heart in 10 cases, liver in 13, airways in 7, kidney in 2 and gastrointestinal tract in 2 .

Imaging studies have been reported in 65 cases. Of these, in vivo imaging was performed in 50 , post mortem in 14 , both in 1 . On in vivo radiographs, the most commonly reported features were bilateral patchy opacities and / or consolidations $(60.7 \%)$, and $39.2 \%$ of chest CT showed ground glass opacity and/or consolidations. Post-mortem chest X-ray was performed in 2 cases and displayed bilateral opacities, while by PMCT, various degrees of pulmonary consolidation $(80 \%)$, presence of reticular pattern $(60 \%)$, pleural and/or pericardial effusions ( $40 \%)$ were described, as well as less represented features, e.g., emphysema, ground glass opacities and evidence of neoplastic lesions.

As for the autopsy room, macroscopic changes were described in several organs, although with a variable frequency, also caused by pre-existing pathologies. The most affected organs were lungs/airways in 51 of 54 cases, heart and vascular system in 33, liver in 12, kidneys in 11, spleen in 9, lymph nodes in 6 and CNS in 5 cases. Lungs were commonly described as heavy and edematous, with or without intraparenchymal hemorrhages or emboli. A macroscopic feature of pneumonia was also quite frequent, while purulent infections, empyema or green exudate were rarer. Extra-pulmonary common 
features included heart hypertrophy, though this is unlikely connected with COVID-19, enlargement of the spleen and of the lymph nodes. Alterations found in the gastrointestinal tract, prostate, skin, testis and other anatomical parts were much rarer. A similar picture was found in microscopic examinations of tissues, with lung/airways affected in all the 84 cases, liver in 40 , heart and vascular system in 37 , kidney in 25 , spleen in 13 , lymph nodes in 7 , gastrointestinal tract in 3 . Alterations reported in the CNS, bone marrow, testis and thyroid had lower frequencies. The most described finding within lung tissues was represented by diffuse alveolar damage (DAD) in exudative or organizing phases, coupled to pulmonary edema, hemorrhages and microthrombi. Less commonly, slight fibrosis, atypical pneumocytes or acute inflammatory infiltrates were noted. Microthrombi, together with signs of acute or chronic inflammation, were also reported in the trachea. Haemophagocytosis was occasionally noted in lymph nodes. In the heart, fibrosis and myocardiocyte hypertrophy have been mostly observed. In the liver, the dominant microscopic picture found was mild to severe hepatic steatosis, though portal/periportal inflammation, hepatocyte necrosis and hepatic congestion have been also described. The spleen commonly showed hyperplasia of the white pulp. In the kidney, arteriolosclerosis was the most frequently encountered finding, often related to chronic hypertensive damage and diabetes.

Regarding other examinations carried out, 9 electron microscopy tests were performed. In 8 of these 9 cases, the authors found viral-like particles within cells of different tissues (such as tracheal epithelial cells, pneumocytes, enterocytes, renal tubular cells). In the remaining case, no viral-like particles were found, but neutrophils in the alveolar capillaries and fibrin deposits in the alveolar spaces were documented. Moreover, the presence of bacteria, fungi or viruses in addition to SARS CoV-2 was documented in 7 of the patients by using cultural tests, rt-PCR and other laboratory tests. In 2 cases, toxicological investigations were also carried out, finding dextromethorphan in one patient (part of the antitussive therapy taken during COVID-19) and in another patient caffeine and naloxone. Causes of death were reported in 71 decedents, while the role of COVID-19 was specified 51 of them, being considered "cause of death" in 37 cases (72.5\%), "contributing factor" in $12(23.5 \%)$ and "significant factor" in $2(3.9 \%)$.

A summary of the results is shown in Figure 2.

\subsection{CSS Application}

The COVID-19 Significance Score was applied to each case found in the literature review. The non-parametric ANOVA comparing the CSS assigned by three independent blinded investigators did not show significant differences $(p>0.05)$. Complete agreement was found in 68 cases. As shown in Table 2, 57 of the 84 reported deaths fell into CSS category 3 for at least 2 raters, which means that "COVID-19 was the leading cause of death".

Twenty-two of the deaths fell into category 2 for at least two raters. In these cases, "COVID-19 likely contributed to the patient's death, together with other factors that may have played a prominent role". Four deaths were included in category 1, where "an alternative cause of death was likely", by at least two raters. In one case, CSS was classified as $U$ by two raters, further specific investigation being necessary, and as 0 for the third one.

\subsection{Hamburg Score}

The two classifications of deaths were compared in the cases reported in this work also described in the study by Edler et al., specifically in 13 of the 84 deaths collected in this paper (Table 2). Considering the Hamburg category 1 (defined COVID-19 death) equivalent to the CSS category 3, and the Hamburg category 2 (probable COVID-19 death) equivalent to the CSS category 2, the results of the two classification systems agreed in 8 out of the 13 cases. In the remaining 5 cases, differences in assessment emerged. Particularly: 
- in cases 1, 3, 4, 12 by Wichmann et al. [40], CSS classified COVID-19 as the cause of death (CSS = 3), while the Hamburg score revealed a probable COVID-19 death (corresponding to CSS $=2$ );

- $\quad$ in case 2 by Wichmann et al. [40], CSS classified COVID-19 as the cause of death (CSS = 3), while Hamburg scored the fatality as possible COVID-19 death (corresponding to CSS $=1$ ).

The $t$-test between the average CSS score and the Hamburg score, converted into CSS, did not yield a statistical significant difference.
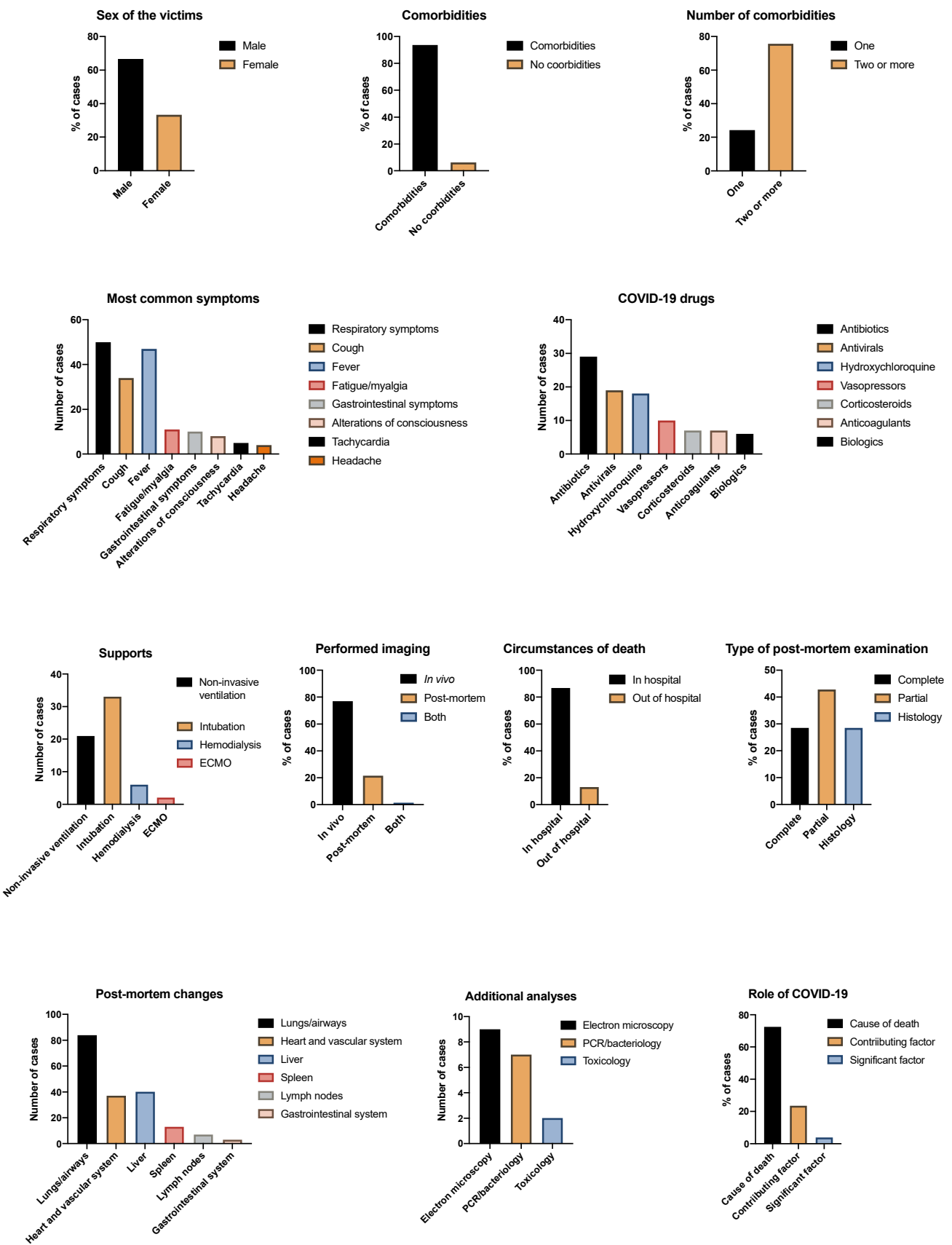

Figure 2. Summary of the main in vivo and post-mortem data emerged from literature cases. 
Table 2. Type of post-mortem examination, role of SARS CoV-2, comparison between scores and inter-raters agreement.

\begin{tabular}{|c|c|c|c|c|c|c|c|c|}
\hline Author & Age & Gender & Type of Examination & Role of SARS CoV-2 & CSS R1 & CSS R2 & CSS R3 & H Score \\
\hline \multirow{14}{*}{$\begin{array}{c}\text { Benjamin } \\
\text { T Bradley } \\
\text { et al. }\end{array}$} & 57 & M & Complete autopsy & Cause of death & 3 & 3 & 3 & - \\
\hline & 74 & F & $\begin{array}{l}\text { Partial autopsy (no } \\
\text { cranial cavity) }\end{array}$ & Contributing factor & 2 & 2 & 2 & - \\
\hline & 54 & M & $\begin{array}{l}\text { Partial autopsy (no } \\
\text { cranial cavity) }\end{array}$ & Contributing factor & 2 & 3 & 3 & - \\
\hline & 74 & M & $\begin{array}{l}\text { Partial autopsy (no } \\
\text { cranial cavity) }\end{array}$ & Contributing factor & 3 & 3 & 3 & - \\
\hline & 73 & $\mathrm{~F}$ & $\begin{array}{l}\text { Partial autopsy (no } \\
\text { cranial cavity) }\end{array}$ & Contributing factor & 3 & 3 & 3 & - \\
\hline & 84 & $\mathrm{~F}$ & $\begin{array}{l}\text { Partial autopsy (no } \\
\text { cranial cavity) }\end{array}$ & Contributing factor & 3 & 3 & 3 & - \\
\hline & 71 & M & $\begin{array}{l}\text { Partial autopsy (no } \\
\text { cranial cavity) }\end{array}$ & Contributing factor & 2 & 3 & 2 & - \\
\hline & 76 & $\mathrm{~F}$ & Complete autopsy & Contributing factor & 2 & 2 & 2 & - \\
\hline & 75 & F & $\begin{array}{l}\text { Partial autopsy (no } \\
\text { cranial cavity) }\end{array}$ & Contributing factor & 3 & 3 & 3 & - \\
\hline & 84 & M & Complete autopsy & Significant factor & 2 & 2 & 2 & - \\
\hline & 81 & $\mathrm{~F}$ & Complete autopsy & Contributing factor & 3 & 3 & 3 & - \\
\hline & 42 & $\mathrm{~F}$ & Complete autopsy & Contributing factor & 3 & 3 & 3 & - \\
\hline & 71 & M & Complete autopsy & contributing factor & 1 & 1 & 1 & - \\
\hline & 73 & $\mathrm{~F}$ & $\begin{array}{l}\text { Partial autopsy (no } \\
\text { cranial cavity) }\end{array}$ & Contributing factor & 3 & 3 & 3 & - \\
\hline \multirow{12}{*}{$\begin{array}{c}\text { Dominic } \\
\text { Wichmann } \\
\text { et al. }\end{array}$} & 52 & M & Complete autopsy & Cause of death & 3 & 3 & 3 & 2 \\
\hline & 70 & M & Complete autopsy & Cause of death & 3 & 3 & 3 & 3 \\
\hline & 71 & M & Complete autopsy & Cause of death & 3 & 3 & 3 & 2 \\
\hline & 63 & M & Complete autopsy & Cause of death & 3 & 3 & 3 & 2 \\
\hline & 66 & M & Complete autopsy & Cause of death & 2 & 2 & 2 & 1 \\
\hline & 54 & $\mathrm{~F}$ & Complete autopsy & Cause of death & 2 & 1 & 1 & 1 \\
\hline & 75 & $\mathrm{~F}$ & Complete autopsy & Cause of death & 3 & 3 & 3 & 1 \\
\hline & 82 & M & Complete autopsy & Cause of death & 2 & 2 & 2 & 1 \\
\hline & 87 & $\mathrm{~F}$ & Complete autopsy & Cause of death & 1 & 2 & 2 & 3 \\
\hline & 84 & M & Complete autopsy & Cause of death & 2 & 2 & 2 & 2 \\
\hline & 85 & M & Complete autopsy & Cause of death & 3 & 3 & 3 & 1 \\
\hline & 76 & M & Complete autopsy & Cause of death & 3 & 3 & 3 & 2 \\
\hline \multirow{4}{*}{$\begin{array}{c}\text { Andrey } \\
\text { Prilutskiy } \\
\text { et al. }\end{array}$} & 72 & M & Complete autopsy & Not specified & 2 & 3 & 3 & - \\
\hline & 91 & M & Complete autopsy & Not specified & 2 & 3 & 3 & - \\
\hline & 72 & M & Complete autopsy & Not specified & 3 & 3 & 3 & - \\
\hline & 64 & $\mathrm{~F}$ & Complete autopsy & Not specified & 3 & 3 & 3 & - \\
\hline \multirow{2}{*}{$\begin{array}{c}\text { Hans } \\
\text { Bösmüller } \\
\text { et al. }\end{array}$} & 78 & $\mathrm{~F}$ & $\begin{array}{l}\text { Partial autopsy (no } \\
\text { cranial cavity) }\end{array}$ & Not specified & 2 & 2 & 3 & - \\
\hline & 78 & M & $\begin{array}{l}\text { Partial autopsy (no } \\
\text { cranial cavity) }\end{array}$ & Not specified & 3 & 3 & 3 & - \\
\hline
\end{tabular}


Table 2. Cont.

\begin{tabular}{|c|c|c|c|c|c|c|c|c|}
\hline Author & Age & Gender & Type of Examination & Role of SARS CoV-2 & CSS R1 & CSS R2 & CSS R3 & H Score \\
\hline & 72 & M & $\begin{array}{l}\text { Partial autopsy (no } \\
\text { cranial cavity) }\end{array}$ & Not specified & 2 & 2 & 2 & - \\
\hline & 59 & M & $\begin{array}{l}\text { Partial autopsy (no } \\
\text { cranial cavity) }\end{array}$ & Not specified & 3 & 3 & 3 & - \\
\hline \multirow{3}{*}{$\begin{array}{l}\text { Louis Max- } \\
\text { imilian } \\
\text { Buja et al. }\end{array}$} & 62 & M & $\begin{array}{l}\text { Partial autopsy (no } \\
\text { cranial cavity) }\end{array}$ & Not specified & 3 & 3 & 3 & - \\
\hline & 34 & M & $\begin{array}{l}\text { Partial autopsy (no } \\
\text { cranial cavity) }\end{array}$ & Not specified & 2 & 2 & 2 & - \\
\hline & 48 & M & Complete autopsy & Not specified & 3 & 3 & 3 & - \\
\hline \multirow{3}{*}{$\begin{array}{l}\text { Esther } \\
\text { Youd et al. }\end{array}$} & 88 & $\mathrm{~F}$ & Complete autopsy & Not specified & 3 & 3 & 3 & - \\
\hline & 86 & $\mathrm{M}$ & Complete autopsy & Not specified & 3 & 2 & 2 & - \\
\hline & 73 & $\mathrm{~F}$ & Complete autopsy & Not specified & 3 & 3 & 3 & - \\
\hline \multirow{2}{*}{$\begin{array}{l}\text { Lisa M. } \\
\text { Barton } \\
\text { et al. }\end{array}$} & 77 & M & Complete autopsy & Cause of death & 3 & 3 & 3 & - \\
\hline & 42 & M & Complete autopsy & Significant factor & 1 & 1 & 1 & - \\
\hline \multirow{2}{*}{$\begin{array}{l}\text { Miroslav } \\
\text { Sekulic } \\
\text { et al. }\end{array}$} & 81 & M & $\begin{array}{l}\text { Partial autopsy (no } \\
\text { cranial cavity) }\end{array}$ & Cause of death & 2 & 2 & 2 & - \\
\hline & 54 & M & $\begin{array}{l}\text { Partial autopsy (no } \\
\text { cranial cavity) }\end{array}$ & Cause of death & 2 & 2 & 2 & - \\
\hline \multirow{2}{*}{$\begin{array}{c}\text { Chaofu } \\
\text { Wang et al. }\end{array}$} & 53 & $\mathrm{~F}$ & Complete autopsy & Not specified & 3 & 3 & 3 & - \\
\hline & 62 & M & Complete autopsy & Not specified & 3 & 3 & 3 & - \\
\hline \multirow{2}{*}{$\begin{array}{l}\text { Zachary } \\
\text { Grimes } \\
\text { et al. }\end{array}$} & $\begin{array}{l}\text { Middle } \\
\text { age }\end{array}$ & M & Complete autopsy & Not specified & 3 & 3 & 3 & - \\
\hline & $\begin{array}{l}\text { Middle } \\
\text { age }\end{array}$ & M & Complete autopsy & Not specified & 3 & 3 & 3 & - \\
\hline $\begin{array}{l}\text { Kristine E. } \\
\text { Konopka } \\
\text { et al. }\end{array}$ & 37 & M & Complete autopsy & Cause of death & 3 & 3 & 3 & - \\
\hline $\begin{array}{l}\text { Randall } \\
\text { Craver } \\
\text { et al. }\end{array}$ & 17 & M & Complete autopsy & Not specified & $\mathrm{U}$ & $\mathrm{U}$ & 0 & - \\
\hline $\begin{array}{l}\text { Lei Yan } \\
\text { et al. }\end{array}$ & 44 & $\mathrm{~F}$ & $\begin{array}{l}\text { Partial autopsy (no } \\
\text { cranial cavity, internal } \\
\text { organs left in situ) }\end{array}$ & Not specified & 2 & 3 & 3 & - \\
\hline $\begin{array}{l}\text { J. Matthew } \\
\text { Lacy et al. }\end{array}$ & 58 & $\mathrm{~F}$ & Complete autopsy & Cause of death & 3 & 3 & 3 & - \\
\hline $\begin{array}{l}\text { Evan A. } \\
\text { Farkash } \\
\text { et al. }\end{array}$ & 53 & M & $\begin{array}{l}\text { Partial autopsy (no } \\
\text { cranial cavity) }\end{array}$ & Cause of death & 1 & 2 & 2 & - \\
\hline $\begin{array}{l}\text { Diego } \\
\text { Aguiar } \\
\text { et al. }\end{array}$ & 31 & $\mathrm{~F}$ & Complete autopsy & Cause of death & 3 & 3 & 3 & - \\
\hline $\begin{array}{c}\text { Takuya } \\
\text { Adachi } \\
\text { et al. }\end{array}$ & 84 & $\mathrm{~F}$ & $\begin{array}{l}\text { Partial autopsy (no } \\
\text { cranial cavity) }\end{array}$ & Cause of death & 2 & 2 & 2 & - \\
\hline
\end{tabular}


Table 2. Cont.

\begin{tabular}{|c|c|c|c|c|c|c|c|c|}
\hline Author & Age & Gender & Type of Examination & Role of SARS CoV-2 & CSS R1 & CSS R2 & CSS R3 & H Score \\
\hline $\begin{array}{l}\text { Parisa } \\
\text { Karami } \\
\text { et al. }\end{array}$ & 27 & $\mathrm{~F}$ & $\begin{array}{l}\text { Partial autopsy (only } \\
\text { lungs reported) }\end{array}$ & Not specified & 3 & 3 & 3 & - \\
\hline $\begin{array}{l}\text { Christine } \\
\text { Suess et al. }\end{array}$ & 59 & M & Complete autopsy & Cause of death & 3 & 3 & 3 & - \\
\hline $\begin{array}{l}\text { Monique } \\
\text { Freire } \\
\text { Santana } \\
\text { et al. }\end{array}$ & 71 & M & Complete autopsy & Not specified & 1 & 1 & 1 & - \\
\hline $\begin{array}{c}\text { James R. } \\
\text { Stone et al. }\end{array}$ & 76 & $\mathrm{~F}$ & $\begin{array}{l}\text { Partial autopsy (only } \\
\text { heart and lungs } \\
\text { examined } \\
\text { macroscopically) }\end{array}$ & Cause of death & 3 & 3 & 3 & - \\
\hline $\begin{array}{c}\text { Sociedad } \\
\text { Espanola } \\
\text { de } \\
\text { Anatomia } \\
\text { Patologica }\end{array}$ & 54 & M & $\begin{array}{l}\text { Partial autopsy (no } \\
\text { cranial cavity, internal } \\
\text { organs left in situ) }\end{array}$ & Not specified & 3 & 3 & 3 & - \\
\hline $\begin{array}{l}\text { Pedro } \\
\text { Navarro } \\
\text { Conde } \\
\text { et al. }\end{array}$ & 69 & M & $\begin{array}{l}\text { Partial autopsy (no } \\
\text { cranial cavity) }\end{array}$ & Cause of death & 3 & 3 & 3 & - \\
\hline $\begin{array}{l}\text { Fabian } \\
\text { Heinrich } \\
\text { et al. }\end{array}$ & 59 & M & Complete autopsy & Cause of death & 3 & 3 & 3 & 1 \\
\hline \multirow{7}{*}{$\begin{array}{c}\text { Inga-Marie } \\
\text { Schaefer } \\
\text { et al. }\end{array}$} & 66 & $\mathrm{~F}$ & $\begin{array}{c}\text { Post mortem } \\
\text { histological samples } \\
\text { (lung, airways) }\end{array}$ & Cause of death & 3 & 3 & 3 & - \\
\hline & 57 & M & $\begin{array}{c}\text { Post mortem } \\
\text { histological samples } \\
\text { (lung, airways) }\end{array}$ & Cause of death & 3 & 3 & 3 & - \\
\hline & 77 & M & $\begin{array}{l}\text { Post mortem } \\
\text { histological samples } \\
\text { (lung, airways) }\end{array}$ & Cause of death & 2 & 2 & 2 & - \\
\hline & 50 & M & $\begin{array}{c}\text { post mortem } \\
\text { histological samples } \\
\text { (lung, airways) }\end{array}$ & Cause of death & 2 & 2 & 2 & - \\
\hline & 68 & $\mathrm{~F}$ & $\begin{array}{l}\text { Post mortem } \\
\text { histological samples } \\
\text { (lung, airways) }\end{array}$ & Cause of death & 3 & 3 & 3 & - \\
\hline & 66 & M & $\begin{array}{c}\text { Post mortem } \\
\text { histological samples } \\
\text { (lung, airways) }\end{array}$ & Cause of death & 3 & 3 & 3 & - \\
\hline & 53 & M & $\begin{array}{c}\text { Post mortem } \\
\text { histological samples } \\
\text { (lung, airways) }\end{array}$ & Cause of death & 2 & 2 & 2 & - \\
\hline
\end{tabular}


Table 2. Cont

\begin{tabular}{|c|c|c|c|c|c|c|c|c|}
\hline Author & Age & Gender & Type of Examination & Role of SARS CoV-2 & CSS R1 & CSS R2 & CSS R3 & H Score \\
\hline \multirow{7}{*}{$\begin{array}{c}\text { Mohammad } \\
\text { Taghi } \\
\text { Beigmo- } \\
\text { hammadi } \\
\text { et al. }\end{array}$} & 58 & M & $\begin{array}{l}\text { Post mortem } \\
\text { histological samples } \\
\text { (lung, airways) }\end{array}$ & Not specified & 3 & 3 & 3 & - \\
\hline & 84 & $\mathrm{~F}$ & $\begin{array}{c}\text { Post mortem } \\
\text { histological samples } \\
\text { (lung, airways) }\end{array}$ & Not specified & 3 & 3 & 3 & - \\
\hline & 72 & $\mathrm{~F}$ & $\begin{array}{c}\text { Post mortem } \\
\text { histological samples } \\
\text { (lung, airways) }\end{array}$ & Not specified & 3 & 3 & 3 & - \\
\hline & 72 & M & $\begin{array}{c}\text { Post mortem } \\
\text { histological samples } \\
\text { (lung, airways) }\end{array}$ & Not specified & 3 & 3 & 3 & - \\
\hline & 68 & M & $\begin{array}{c}\text { Post mortem } \\
\text { histological samples } \\
\text { (lung, airways) }\end{array}$ & Not specified & 2 & 3 & 3 & - \\
\hline & 46 & M & $\begin{array}{c}\text { Post mortem } \\
\text { histological samples } \\
\text { (lung, airways) }\end{array}$ & Not specified & 3 & 3 & 3 & - \\
\hline & 75 & M & $\begin{array}{c}\text { Post mortem } \\
\text { histological samples } \\
\text { (lung, airways) }\end{array}$ & Not specified & 3 & 3 & 3 & - \\
\hline \multirow{4}{*}{$\begin{array}{c}\text { Sufang } \\
\text { Tian et al. }\end{array}$} & 78 & $\mathrm{~F}$ & $\begin{array}{c}\text { Post mortem } \\
\text { histological samples } \\
\text { (lung, airways) }\end{array}$ & Cause of death & 3 & 3 & 3 & - \\
\hline & 74 & M & $\begin{array}{c}\text { Post mortem } \\
\text { histological samples } \\
\text { (lung, airways) }\end{array}$ & Cause of death & 3 & 3 & 3 & - \\
\hline & 81 & M & $\begin{array}{c}\text { Post mortem } \\
\text { histological samples } \\
\text { (lung, airways) }\end{array}$ & Cause of death & 3 & 3 & 3 & - \\
\hline & 59 & M & $\begin{array}{c}\text { Post mortem } \\
\text { histological samples } \\
\text { (lung, airways) }\end{array}$ & Cause of death & 2 & 3 & 3 & - \\
\hline \multirow{2}{*}{$\begin{array}{l}\text { Zsuzsanna } \\
\text { Varga et al. }\end{array}$} & 71 & M & $\begin{array}{c}\text { Post mortem } \\
\text { histological samples } \\
\text { (lung, airways) }\end{array}$ & Not specified & 2 & 2 & 2 & - \\
\hline & 58 & $\mathrm{~F}$ & $\begin{array}{c}\text { Post mortem } \\
\text { histological samples } \\
\text { (lung, airways) }\end{array}$ & Not specified & 2 & 2 & 2 & - \\
\hline $\begin{array}{c}\text { Zhe Xu } \\
\text { et al. }\end{array}$ & 50 & M & $\begin{array}{c}\text { Post mortem } \\
\text { histological samples } \\
\text { (lung, airways) }\end{array}$ & Cause of death & 3 & 3 & 3 & - \\
\hline $\begin{array}{l}\text { Christine } \\
\text { M. Lovly, } \\
\text { M.D. et al. }\end{array}$ & 56 & M & $\begin{array}{l}\text { Post mortem } \\
\text { histological samples } \\
\text { (lung, airways) }\end{array}$ & Not specified & 1 & 3 & 3 & - \\
\hline
\end{tabular}




\section{Discussion}

Information about 84 deaths involving SARS CoV-2 positiveness or infection have been collected in the present study, showing the growing interest of the literature with respect to post-mortem findings in COVID-19 pandemic.

So far, several tests have been developed in order to confirm a patient's positivity to the virus, none of them free from issues of sensitivity [31]. The most used is certainly rt-PCR performed on swabs collected from the upper airways. All patients included in this study tested positive for airway swabs, performed in vivo or post-mortem. However, the accuracy of post-mortem swabs is yet to be clearly defined and false negative are theoretically possible [69]. Indeed, even though different studies report positive swabs even after several days, the influence of post-mortem interval and bacterial superimposition is unknown. One study suggested it might be reliable until 5 days [70]. C. Edler et al. verified the post-mortem sensitivity of the nasopharyngeal and oropharyngeal swabs by performing the test on 30 deceased at the time of dissection, finding a positive swab in 100\% of cases, with a maximum time elapsed from death to the test of 12 days [38]. Furthermore, a study by Marco Dell'Aquila et al. highlighted the importance of performing multiple swabs in the post-mortem examination [71]. COVID-19 has been detected by nasopharyngeal and oropharyngeal swabs up to $27 \mathrm{~h}$ after death [72], while in another study the positivity of throat swabs lasted up to $128 \mathrm{~h}$ [73]. By performing rhino-pharyngeal, tracheal and lung swabs in 12 autopsy cases of patients with a clinical diagnosis of Sars-CoV-2 related pneumonia, 9 out of 12 cases had at least one post-mortem swab positive for Sars-CoV-2, with the virus found in samples up to $310 \mathrm{~h}$ from the post mortem sampling [71]. Moreover, a paper by Prema Seetulsingh et al. described the case of a patient who died of respiratory failure during transport to the hospital, with a negative upper airway swab, but with SARS CoV-2 found in the lung at an analysis performed 27 days following the death [74]. However, a correlation between the negativity of the lung swabs and the number of days elapsed from the ante mortem swabs was also found, as well as a negative correlation between the positivity of the other swabs and the number of days passed from the ante mortem swabs [71]. Thus, results of swabs should be interpreted with caution and never taken as an evidence of COVID-19 when singularly considered.

As a matter of fact, despite multiple reports allowed to assess the vitality of SARS CoV-2, scientific evidence regarding the risk of becoming infected for health care personnel arising from human dead hosts is lacking. Notwithstanding this, the risk of contagion involved in the post-mortem examination led some countries to discourage the performance of autopsies, as happened in Italy [75]. This might explain why the number of cases here considered, although significant, is rather low when compared to the high worldwide mortality for COVID-19. An additional possible explanation for the decline of the autopsy rate might be connected to the guidance for the safe management of a dead body, published by the World Health Organization and by the Center for Disease Control and Prevention [76,77]. Indeed, not all the autopsy facilities could be equipped with the required safety measures (e.g., negative pressure rooms) and the lack of "safe" autopsy rooms might have additionally led to a reduction in postmortem examinations [69,76].

The epidemiology of the victims, and the rate of comorbidities (absent in $28 \%$ of the cases), do not allow to confirm that SARS-CoV-2 is only affecting the elderly or patients who bear in already critical conditions. Rather, this is a confirmation that COVID-19 can be lethal even in healthy people and this should be taken in mind by forensic pathologists, who might incur in an otherwise unexplained death. As for the history of the disease, reported symptoms, laboratory alterations and macro as well as microscopic findings of the cases collected in this study were in line with those reported by other works, showing a prevalence of lung damage with edema, acute and late phase of DAD, presence of microthrombi in the pulmonary vessels or pneumonia [78-83], but also involvement of other organs, such as kidneys, heart and liver [84-87]. This also highlights that investigations limited to the lungs might not be enough to obtain a clear clinical post-mortem picture. Moreover, the 
complexity of the histological features shown even within the lungs might suggest that a biopsy-based approach might not be representative of the whole parenchyma.

As for the type of analyses performed, in vivo imaging was far more common than in the post-mortem setting (only 15 cases). Particularly, post-mortem imaging was performed when in vivo instrumental analysis was missing, e.g., cases 1,3,5,7-12 by Dominic Wichmann et al. [40], and its concordance or discordance with pathological findings allowed a high inter-rater agreement in the assignment of the CSS. Its application is strongly encouraged, especially when other info might be missing. Toxicology was extremely rarely applied. However, several drugs were administered before and during COVID-19 in most cases and, in this condition, it would appear reasonable to confirm the effectiveness of the administration, e.g., by excluding under- as well as over-doses.

A rather worrying picture emerged from the type of post-mortem examination performed, since the majority of cases ( 55 in total, out of 84 ) were not complete, nor performed with respect to the international guidelines $[88,89]$. Indeed, even though micro-invasive autopsies, especially if coupled to post-mortem imaging and extensive sampling of tissues for histology and electronic microscope-based analyses, might represent a viable alternative to reduce the risk of infection for health care personnel, the exclusion of some organs (most often, the brain) or the loss of a global view on the health status of the victim might lead to false conclusions. Especially in the case of such a widespread and systemic infection as COVID-19, which might affect multiple organs and lead to an unpredictable and severe immune response, the careful dissection of each organ appears of paramount importance. Indeed, a full autopsy is the only chance to observe the systemic changes and take optimal samples to identify the cause of death [28].

As already emerged for some toxicological issues, when the scientific data are scarce [35,36], a multidisciplinary evaluation is necessary and shared criteria might aid forensic pathologists in their delicate task, which has many consequences.

By observing the CSS applied to the collected cases, it can be noted that most of the deceased fall into the category "deaths from COVID-19". A similar result is reported by an interesting study by Francesco Grippo et al. [5] By analyzing more than 5000 death certificates compiled according to the ICD, it was observed that COVID-19 was reported as the leading cause of death in $88 \%$ of cases. Sefer Elezkurtaj also confirms, by performing autopsies on 26 patients, that in the majority of decedents, the causes of death were directly related to SARS CoV-2 [90]. According to this study, the majority of patients had "died of COVID-19", with only a contributory implication of pre-existing health conditions to the mechanism of death. However, the influence of a publication bias should be considered.

The very good agreement found by three blind and independent raters allows to hypothesize that the CSS is an easy tool which could be applied in the everyday routine of post-mortem examination on SARS-CoV-2 positive deceased, even by less experienced pathologists. Regarding the comparison with the Hamburg score by Edler et al. [38], as previously mentioned, it was not possible to apply that categorization in all cases, but only in the autopsies performed in Hamburg which were also reported in the studies by Wichmann et al. [40] and Heinrich et al. [57]. The study of the University of Hamburg, in fact, collected the key points of the first 80 consecutive autopsies carried out in the federal state of Hamburg, then applied a categorization of deaths on the basis of the causes of death reported, making this scale not usable in different studies. Furthermore, the 80 cases described by Edler et al. do not contain extractable information, particularly regarding post-mortem findings [38]. Therefore, they could not be included in our database of literature cases. The Hamburg score mostly considered the findings of "pneumonia", "ARDS" and "pulmonary embolism" as indicators for a COVID-19-related death. Even if these findings are certainly fundamental in the evaluation of the role of SARS-CoV-2, we believe that a more comprehensive overview, as well as a valorization of past history and of the status of the other organs and functions (e.g., of coagulation), are needed. For example, findings of aspiration pneumonia in a patient with neurological comorbidities might be misinterpreted as SARS-CoV-2-related, when they might have occurred even 
in the absence of this pathogen and in any moment of the patient's life (e.g., case 6 by Wichmann et al. [40], assigned CSS $=1$ ). This further underlies the importance of collecting in vivo data when performing a post-mortem assessment. Clinical risk prediction models (e.g., QCOVID) have already been developed and validated on large population sets, to estimate the risk of becoming infected and then of dying of COVID-19, or of dying when admitted to hospital with COVID-19 [18,91,92].

The quantification of such risks might be certainly useful even in the postmortem setting, and might give forensic pathologists strong indications on the most important clinical predictors of death. However, these statistical ex ante tools do not allow one to assess ex post the cause of death and the role of the virus in the specific evaluated case. Thus, in the post-mortem evaluation, clinical stratification risk models or image-based outcome models should be always integrated with the CSS [93].

Even though the results, by comparing the converted Hamburg score and the CSS, were not significantly different, this type of analysis has been made possible only in a minority of cases and further studies would be needed to establish whether they are interchangeable. Nevertheless, we agree that, when the cause of death is difficult to be ascertained, a high degree of suspicion for COVID-19 should be maintained, and this probably had a reflection in the above-mentioned high degree of CSS 3 and 2 assigned.

Beside the difference in numbers among cases classified by Hamburg score and by CSS, the study has several limitations. Until July 31, only a few reports of complete autopsies had been published. The early publication of the present study has the aim to provide a quick overview and practical instruments which might be helpful for further cases evaluation. Despite the diffusion of safety protocols, very often these were not applied due to the infectious risk, preferring minimally invasive approaches such as ultrasound guided biopsies or partial autopsies, by opening of the thoracic and abdominal cavity, but leaving the organs in situ. Additionally, not all the articles reported information such as laboratory tests performed, comorbidities, circumstances of death and radiology. Regarding the swabs, all cases found were positive for the virus, but it has not always been reported whether the swab was performed in vivo or post mortem and, when performed post mortem, when with respect to the post-mortem interval. This information could be important in understanding how long the virus remains detectable in the patient's airways after death, with implications in CSS, built to evaluate SARS CoV-2 positive patients. The lack of one or some of the CSS key points could make the score less accurate. A possible solution could consist in the creation of a register that contains all the autopsies performed on patients affected by COVID-19, with findings organized in a systematic way.

\section{Limitations}

The present systematic review has several limits. Firstly, the time of publication chosen was quite narrow, from the early months of 2020 to 31 July 2020. However, this was necessary due to the urgency of the matter. A broader period of observation would certainly provide more relevant data. Secondly, only papers at least providing some results of a post-mortem examination were included. This was motivated by the will of obtaining stronger evidence, even though we are aware that this might have resulted in a lower number of cases. Indeed, the total number of cases herein reported is certainly low, when compared to the worldwide mortality from Covid-19. This might be due to the limitations in performing autopsies which have been established, due to the infective risk for health care personnel and forensic pathologists, in many countries. Thirdly, the comparison between the CSS and the Hamburg score was only limited to a few cases. Finally, all relevant studies were included, with no distinction on the basis of the adherence to ethical standards and of the conflicts of interest, neither selecting only high-impact journal. This was done in order to offer a broad collection of cases, though it has resulted in the inclusion of a withdrawn article. However, the corresponding paper only provided a single case; thus, statistics were only minimally affected. 


\section{Conclusions}

As the pandemic continues to claim victims, it is fundamental to distinguish those patients who have died "from COVID-19" from those who have died "with COVID-19". The SARS CoV-2 Significance Score (CSS) used after a complete accurate post-mortem examination, coupled to the retrieval of in vivo data, post-mortem radiology, histology and toxicology, as well as to additional required analyses (e.g., electronic microscopy) aims to be a useful, concise tool helping in the assessment of the cause of death and the role played by this virus. A shared use of this scale might hopefully lower the inhomogeneities in forensic evaluation of SARS-CoV-2.

Funding: This research received no external funding.

Data Availability Statement: Data are available from the author upon request.

Acknowledgments: The authors thank Antonella Bacosi and Simonetta di Carlo for technical help.

Conflicts of Interest: The authors declare no conflict of interest.

\section{References}

1. WHO Director-General's Opening Remarks at the Media Briefing on COVID-19-11 March 2020. Available online: https: / / www.who.int/director-general/speeches/detail/who-director-general-s-opening-remarks-at-the-media-briefing-oncovid-19---11-march-2020 (accessed on 9 December 2020).

2. Worldometer. Available online: https://www.worldometers.info/coronavirus (accessed on 9 December 2020).

3. Pfizer and BioNTech Announce Vaccine Candidate Against COVID-19 Achieved Success in First Interim Analysis from Phase 3 Study I Pfizer. Available online: https://www.pfizer.com/news/press-release/press-release-detail/pfizer-and-biontechannounce-vaccine-candidate-against (accessed on 9 December 2020).

4. Moderna's COVID-19 Vaccine Candidate Meets its Primary Efficacy Endpoint in the First Interim Analysis of the Phase 3 COVE Study I Moderna, Inc. Available online: https://investors.modernatx.com/news-releases/news-release-details/modernascovid-19-vaccine-candidate-meets-its-primary-efficacy (accessed on 9 December 2020).

5. Grippo, F.; Navarra, S.; Orsi, C.; Manno, V.; Grande, E.; Crialesi, R.; Frova, L.; Marchetti, S.; Pappagallo, M.; Simeoni, S.; et al. The Role of COVID-19 in the Death of SARS-CoV-2-Positive Patients: A Study Based on Death Certificates. J. Clin. Med. 2020, 9, 3459. [CrossRef] [PubMed]

6. Slater, T.A.; Straw, S.; Drozd, M.; Kamalathasan, S.; Cowley, A.; Witte, K.K. Dying 'due to' or 'with' COVID-19: A cause of death analysis in hospitalised patients. Clin. Med. 2020, 5, 189-190. [CrossRef] [PubMed]

7. Yang, J.; Zheng, Y.; Gou, X.; Pu, K.; Chen, Z.; Guo, Q.; Ji, R.; Wang, H.; Wang, Y.; Zhou, T. Prevalence of comorbidities and its effects in coronavirus disease 2019 patients: A systematic review and meta-analysis. Int. J. Infect. 2020, 94, 91-95. [CrossRef]

8. Caci, G.; Albini, A.; Malerba, M.; Noonan, D.M.; Pochetti, P.; Polosa, R. COVID-19 and Obesity: Dangerous Liaisons. J. Clin. Med. 2020, 9, 2511. [CrossRef] [PubMed]

9. Roncon, L.; Zuin, M.; Rigatelli, G.; Zuliani, G. Diabetic patients with COVID-19 infection are at higher risk of ICU admission and poor short-term outcome. J. Clin. Virol. 2020, 127. [CrossRef]

10. Kang, S.J.; Jung, S.I. Age-Related Morbidity and Mortality among Patients with COVID-19. Infect. Chemother. 2020, 52, 154-164. [CrossRef]

11. Huang, I.; Lim, M.A.; Pranata, R. Diabetes mellitus is associated with increased mortality and severity of disease in COVID-19 pneumonia-A systematic review, meta-analysis, and meta-regression: Diabetes and COVID-19. Diabetes Metab. Syndr. Clin. Res. Rev. 2020, 14, 395-403. [CrossRef]

12. Imam, Z.; Odish, F.; Gill, I.; O'Connor, D.; Armstrong, J.; Vanood, A.; Ibironke, O.; Hanna, A.; Ranski, A.; Halalau, A. Older age and comorbidity are independent mortality predictors in a large cohort of 1305 COVID-19 patients in Michigan, United States. J. Intern. Med. 2020, 288, 469-476. [CrossRef]

13. Li, K.; Wu, J.; Guo, D.; Chen, L.; Fang, Z.; Li, C. The Clinical and Chest CT Features Associated with Severe and Critical COVID-19 Pneumonia. Invest. Radiol. 2020, 55, 327-331. [CrossRef] [PubMed]

14. Lluís Cirera, L.; Andreu Segura, A.; Hernández, I. Defunciones por COVID-19: No están todas las que son y no son todas las que están, Gaceta Sanitaria 2020. Gac. Sanit. 2020. [CrossRef]

15. International Guidelines for Certification and Classification (Coding) of Covid-19 as Cause of Death. Based on ICD International Statistical Classification of Diseases. 2020. Available online: https://www.who.int/classifications/icd/Guidelines_Cause_of_ Death_COVID-19.pdf (accessed on 9 December 2020).

16. Groenewald, P.; Awotiwon, O.; Hanmer, L.; Bradshaw, D. Guideline for medical certification of death in the COVID-19 era. S. Afr. Med. J. 2020, 110, 721-723. [CrossRef]

17. Roulson, J.; Benbow, E.W.; Hasleton, P.S. Discrepancies between clinical and autopsy diagnosis and the value of post mortem histology; a meta-analysis and review. Histopathology 2005, 47, 551-559. [CrossRef] [PubMed] 
18. Brooks, E.G.; Reed, K. Principles and Pitfalls: A Guide to Death Certification. Clin. Med. Res. 2015, 13, 74-82. [CrossRef] [PubMed]

19. Gill, J.R.; DeJoseph, M.E. The importance of Proper Death Certification During the COVID-19 Pandemic. JAMA 2020, 324, 27-28. [CrossRef]

20. Shojania, K.; Burton, E.C.; McDonald, M.; Goldman, L. Changes in Rates of Autopsy-Detected Diagnostic Errors over Time: A Systematic Review. JAMA 2003, 289, 2849-2856. [CrossRef]

21. Salerno, M.; Sessa, F.; Piscopo, A.; Montana, A.; Torrisi, M.; Patanè, F.; Murabito, P.; Li Volti, G.; Pomara, C. No Autopsies on COVID-19 Deaths: A Missed Opportunity and the Lockdown of Science. J. Clin. Med. 2020, 9, 1472. [CrossRef]

22. Jurek, T.; Teresiński, G. Classification criteria for the deceased referred for forensic post-mortem examinations with regard to epidemiological risk posed by SARS CoV-2/COVID-19 during the pandemic. Arch. Med. Sadowej Kryminol. 2019, 69, 158-163.

23. Tambone, V.; Boudreau, D.; Ciccozzi, M.; Sanders, K.; Campanozzi, L.L.; Wathuta, J.; Violante, L.; Cauda, R.; Petrini, C.; Abbate, A.; et al. Ethical Criteria for the Admission and Management of Patients in the ICU Under Conditions of Limited Medical Resources: A Shared International Proposal in View of the COVID-19 Pandemic. Front. Public Health. 2020, 8, 284. [CrossRef]

24. Keten, D.; Okdemir, E.; Keten, A. Precautions in postmortem examinations in Covid-19-Related deaths: Recommendations from Germany. J. Forensic Leg. Med. 2020, 73, 102000. [CrossRef]

25. Mao, D.; Zhou, N.; Zheng, D.; Yue, J.; Zhao, Q.; Luo, B.; Guan, D.; Zhou, Y.; Hu, B. Guide to forensic pathology practice for death cases related to coronavirus disease 2019 (COVID-19) (Trial draft). Forensic Sci. Res. 2020, 5, 1-7. [CrossRef]

26. Osborn, M.; Lucas, S.; Stewart, R.; Swift, B.; Youd, E. Briefing on COVID-19 Autopsy practice relating to possible cases of COVID-19 (2019-nCov, novel coronavirus from China 2019/2020). R. Coll. Pathol. 2020, 19, 1-14.

27. Hanley, B.; Lucas, S.B.; Youd, E.; Swift, B.; Osborn, M. Autopsy in suspected COVID-19 cases. J. Clin. Pathol. 2020, 73, 239-242. [CrossRef] [PubMed]

28. Basso, C.; Calabrese, F.; Sbaraglia, M.; Del Vecchio, C.; Carretta, G.; Saieva, A.; Donato, D.; Flor, L.; Crisanti, A.; Dei Tos, A.P. Feasibility of postmortem examination in the era of COVID-19 pandemic: The experience of a Northeast Italy University Hospital. Virchows Arch. 2020, 477, 341-347. [CrossRef] [PubMed]

29. Santurro, A.; Scopetti, M.; D’Errico, S.; Fineschi, V. Response to the letter by Meng-jun Zhan et al. regarding the paper “A technical report from the Italian SARS-CoV-2 outbreak. Postmortem sampling and autopsy investigation in cases of suspected or probable COVID-19". Forensic Sci. Med. Pathol. 2020, 16, 746. [CrossRef] [PubMed]

30. Carpenito, L.; D’Ercole, M.; Porta, F.; Di Blasi, E.; Doi, P.; Redolfi Fagara, G.; Rey, R.; Bulfamante, G. The autopsy at the time of SARS-CoV-2: Protocol and lessons. Ann. Diagn. Pathol. 2020, 48, 151562. [CrossRef]

31. Sessa, F.; Bertozzi, G.; Cipolloni, L.; Baldari, B.; Cantatore, S.; D’Errico, S.; Di Mizio, G.; Asmundo, A.; Castorina, S.; Salerno, M.; et al. Clinical-Forensic Autopsy Findings to Defeat COVID-19 Disease: A Literature Review. J. Clin. Med. 2020, 9, 2026. [CrossRef]

32. Kanchan, T.; Shrestha, R.; Krishan, K. Post-mortem ultrasonography: A safer alternative to autopsies in COVID-19 deaths. J. Ultrasound 2020, 1-2. [CrossRef]

33. Monteiro, R.A.; Duerte Neto, A.N.; Da Silva, L.F.F.; De Oliveira, E.P.; Theodoro Filho, J.; Dos Santos, G.A.B.; De Oliverira, I.R.S.; Mauad, T.; Saldiva, P.H.N.; Dolhnikoff, M. Ultrasound-guided minimally invasive autopsies: A protocol for the study of pulmonary and systemic involvement of COVID-19. Clinics 2020, 75, 1-2. [CrossRef]

34. Giorgetti, A.; Giorgetti, R. Hic est locus ubi mors gaudet succurrere vitae. BMJ J. Clin. Pathol. 2020, 73, 5.

35. Elliott, S.; Sedefov, R.; Evans-Brown, M. Assessing the toxicological significance of new psychoactive substances in fatalities. Drug Test Anal. 2018, 10, 120-126. [CrossRef]

36. Giorgetti, A.; Busardò, F.P.; Tittarelli, R.; Auwärter, V.; Giorgetti, R. Post-Mortem Toxicology: A Systematic Review of Death Cases Involving Synthetic Cannabinoid Receptor Agonists. Front. Psychiatry 2020, 11, 464. [CrossRef] [PubMed]

37. Buschmann, C.; Tsokos, M. Corona-associated suicide-Observations made in the autopsy room. Leg. Med. 2020, 46, 101723. [CrossRef] [PubMed]

38. Edler, C.; Schroder, A.S.; Aepfelbacher, M.; Fitzek, A.; Heinemann, A.; Heinrich, F.; Klein, A.; Klein, A.; Langenwalder, F.; Lutgehetmann, M.; et al. Dying with SARS-CoV-2 infection-An autopsy study of the first consecutive 80 cases in Hamburg, Germany. Int. J. Legal Med. 2020, 134, 1275-1284. [CrossRef]

39. Bradley, B.T.; Maioli, H.; Johnston, R.; Chaudhry, I.; Fink, S.L.; Xu, H.; Najafian, B.; Deutsch, G.; Lacy, J.M.; Williams, T.; et al. Histopathology and ultrastructural findings of fatal COVID-19 infections in Washington State: A case series. Lancet 2020, 396, 320-332. [CrossRef]

40. Wichmann, D.; Sperhake, J.P.; Lutgehetmann, M.; Steurer, S.; Edler, C.; Heinemann, A.; Heinrich, F.; Mushumba, H.; Hniep, I.; Schroder, A.S.; et al. Autopsy Findings and Venous Thromboembolism in Patients With COVID-19: A Prospective Cohort Study. Ann. Intern. Med. 2020, 173, 268-277. [CrossRef]

41. Schaefer, I.M.; Padera, R.F.; Solomon, I.H.; Kanjilal, S.; Hammer, M.M.; Hornick, J.H.; Sholl, L.M. In situ detection of SARS-CoV-2 in lungs and airways of patients with COVID-19. Mod. Pathol. 2020, 33, 2104-2114. [CrossRef]

42. Beigmohammadi, M.T.; Jahanbin, B.; Safaei, M.; Amoozadeh, L.; Khoshavi, M.; Mehrtash, V.; Jafarzadeh, B.; Abdollahi, A. Pathological Findings of Postmortem Biopsies from Lung, Heart, and Liver of 7 Deceased COVID-19 Patients. Int. J. Surg. Pathol. 2020. [CrossRef]

43. Tian, S.; Xiong, Y.; Liu, H.; Niu, L.; Guo, J.; Liao, M.; Xiao, S.Y. Pathological study of the 2019 novel coronavirus disease (COVID-19) through postmortem core biopsies. Mod. Pathol. 2020, 33, 1007-1014. [CrossRef] 
44. Varga, Z.; Flammer, A.J.; Steiger, P.; Haberecker, M.; Andermatt, R.; Zinkernagel, A.S.; Mehra, M.R.; Schuepbach, R.A.; Ruschitzka, F.; Moch, H.; et al. Endothelial cell infection and endotheliitis in COVID-19. Lancet 2020, 395, 1417-1418. [CrossRef]

45. Prilutskiy, A.; Kritselis, M.; Shevtsov, A.; Yambayev, I.; Vadlamudi, C.; Zhao, Q.; Kataria, Y.; Sarosiek, S.R.; Lerner, A.; Sloan, J.M.; et al. SARS-CoV-2 Infection-Associated Hemophagocytic Lymphohistiocytosis. Am. J. Clin. Pathol. 2020, 154, 466-474. [CrossRef]

46. Bösmüller, H.; Traxler, S.; Bitzer, M.; Haberle, H.; Raiser, W.; Nann, D.; Frauendeld, L.; Vogelsberg, A.; Klingel, K.; Fend, F. The evolution of pulmonary pathology in fatal COVID-19 disease: An autopsy study with clinical correlation. Virchows Arch. 2020, 477, 349-357. [CrossRef] [PubMed]

47. Buja, L.; Wolf, D.A.; Zhao, B.; Akkanti, B.; McDonald, M.; Lelenwa, L.; Reilly, N.; Ottaviani, G.; Elgheyany, M.T.; Ocazionez Trujillo, D.; et al. The emerging spectrum of cardiopulmonary pathology of the coronavirus disease 2019 (COVID-19): Report of 3 autopsies from Houston, Texas, and review of autopsy findings from other United States cities. Cardiovasc. Pathol. 2020, 48, 107233. [CrossRef] [PubMed]

48. Youd, E.; Moore, L. COVID-19 autopsy in people who died in community settings: The first series. J. Clin. Pathol. 2020, 73, 840-844. [CrossRef] [PubMed]

49. Barton, L.M.; Duval, E.J.; Stroberg, E.; Ghosh, S.; Mukhopadhyay, S. COVID-19 Autopsies, Oklahoma, USA. Am. J. Clin. Pathol. 2020, 153, 725-733. [CrossRef] [PubMed]

50. Sekulic, M.; Harper, H.; Nezami, B.G.; Shen, D.L.; Pichler Sekulic, S.; Koeth, A.T.; Harding, C.V.; Gilmore, H.; Sadri, N. Molecular detection of SARS-CoV-2 infection in FFPE samples and histopathologic findings in fatal SARS-CoV-2 cases. Am. J. Clin. Pathol. 2020, 154, 190-200. [CrossRef] [PubMed]

51. Wang, C.; Xie, J.; Zhao, L.; Fei, X.; Zhang, H.; Tan, Y.; Nie, X.; Zhou, L.; Liu, Z.; Ren, Z. Alveolar macrophage dysfunction and cytokine storm in the pathogenesis of two severe COVID-19 patients. EBioMedicine 2020, 57, 102833. [CrossRef]

52. Grimes, Z.; Bryce, C.; Sordillo, E.M.; Gordon, R.E.; Reidy, J.; Painz Mandolfi, A.E.; Fowkes, M. Fatal Pulmonary Thromboembolism in SARS-CoV-2-Infection. Cardiovasc. Pathol. 2020, 48, 107227. [CrossRef]

53. Konopka, K.E.; Wilson, A.; Myers, J.L. Postmortem Lung Findings in an Asthmatic Patient with Coronavirus Disease 2019. Chest 2020, 158, 99-101. [CrossRef]

54. Craver, R.; Huber, S.; Sandomirskky, M.; McKenna, D.; Schieffelin, J.; Finger, L. Fatal Eosinophilic Myocarditis in a Healthy 17-Year-Old Male with Severe Acute Respiratory Syndrome Coronavirus 2 (SARS-CoV-2c). Fetal Pediatr. Pathol. 2020, 39, 263-268. [CrossRef]

55. The COVID-19 Autopsy. The first COVID-19 autopsy in Spain performed during the early stages of the pandemic. Rev. Esp. Patol. 2020, 53, 182-187.

56. Navarro Conde, P.; Monraval, P.A.; Medina, C.M.; Sanchez, A.J.; Teruel, J.C.A.; Marco, J.F.; Puglia Santos, V.; Aranda, E.M. Autopsy findings from the first known death from Severe Acute Respiratory Syndrome SARS-CoV-2 in Spain. Rev. Esp. Patol. 2020, 53, 188-192. [CrossRef] [PubMed]

57. Heinrich, F.; Sperhake, J.P.; Heinemann, A.; Mushumba, H.; Lennartz, M.; Norz, D.; Glatzel, M.; Lutgehetmann, M.; Puschel, K. Germany's first COVID-19 deceased: A 59-year-old man presenting with diffuse alveolar damage due to SARS-CoV-2 infection. Virchows Arch. 2020, 477, 335-339. [CrossRef] [PubMed]

58. Xu, Z.; Shi, L.; Wang, Y.; Zhang, J.; Huang, L.; Zhang, C.; Liu, S.; Zhao, P.; Liu, H.; Zhu, L.; et al. Pathological findings of COVID-19 associated with acute respiratory distress syndrome. Lancet Respir. Med. 2020, 8, 420-422. [CrossRef]

59. Lovly, C.; Boyd, K.L.; Gonzalez Ericsson, P.I.; Lowe, C.L.; Brown, H.M.; Hoffman, R.D.; Sterling, B.C.; Kapp, M.E.; Johnson, D.B.; Kopparapu, P.R.; et al. Rapidly fatal pneumonitis from immunotherapy and concurrent SARS-CoV-2 infection in a patient with newly diagnosed lung cancer. medRxiv 2020. [CrossRef]

60. Adachi, T.; Chong, J.M.; Nakajima, N.; Sano, M.; Yamazaki, J.; Miyamoto, I.; Nishioka, H.; Akita, H.; Sato, Y.; Kataoka, M.; et al. Clinicopathologic and immunohistochemical findings from autopsy of patient with COVID-19, Japan. Emerg. Infect. Dis. 2020, 26, 2157-2161. [CrossRef]

61. Yan, L.; Mir, M.; Sanchez, P.; Beg, M.; Peters, J.; Enriquez, O.; Gilbert, A. COVID-19 in a hispanic woman: Autopsy report with clinical-pathologic correlation. Arch. Pathol. Lab. Med. 2020, 144, 1041-1047. [CrossRef]

62. Lacy, J.M.; Brooks, E.G.; Akers, J.; Armstrong, D.; Decker, L.; Gonzalez, A.; Humphrey, W.; Mayer, R.; Miller, M.; Perez, C.; et al. COVID-19: Postmortem diagnostic and biosafety considerations. Am. J. Forensic Med. 2020, 41, 143-151. [CrossRef]

63. Farkash, E.A.; Wilson, A.M.; Jentzen, J.M. Ultrastructural evidence for direct renal infection with sars-cov-2. J. Am. Soc. Nephrol. 2020, 31, 1683-1687. [CrossRef]

64. Aguiar, D.; Lobrinus, J.A.; Schibler, M.; Fracasso, T.; Lardi, C. Inside the lungs of COVID-19 disease. Int. J. Legal Med. 2020, 134, 1271-1274. [CrossRef]

65. Karami, P.; Naghavi, M.; Feyzi, A.; Aghamohammadi, M.; Novin, M.S.; Mobaien, A.; Norooznezhad, A.H. Mortality of a pregnant patient diagnosed with COVID-19: A case report with clinical, radiological, and histopathological findings. Travel Med. Infect. Dis. 2020. [CrossRef]

66. Suess, C.; Hausmann, R. Gross and histopathological pulmonary findings in a COVID-19 associated death during self-isolation. Int. J. Legal Med. 2020, 134, 1285-1290. [CrossRef] [PubMed] 
67. Santana, M.F.; Pivoto, G.; Araujo Alexandre, M.A.; Baia da Silva, D.C.; Da Silva Borba, M.G.; Almeida Val, F.; Brito Sousa, J.D.; Cardoso Melo, G.; Monteiro, W.M.; Barga Souza, J.V.; et al. Confirmed invasive pulmonary aspergillosis and COVID-19: The value of postmortem findings to support antemortem management. Rev. Soc. Bras. Med. Trop. 2020, 53, 1-4. [CrossRef] [PubMed]

68. Stone, J.R.; Tran, K.M.; Conklin, J.; Mino Kenudson, M. Case 23-2020: A 76-Year-Old Woman Who Died from Covid-19. N. Engl. J. Med. 2020, 383, 380-387. [CrossRef] [PubMed]

69. Barranco, R.; Ventura, F. The role of forensic pathologists in coronavirus disease 2019 infection: The importance of an interdisciplinary research. Med. Sci. Law. 2020, 60, 237-238. [CrossRef] [PubMed]

70. Ventura, F.; Barranco, R. Cadaveric Nasopharyngeal Swab in Coronavirus Disease 2019 Infections: Can it be Useful for MedicoLegal Purposes? Am. J. Forensic Med. Pathol. 2020, 41, 238-239. [CrossRef]

71. Dell'Aquila, M.; Cattani, P.; Fantoni, M.; Marchetti, S.; Aquila, I.; Stigliano, E.; Carbone, A.; Oliva, A.; Arena, V. Postmortem Swabs in the Severe Acute Respiratory Syndrome Coronavirus 2 Pandemic: Report on 12 Complete Clinical Autopsy Cases. Arch. Pathol. Lab. Med. 2020, 144, 1298-1302. [CrossRef]

72. Dijkhuizen, L.G.M.; Gelderman, H.T.; Duijst, W.L.J.M. Review: The safe handling of a corpse (suspected) with COVID-19. J. Forensic Leg. Med. 2020, 73, 101999. [CrossRef]

73. Skok, K.; Stelzl, E.; Trauner, M.; Kessler, H.H.; Lax, S.F. Post-mortem viral dynamics and tropism in COVID-19 patients in correlation with organ damage. Virchows Arch. 2020, 1-11. [CrossRef]

74. Seetulsingh, P.; Kannangara, C.I.; Richman, P. Undetectable SARS-CoV-2 in a nasopharyngeal swab but persistent viral RNA from deep lung swabs: Findings from an autopsy. BMJ Case Rep. 2020, 13, e237446. [CrossRef]

75. Italian Ministry of Health. Emergency Indications Related to the COVID-19 Epidemic Concerning the Funeral Sector, Cemetery, and Cremation-Update Following the New Legislative Indications and Epidemiological Data. Circular of General Direction of Health Prevention. 2020. Available online: https://opi.roma.it/archivio_news/news/1949/5740\%20Aggiornamento\%20 Circolare\%20serv\%20funebri\%2028_5_2020.pdf (accessed on 13 January 2021).

76. Infection Prevention and Control for the Safe Management of a Dead Body in the Context of COVID-19. Available online: https:/ /apps.who.int/iris/bitstream/handle/10665/331538/WHO-COVID-19-1PC_DBMgmt-2020.1-eng.pdf (accessed on 13 January 2021).

77. Centers for Disease Control and Prevention. Healthcare workers. Postmortem Guidance. Available online: https://www.cdc. gov / coronavirus/2019-ncov/hcp/guidance-postmortem-specimens.html\#biosafety (accessed on 13 January 2021).

78. Prieto-Pérez, L.; Fortes, J.; Soto, C.; Vidal Gonzalez, A.; Alonso Riano, M.; Lafarga, M.; Cortti, M.J.; Lazaro Garcia, A.; Perez Tanoira, R.; Trascasa, A.; et al. Histiocytic hyperplasia with hemophagocytosis and acute alveolar damage in COVID-19 infection. Mod. Pathol. 2020, 33, 2139-2146. [CrossRef]

79. Menter, T.; Haslbauer, J.D.; Nienhold, R.; Savic, S.; Hopfer, H.; Deigendesch, N.; Frank, S.; Turek, D.; Willi, N.; Pargger, H.; et al. Postmortem examination of COVID-19 patients reveals diffuse alveolar damage with severe capillary congestion and variegated findings in lungs and other organs suggesting vascular dysfunction. Histopathology 2020, 77, 198-209. [CrossRef] [PubMed]

80. Fox, S.; Akmatbekov, A.; Harbert, J.; Li, G.; Brown, J.Q.; Vander Heide, R.S. Pulmonary and Cardiac Pathology in African American patients with Covid-19: An autopsy series from New Orleans. Lancet Respir. Med. 2020, 8, 681-689. [CrossRef]

81. Duarte Neto, A.N.; Monteiro, R.A.A.; Da Silva, L.F.F.; Malheiros, D.M.A.C.; De Oliveira, E.P.; Theodoro Filho, J.; Pinho, J.R.R.; Gomes Gouvea, M.S.; Salles, A.P.M.; De Oliveira, I.R.S.; et al. Pulmonary and systemic involvement in COVID-19 patients assessed with ultrasound-guided minimally invasive autopsy. Histopathology 2020, 77, 186-197. [CrossRef] [PubMed]

82. Carsana, L.; Sonzogni, A.; Nasr, A.; Rossi, R.S.; Pellegrinelli, A.; Zerbi, P.; Rech, R.; Colombo, R.; Antinori, S.; Corbellino, M.; et al. Pulmonary post-mortem findings in a series of COVID-19 cases from northern Italy: A two-centre descriptive study. Lancet Infect. Dis. 2020, 20, 1135-1140. [CrossRef]

83. Ackermann, M.; Verleden, S.E.; Kuehnel, M.; Haverich, A.; Welte, T.; Lenger, F.; Vanstapel, A.; Werlein, C.; Stark, H.; Tzankov, A.; et al. Pulmonary Vascular Endothelialitis, Thrombosis, and Angiogenesis in Covid-19. N. Engl. J. Med. 2020, 383, 120-128. [CrossRef]

84. Golmai, P.; Larsen, C.P.; DeVita, M.V.; Wahl, S.J.; Weins, A.; Rennkeet, H.G.; Bijol, V.; Rosenstock, J.L. Histopathologic and Ultrastructural Findings in Postmortem Kidney Biopsy Material in 12 Patients with AKI and COVID-19. J. Am. Soc. Nephrol. 2020, 31, 1944-1947. [CrossRef]

85. Sonzogni, A.; Previtali, G.; Seghezzi, M.; Alessio, M.G.; Gianatti, A.; Licini, L.; Morotti, D.; Zerbi, P.; Carsana, L.; Rossi, R.; et al. Liver histopathology in severe COVID 19 respiratory failure is suggestive of vascular alterations. Liver Int. 2020, 40, 2110-2116. [CrossRef]

86. Su, H.; Yang, M.; Wan, C.; Yi, L.X.; Tang, F.; Zhu, H.Y.; Yi, F.; Yang, H.C.; Fogo, B.A.; Nie, X.; et al. Renal histopathological analysis of 26 postmortem findings of patients with COVID-19 in China. Kidney Int. 2020, 98, 219-227. [CrossRef]

87. Pesaresi, M.; Pirani, F.; Tagliabracci, A.; Valsecchi, M.; Procopio, A.D.; Busardò, F.P.; Graciotti, L. SARS-CoV-2 identification in lungs, heart and kidney specimens by transmission and scanning electron microscopy. Eur. Rev. Med. Pharmacol. Sci. 2020, $24,5186-5188$.

88. Brinkmann, B. Harmonization of medico-legal autopsy rules. Council of Europe. Int. J. Legal Med. 1999, 113, 1-14. [CrossRef]

89. European Council of Legal Medicine. Harmonization of Medico-Legal Autopsy Rules. Available online: http:/ / development. fullscreen.pt/eclm/client/files/0000000001/eclmharmonisationofautopsyrules2014_70.pdf (accessed on 13 January 2021). 
90. Elezkurtaj, S.; Greuel, S.; Ihlow, J.; Michaelis, E.; Bischoff, P.; Kunze, C.A.; Sinn, B.V.; Gerhold, M.; Hauptmann, K.; Ingold Heppner, B.; et al. Causes of Death and Comorbidities in Patients with COVID-19. MedRxiv 2020. [CrossRef]

91. Knight, S.R.; Ho, A.; Pius, R.; Buchan, I.; Carson, G.; Drake, T.M.; Dunning, J.; Fairfield, C.J.; Gamble, C.; Green, C.A.; et al Risk stratification of patients admitted to hospital with covid-19 using the ISARIC WHO Clinical Characterisation Protocol: Development and validation of the 4C Mortality Score. BMJ 2020. [CrossRef] [PubMed]

92. Bartoletti, M.; Giannella, M.; Scudeller, L.; Tedeschi, S.; Rinaldi, M.; Bussini, L.; Fornaro, G.; Pascale, R.; Pancaldi, L.; Pasquini, Z.; et al. PREDICO study group. Development and validation of a prediction model for severe respiratory failure in hospitalized patients with SARS-CoV-2 infection: A multicentre cohort study (PREDI-CO study). Clin. Microbiol. Infect. 2020, 26, 1545-1553. [CrossRef] [PubMed]

93. Chao, H.; Fang, X.; Zhang, J.; Homayounieh, F.; Arru, C.D.; Digumarthy, S.R.; Babaei, R.; Mobin, H.K.; Mohseni, I.; Saba, L.; et al. Integrative analysis for COVID-19 patient outcome prediction. Med. Image Anal. 2021, 67, 101844. [CrossRef] [PubMed] 